\title{
EFFORTS TO IDENTIFY LARGE OFFSPRING SYNDROME DURING \\ PREGNANCY THROUGH ULTRASONOGRAPHY AND MATERNAL BLOOD \\ TRANSCRIPTOME ANALYSES
}

\author{
A Thesis \\ Presented to \\ The Faculty of the Graduate School \\ University of Missouri-Columbia
}

In Partial Fulfillment

Of the Requirements for the Degree

Master of Science

\author{
By \\ Bhaumik Narendrabhai Patel \\ Dr. Rocío Melissa Rivera, Thesis Supervisor \\ January 2021
}


The undersigned, appointed by the dean of the Graduate School, have examined the thesis entitled

\section{EFFORTS TO IDENTIFY LARGE OFFSPRING SYNDROME DURING PREGNANCY THROUGH ULTRASONOGRAPHY AND MATERNAL BLOOD TRANSCRIPTOME ANALYSES}

Presented by Bhaumik Narendrabhai Patel

A candidate for the degree of Master of Science

And hereby certify that, in their opinion, it is worthy of acceptance.

Dr. Rocío Melissa Rivera

Dr. Martha Sofía Ortega

Dr. Christine Spinka 


\section{ACKNOWLEDGEMENTS}

There are many people I would like to thank for their help and support and without them I would not be able to finish my Master of Science degree. First, I want to thank my mentor Dr. Rocío Rivera for giving me the opportunity to pursue the degree under her supervision. Dr. Rivera's passion towards science and sense of responsibility to her students really inspired me. Thank you for giving me many valuable advices, encouraging me during hard times, and training me to be a researcher. Next, I would like to thank my committee members Dr. Darren Hagen, Dr. Martha Sofía Ortega, and Dr. Christine Spinka for their time, advice, and guidance during my master project. I am especially grateful to Dr. Hagen and Dr. Spinka for helping me analyze the sequencing data and statistics, and Dr. Ortega for her advice and guidance for farm management.

I would also like to thank Dr. Christine Elsik for her advice regarding bioinformatics programming. In addition, I want to thank all faculty in the Animal Science department for their open-door policy regarding equipment and advice. I also want to thank my current labmates Edgar Joel Soto-Moreno, Yahan Li, Chris Kim and Astrid Roshealy Brau-Rodriguez who helped me a lot on my research and help make life a little easier while in a foreign country. I would like to acknowledge all my previous labmates, graduate students, faculty and staff in the Division of Animal Sciences for their support and advice.

Finally, I would like to thank my friends and especially my family members my late father Narendrabhai, my mother Jyotsnaben, my brother Pratik, my 
sister-in-law Siddhi and my nephew Om, for their continuous support throughout my life and career. 


\section{TABLE OF CONTENTS}

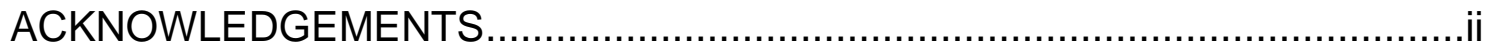

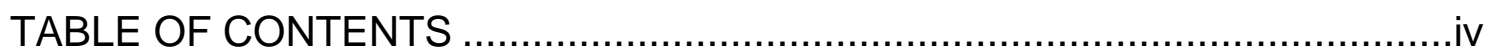

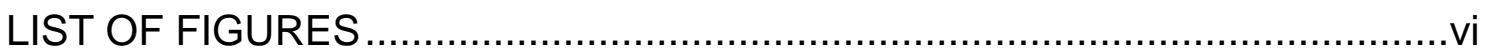

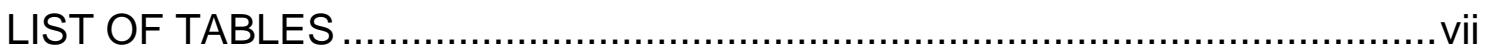

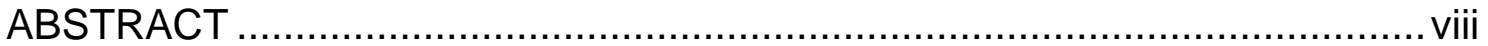

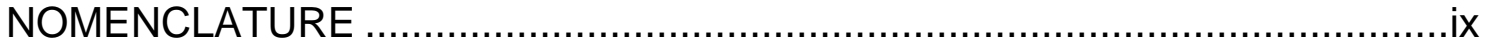

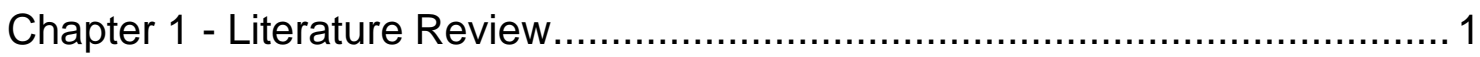

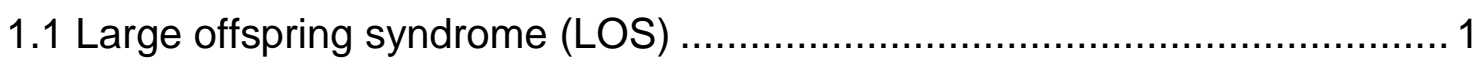

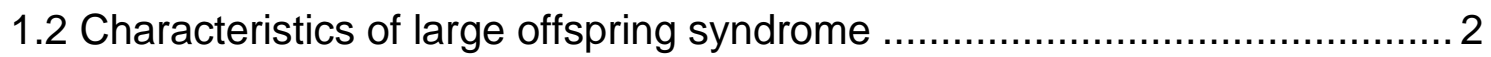

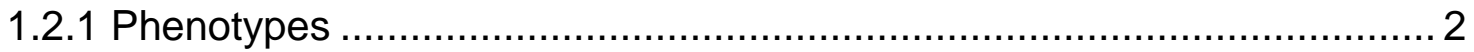

1.2.2 Molecular Associations ........................................................... 4

1.3 Beckwith Wiedemann Syndrome ........................................................... 5

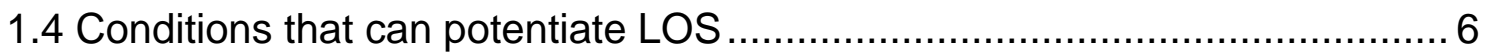

1.4.1 Serum supplementation and/or co-culture with somatic cells ................6

1.4.1.1 Preimplantation stage embryos ........................................... 6

1.4.1.2 Fetal and placental growth ................................................. 8

1.4.2 Asynchronous uterine environment ............................................. 11

1.4.3 High urea diet during pregnancy ......................................... 11

1.5 LOS-associated financial burden to the industry ................................. 12

1.5.1 Example 1 (Oklahoma, 2019) .................................................. 13

1.5.2 Example 2 (Missouri, 2019) ................................................ 13

1.6 Ultrasonographic morphometry as a non-invasive method to identify LOS 16

1.6.1 Use of transrectal ultrasonography to identify fetal abnormalities .......... 16

1.6.2 Relationship between fetal development and fetal morphometry .......... 17

1.7 Fetal-maternal communication and their influence on pregnancy associated

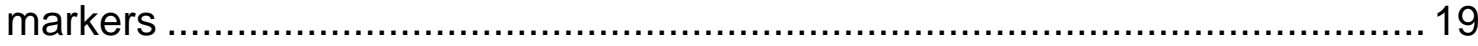

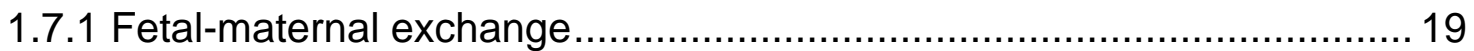

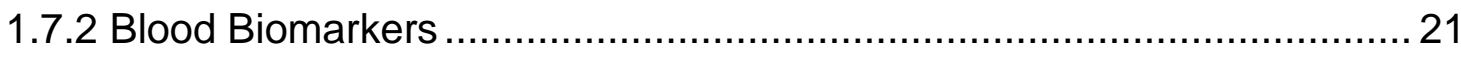

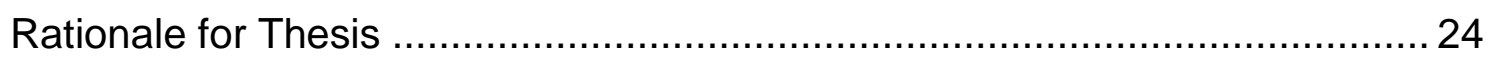

Chapter 2 - Efforts to identify the large offspring syndrome during pregnancy through ultrasonography and maternal blood transcriptome analyses ............ 26 


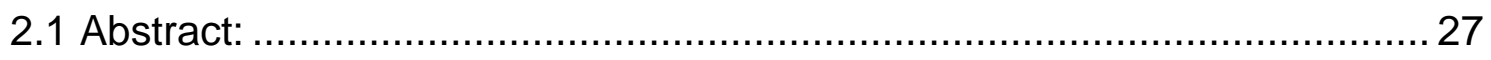

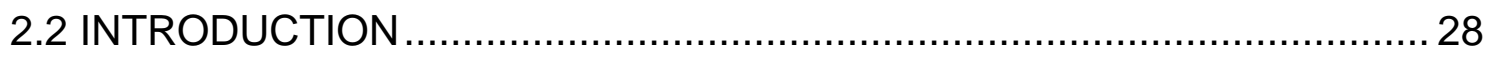

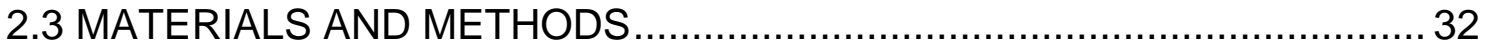

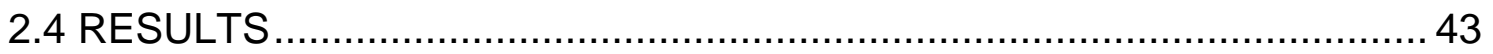

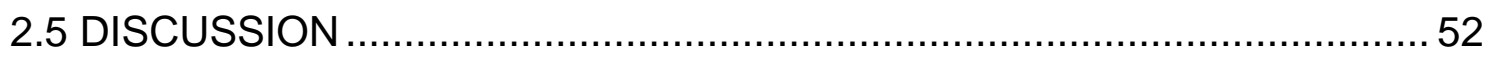

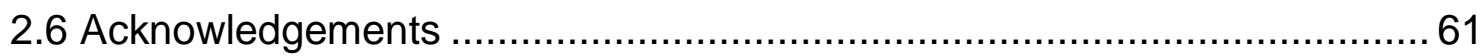

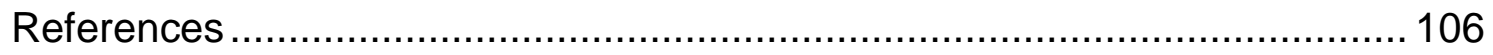




\section{LIST OF FIGURES}

Figure 1.1 Estimated economic loss........................................................... 14

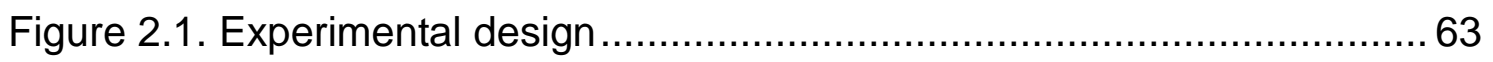

Figure 2.2. Fetal morphometry of fetuses collected on day 105 gestation. ...... 65

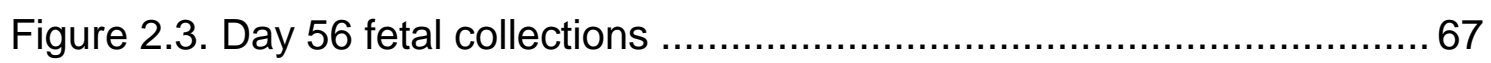

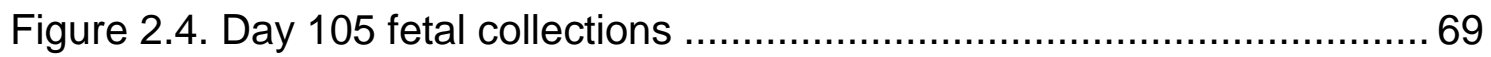

Figure 2.5. Fetal measurements of fetuses collected on day 56 of gestation... 71

Figure 2.6. Day 55 fetal morphometry of fetuses collected on day 56 of

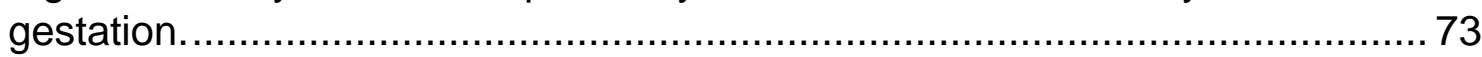

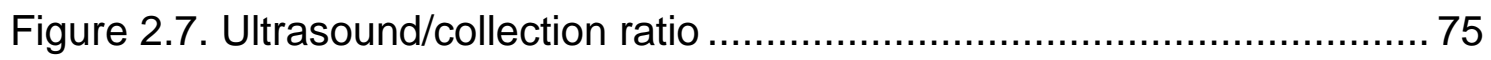

Figure 2.8. Fetal measurements of fetuses collected on day 105 of gestation. 77

Figure 2.9. Ratio of gestation day 105 umbilicus to CRL................................ 79

Figure 2.10. Combined Day 55 fetal morphometry of fetuses collected on day

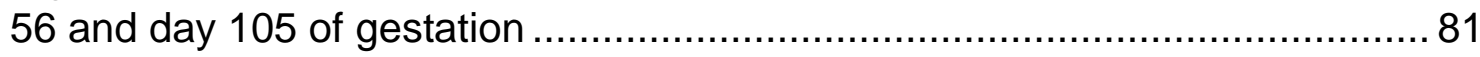

Figure 2.11. Unsupervised hierarchical clustering of white blood cells transcriptome in day 55 and day 105 of pregnancy.

Figure 2.12. Quantitative RT-PCR corroborations of genes identified as differentially expressed by RNAseq in maternal white blood cells 85

Supplementary Figure S2.1. Day 19 ISG15 gene expression. 87 


\section{LIST OF TABLES}

Supplementary Table S2.1 Ratio of day 105 umbilicus and CRL. 89

Supplementary Table S2.2A. Gestation day 55 and day 105 maternal leucocyte RNAseq summary using NCBI Bos taurus assembly ARS-UCD 1.2 ..............91

Supplementary Table S2.2B. Gestation day 55 and day 105 maternal leucocyte RNAseq summary using Ensembl Bos taurus assembly ARS-UCD 1.2 ......... 93

Supplementary Table S2.3A. Read counts of normalizers as per RNAseq..... 95

Supplementary Table S2.3B. Selection of normalizers for RT-PCR ................ 96

Supplementary Table S2.4A. Number of animals that expressed estrus and selection of animals for Exp IA

Supplementary Table S2.4B. Number of animals that expressed estrus and selection of animals for Exp IB and II. 98

Supplementary Table S2.5. Day 77 ultrasonography. 99

Supplementary Table S2.6A. Differentially expressed genes of day $105 \mathrm{Al}$, ART-normal and ART-LOS in maternal WBC transcriptome. 100

Supplementary Table S2.6B. Differentially expressed genes of day $105 \mathrm{Al}$, ART-normal and ART-LOS in maternal WBC transcriptome 101

Supplementary Table S2.6C. Differentially expressed genes of day $105 \mathrm{Al}$, ART-normal and ART-LOS in maternal WBC transcriptome. 102

Supplementary Table S2.6D. Differentially expressed genes of day $105 \mathrm{Al}$, ART-normal and ART-LOS in maternal WBC transcriptome. 103

Supplementary Table S2.6E. Differentially expressed genes of day $105 \mathrm{Al}$, ART-normal and ART-LOS in maternal WBC transcriptome. 104

Supplementary Table S2.6F. Differentially expressed genes of day $105 \mathrm{Al}$, ART-normal and ART-LOS in maternal WBC transcriptome. 105 


\begin{abstract}
Large offspring syndrome (LOS) is a fetal overgrowth condition observed in some bovine offspring produced in vitro. The main phenotypes of LOS is large body size due to overgrowth during development which can result in difficult birth, can lead to death of the dam and/or calf and can lead to financial losses to producers. Currently, no method exists that can be used to identify LOS during pregnancy. The goal of this study is to investigate if ultrasonographic measurements at day 55 of gestation and maternal blood biomarkers at day 55 and day 105 can be helpful to detect LOS carrying pregnancies.

Chapter 1, the literature review, will introduce LOS its phenotypes and molecular associations as well as the conditions that can potentiate LOS. In addition, two examples of spontaneous LOS and their associated financial losses are discussed. Chapter 1 will also introduce the usefulness of ultrasonographic fetometry and maternal blood biomarkers in bovine. Chapter 2, the research chapter, was set to determine if LOS in cattle is identifiable in the maternal blood during pregnancy and/or if fetal ultrasonographies of day 55 gestation may be used for the same purpose. Data included are: characterization of phenotypes associated with LOS, description of maternal white blood cell transcriptomes and information pertaining fetal size as determined by ultrasonographies and after collection of day 56 and 105 fetuses. This chapter has been submitted as a manuscript and it is currently under review.
\end{abstract}




\section{NOMENCLATURE}

$\begin{array}{ll}\text { 100PE } & \text { 100bp paired end } \\ \text { AD } & \text { Abdominal diameter } \\ \text { AH } & \text { Abdominal height } \\ \text { AML } & \text { Acute myeloid leukemia } \\ \text { ANOVA } & \text { Analysis of variance } \\ \text { ANRIL } & \text { Antisense non-coding RNA in the INK4 locus } \\ \text { AOS } & \text { Abnormal offspring syndrome } \\ \text { AI } & \text { Artificial insemination } \\ \text { ART } & \text { Assisted reproductive technologies } \\ \text { BWS } & \text { Beckwith-Wiedemann syndrome } \\ \text { BGI } & \text { Beijing Genomic Institute } \\ \text { BPD } & \text { Biparietal diameter } \\ \text { BSA } & \text { Bovine serum albumin } \\ \text { CA } & \text { Carbohydrate antigens } \\ \text { CV } & \text { Coefficient of variance } \\ \text { CIDR } & \text { Controlled internal drug release } \\ \text { CPM } & \text { Counts per million } \\ \text { CAU } & \text { Cross-section of the abdomen at the insertion of the } \\ \text { CRL } & \text { umbilical-cord } \\ \text { DE } & \text { Crown rump length } \\ \text { DEG } & \text { Differentially expressed } \\ \text { DMR } & \text { Differentially expressed genes } \\ \text { DPBS } & \text { Embrentially methylated regions } \\ \text { ET } & \text { EGFP }\end{array}$




\begin{tabular}{ll} 
FDR & False discovery rate \\
FL & Forelimb length \\
GnRH & Gonadotropin releasing hormone \\
GPCR & G-protein coupled receptor \\
HC & Head circumference \\
HL & Head length \\
HF & Heart failure \\
HG & Heart girth \\
IVP & In vitro production \\
ISG-15 & Interferon stimulated gene-15 \\
IETS & International embryo technology society \\
LIPCAR & Long non-coding cardiac associated RNA \\
LOS & Large offspring syndrome \\
LV & Left ventricle \\
MOET & Multiple ovulation embryo transfer \\
MI & Myocardial infarction \\
MU & University of Missouri \\
PBMCs & Peripheral blood monocytes \\
PVA & Polyvinyl alcohol \\
PAGs & Pregnancy associated glycoproteins \\
PG & Prostaglandin \\
PGF2a & Prostaglandin F2 alpha \\
SCNT & Thorandic cell nuclear transfer \\
SD & Thoracic diameter \\
TH & Uneight \\
UF & Stoviation \\
\hline
\end{tabular}


WBC

White blood cell 


\section{Chapter 1 - Literature Review}

\subsection{Large offspring syndrome (LOS)}

Technologies like somatic cell nuclear transfer (SCNT) and assisted reproductive technologies (ART) are useful to improve the genetic potential of the herd by selective breeding. ART or in vitro production (IVP) of embryos involves a variety of laboratory techniques to fertilize the oocyte and sperm to obtain large number of offspring from genetically superior animals or to obtain offspring from infertile animals. Collection of oocytes can be done either from the ovaries of live animals through transvaginal ovum retrieval method by piercing ovarian follicles through the vagina guided by ultrasonography, or from slaughterhouse ovaries. Collected oocytes are first matured in maturation medium in vitro and then fertilized in vitro with capacitated sperm and then zygotes are cultured to the desired stage of development up to the blastocyst stage. If desired, embryo transfer (ET) is done to synchronized animals or embryos are stored after freezing for later use.

If superovulation has been used to get multiple oocytes from live animals, it is generally followed by artificial insemination ( $\mathrm{Al})$ and then embryos are collected by flushing the uterus. Embryos then may be frozen or immediately transferred to recipient animals. This procedure is called multiple ovulation embryo transfer (MOET). 
In SCNT, however, embryos are produced using the DNA of somatic cells which is injected into enucleated oocytes instead of by in vitro fertilization. Compared to SCNT, IVP is a less invasive method which more closely mimics natural fertilization and embryo development.

Since the inception of ART, various reports of offspring with various abnormalities have been noted. The first such case of a "large calf" was reported in cattle in an SCNT study by Willadsen et al. in 1991 (1), while Behboodi and coworkers reported the first large calf produced by ART in 1995 (2). In subsequent years, more cases of large calves were reported (3-5) and the phenomenon was described as "large offspring phenomenon" by Walker and coworkers (6) and then coined as "large offspring syndrome" (LOS) in a review by Young (7). Besides the overgrowth phenotype, other abnormalities such as large organs and placental abnormalities were also observed in ART/SCNTproduced offspring of ruminants (cow and sheep; $(1-3,5,8-13)$ and the syndrome was then also classified as abnormal offspring syndrome (AOS; (14).

\subsection{Characteristics of large offspring syndrome}

\subsubsection{Phenotypes}

As the name implies, the main characteristic of LOS is fetal or calf overgrowth. In some instances, this fetal overgrowth leads to difficulty in birth 
and in some cases, caesarean section or assisted delivery is required (15). Another feature of LOS in ruminants is visceromegaly (large internal organs) which was observed in sheep produced in vitro (11). In that study, the liver, heart, kidneys and plantaris and tibialis anterior muscle masses of day 61 fetuses and the liver and heart of fetuses at day 125 of gestation produced in vitro were larger than the control fetuses (11). The control fetuses for that study were produced in vivo after embryo transfer of day 6 blastocysts harvested from superovulated donor ewes which suggests that the embryo transfer technique does not affect fetal development, although it is difficult to determine this fact in the absence of controls produced from artificial insemination. In some instances, LOS calves or fetuses also show ear malformation (16), musculoskeletal deformities, abnormal spinal cords and limbs (8) and paresis of hind limbs or ataxia $(5,15)$.

Notable placental abnormalities such as hydro-allantois (1), polyhydramnios, umbilical hernias, allantois development defects and abnormal placental vasculature $(3,5,8)$ had been also observed in LOS fetuses. In addition, SCNT LOS fetuses have also been shown to have placental overgrowth (17) with the ratio of fetal to total placentome weight being lower in the SCNT group than in the control group at 220 days of gestation. Furthermore, in that study, stereological analysis of the placenta showed deregulation of the growth of cotyledons which led to the thinning of the maternal epithelium within the placentomes and increased trophoblastic surface in the placenta (17). They suggested that abdominal ascites, the larger heart and umbilical cord observed in 
those SCNT fetuses may have been the consequences of these placental abnormalities and named LOS as "large placenta syndrome" (17). This suggests that the level of perturbation in placental development can define the outcome of the fetuses. However, the rudimentary or marginal chorioallantois development during day 35 to day 60 of gestation of cloned fetuses can lead to higher embryonic mortality when compared to in vivo or in vitro derived fetuses (18) which may partially explain those findings.

\subsubsection{Molecular Associations}

Besides, phenotypic abnormalities, LOS also has epigenetic irregularities such as loss-of-imprinting (16). Imprinted genes are genes which show monoallelic parental-specific expression in a developmental stage-specific, cellspecific or species-specific manner. Imprinting disorder are disorders which occurs due to misregulation of imprinted gene expression resulting from perturbations in epigenetic mechanisms. In Chen et al (2013) they observed that seven out of 27 fetuses produced by ART along with serum supplementation were overgrown (>97 percentile of the average weight of $\mathrm{Al}$ [control] fetuses) at day 105 of gestation and two out of these seven overgrown ART fetuses had shown biallelic expression of the imprinted gene KCNQ1OT1 in various organs (16). Furthermore, the loss of monoallelic expression of KCNQ1OT1 was shown to be associated with loss of methylation on the maternal allele at the KvDMR1 locus, an imprinting control region (16). Furthermore, other imprinted genes 
were also misregulated in LOS fetuses and this loss-of-imprinting was positively associated with fetal overgrowth (19). In addition, when transcriptome analyses of muscle, liver, kidney and brain were compared between LOS and Al fetuses, multiple differentially expressed genes (DEG) in LOS fetuses were associated with distinct gene pathways, including pathways associated with myoblast proliferation and fusion into myotubes in skeletal muscle (20). Furthermore, DNA methylome analysis of skeletal muscle of LOS fetuses found multiple differentially methylated regions (DMR) but most of them were not associated with identified DEGs (20). However, misregulation of IGF2R in LOS fetuses was associated with altered DNA methylation at DMR1 and DMR2 of the IGF2R locus (20) which is similar to the loss-of-imprinting at IGF2R observed in sheep LOS fetuses (21). This suggests that LOS in sheep and cattle share misregulation of the IGF2R locus.

\subsection{Beckwith Wiedemann Syndrome}

Beckwith-Wiedemann syndrome (BWS), a congenital epigenetic overgrowth disorder in humans, has several phenotypic and epigenetic similarities with LOS (16). In 2013, there was an epidemiological prevalence study of BWS which suggested that in northwest Italy the prevalence of BWS is 1 in 10,340 live births (22). Use of ART has been associated with an increased incidence of BWS. When populations of naturally occurring BWS and ARTinduced BWS in Piemonte Italy were compared, the relative risk of BWS in the ART group was 10.7 (23). Major cardinal phenotypes of BWS are macrosomia, exomphalos, lateralized overgrowth and multifocal and/or bilateral Wilms tumor 
or nephroblastomatosis (24). Exomphalos is the condition when the herniation of abdominal organs occurs through a central abdominal wall defect.

Furthermore, secondary phenotypes of BWS are ear creases, nephromegaly, transient hypoglycaemia, facial nevus flammeus, and umbilical hernia (24). The main molecular defects which lead to BWS in humans, is on chromosome $11 \mathrm{p} 15$ which includes defects in DNA methylation, incorrect expression of imprinted genes, changes of chromosomal contents and gene mutations (25). Loss-ofimprinting at KvDMR1, leading to downregulation of the maternally-expressed gene CDKN1C, has been shown to occur in BWS (26), which is similar to what has been shown for LOS (16), making LOS an appropriate animal model to study BWS.

\subsection{Conditions that can potentiate LOS}

It is not yet clear how ART induces LOS nor the mechanisms which can lead to LOS. However, possible factors which can lead to this syndrome are serum and/or co-coculture of embryos with somatic cells during in vitro embryo culture, asynchronous uterine environment, and high urea diet during the pregnancy.

\subsubsection{Serum supplementation and/or co-culture with somatic cells}

\subsubsection{Preimplantation stage embryos}

ART procedures can cause cellular differences in growing embryos.

When preimplantation stage embryos cultured in serum-free and serum- 
supplemented media along with bovine cumulus/granulosa cells were analyzed using electron microscopy, the ultrastructural features of morula stage and blastocyst were different (27). For example, serum-supplemented cultured embryos had large lipid droplets and fewer lysosome-like vesicles at the morula stage and in the cytoplasm of trophoblast and inner cell mass cells at the blastocyst stage compared to serum-free cultured embryos (27). Further, culturing embryos in the presence of high concentrations of serum or bovine serum albumin (BSA) show an increased number of cells on day seven and they are larger on day 12 when compared to their in vivo counterparts (28).

Supplementation of serum during culture has been also shown to alter mRNA expression in preimplantation stage embryos. For example, the relative abundance of transcripts such as $H s p$ and $D c$ III were higher in morula stage in vitro produced embryos compare to in vivo controls (29). In addition, developmentally important genes such as Hsp70.1, Cu/Zn-SOD, Glut-3, Glut-4, $b F G F$, and IGFI-R were also been reported as misregulated in day 12 in vitro produced blastocysts compare to in vivo produced embryos (28). From the aforementioned studies, it may be concluded that the differences in mRNA expression might be due to the serum, however, one cannot eliminate the possibility that the effects observed may be the result of culture itself, and not serum, since all the comparisons were made with in vivo produced embryos. To this effect, comparison of mRNA abundance of morula, blastocyst and hatched blastocyst cultured in two different culture media (i.e. serum or polyvinyl alcohol (PVA)), showed differences in specific mRNA transcripts between those cultured 
systems (30). For example, connexin43 mRNA expression virtually disappeared from the morula stage onward in serum-supplemented group, but then reappeared in hatched blastocyst, whereas it was present in all three stages in PVA medium grown group (30). Thus, one can hypothesize that these perturbations in gene expression during preimplantation development, may lead to deviations in embryo and fetal development and may lead to an increased incidence of oversized fetuses or calves. However, to date no data exists that can make this correlation since no studies have been done in which experimental embryos are followed to later stages of pregnancy or birth, to arrive at those conclusions.

\subsubsection{Fetal and placental growth}

During the 1990's, various IVF and ET studies produced fetuses with serum supplementation and/or coculture embryos with somatic cells derived from buffalo rat liver cells or bovine granulosa or oviductal epithelial cells and they observed increase incidences of higher fetal or calf weight, dystocia and calf mortalities $(2,3,31)$. For example, fetal weight of day 125 sheep fetuses derived from co-cultured embryos were $34 \%$ heavier than controls (11). Similarly, in cattle, there was a report of birth of larger calves derived from cocultured embryos compare to calves derived from Al (2). At first, LOS was thought to be due to extended gestation, but when comparison of gestation length between large calves derived from ART ((271 \pm 2.4$)$ days $)$ and normal weighing Al calves ((277 \pm 1.2$)$ days) was done, it showed that there was no association between the birth of large calves and increased gestation length (2). 
However, not all fetuses produced by ART lead to an oversized fetus. For example, when using a granulosa cell coculture in vitro system in sheep, only four out of 20 day 61 and three out of 13 day 125 were oversized (greater than 3 SD of mean of control fetal weight) when compared to their control counterparts (11). In addition, the variations observed in LOS phenotypes varies between laboratories and may depend on the type of ART procedure used to produce the embryos (7). For example, when comparing fetuses produced from embryos grown with $5 \%$ vs. $10 \%$ serum supplementation and compared to Al fetuses at day 80 of gestation, fetuses from the $10 \%$ serum-supplemented group were heavier and their internal organs such as liver and heart were larger when compared to Al fetuses, whereas fetuses from $5 \%$ serum-supplemented group didn't show any overgrowth phenotype (32).

ART has also been shown to modify the fetal musculature. For example, in sheep, when in vivo produced zygotes were cocultured with bovine granulosa cells for five days and transferred to synchronous ewes, an increase in day 125 plantaris muscle weights were seen when compared to control fetuses (33). Furthermore, examination of myogenesis in plantaris muscle revealed that primary and secondary muscle fiber areas of day 61 and day 125 collected fetuses from cocultured group were higher when compared to those observed in control fetuses (33). Thus, it is suggested that coculturing embryos with bovine granulosa cells alters the myogenic programming and can lead to abnormally large muscles in oversized fetuses (33). Here, control fetuses were produced from in vivo embryo collected at day 6 of development and transferred to 
synchronous ewes which eliminates potential problems with in vitro oocyte maturation and in vitro fertilization, which supports the notion that embryo culture can affect subsequent fetal development.

Besides overgrowth, fetuses derived from embryos, cocultured with bovine oviductal epithelial cells show various placental variations when compared to their in-vivo counterparts (34). Placentomes of day 37 in vitro produced singleton or twin fetuses were smaller and thinner compared to controls, whereas placentomes of in-vitro derived singleton fetuses collected at day 72 and day 93 of pregnancy, were longer and thinner. However, at term, larger cotyledons were found in the in vitro group which were also shown to be associated with a larger cotyledonary surface area found in the fetal horn compare to the in vivo group (34).

As mentioned earlier, ART can alter imprinted and no-imprinted gene expression in various tissues of developing fetuses and also had been shown to be associated with fetal overgrowth (19). When comparison of placental gene expression at day 50 of pregnancy between in-vitro produced embryos and invivo embryos was done, several genes associated with immune system, organ and blood vessel development and extracellular matrix organization were found to be misregulated in the in vitro group (35). That suggests that this aberrant gene expression may lead to placental abnormalities and can have adverse impact on development and health of the offspring (35). 


\subsubsection{Asynchronous uterine environment}

Asynchronous uterine environment during pregnancy can also induce fetal growth. For example, when day three ovine embryos were transferred to ewes which were three days more advanced that their chronological age, fetal growth was accelerated when compared to the synchronous controls (Wilmut and Sales, 1981). However, mortality rate of those asynchronous embryos was also higher (36). In another study, when progesterone was administered during early pregnancy (one to three days of gestation) in sheep, to induce an asynchronized uterine environment, fetuses were heavier and had a larger heart, increased skeletal muscle weight, and brain weight at day 74 of pregnancy (38). The reason behind this phenomenon may be that embryos in an advanced uterine environment might have received one or more secretory signals earlier than expected time, which led to earlier growth of those embryos. Similar to ART, transferring day three embryos into a day six uterine environment led to an increase in the total number of muscle fibers in plantaris muscles of day 110 and day 125 fetuses which suggested a prolonged hyperplasia (39). Furthermore, they also observed alterations in the ratio of secondary-to-primary fibers in plantaris muscle from the asynchronous group (39). However, they did not see a difference in fetal weight at day 110 or 125 of gestation (39).

\subsubsection{High urea diet during pregnancy}

High urea diet has been shown to be associated with an increase in fetal growth in sheep. For example, ewes fed excess amounts of urea from 21 days 
before mating to day 63 of gestation, showed increased embryo mortality and fetal growth in the surviving embryos, as well as a higher birth weight (40). Furthermore, they observed increased urea and ammonia in the plasma and uterus of ewes which might have caused up regulation in metabolism in some embryos which could have affected either the oocyte or embryo (or both) leading to enhanced fetal growth (40).

\subsection{LOS-associated financial burden to the industry}

Since LOS calves can have higher bodyweight and greater size than control calves, it can lead to dystocia and can require surgical fetal extraction (15). Furthermore, LOS calves have been associated with lower neonatal viability (2). However, there is no published data on the economic loss experienced by the industry.

As oversized calves can lead to dystocia, one can relate the consequences of dystocia to LOS. Often cesarean section or assisted delivery is required to deal with dystocia, and this could have adverse impact on cows and newborn calves. A study by Linden et. showed that higher calf birthweight and calf size can increase the chances of lameness in cows after delivery (41). It has been also shown that calf mortality rate (12.4\%) after caesarean section is higher than calves delivered from normal delivery (5.2\%) (42). In addition, severe dystocia increases the chances of stillbirth by approximately 20 times (43) and also increase the respiratory and digestive disorders in calves born from these cows (43). In addition, dystocia can also have an adverse impact on milk production and increase the calving to conception interval. For example, dystocia 
leads to an average loss of $4.9 \mathrm{~kg}$ of milk per day in high yielding cows (44). Furthermore, It can also increase 2 to 3 days from calving to next service in cows (45) and decrease the conception rate at first service after it which together increase calving to conception interval 6 to 12 days (45). In short, economic losses also depend on consequences after birth of LOS calves.

Next are two examples of estimated economic losses as a result of LOS:

\subsubsection{Example 1 (Oklahoma, 2019)}

Six continental large calves were produced through embryo transfer by MOET and they weighed 51 to $65 \mathrm{~kg}$ and needed induced delivery or cesarean section. Furthermore, four out of six recipient cows also died after delivery. Below is the figure summarizing the estimated economic losses incurred by this embryo transfer technician. The estimated total loss in terms of dollars was $\$ 28,832.37$ (Figure 1.1A).

\subsubsection{Example 2 (Missouri, 2019)}

Another case of LOS is from a local farm in Missouri. A dead Charolais calf weighing $78 \mathrm{~kg}$ was delivered at the University of Missouri Veterinary hospital through cesarean section. Figure 1.1 B shows the estimated economic loss $(\$ 29,200)$ suffered by this local producer. 

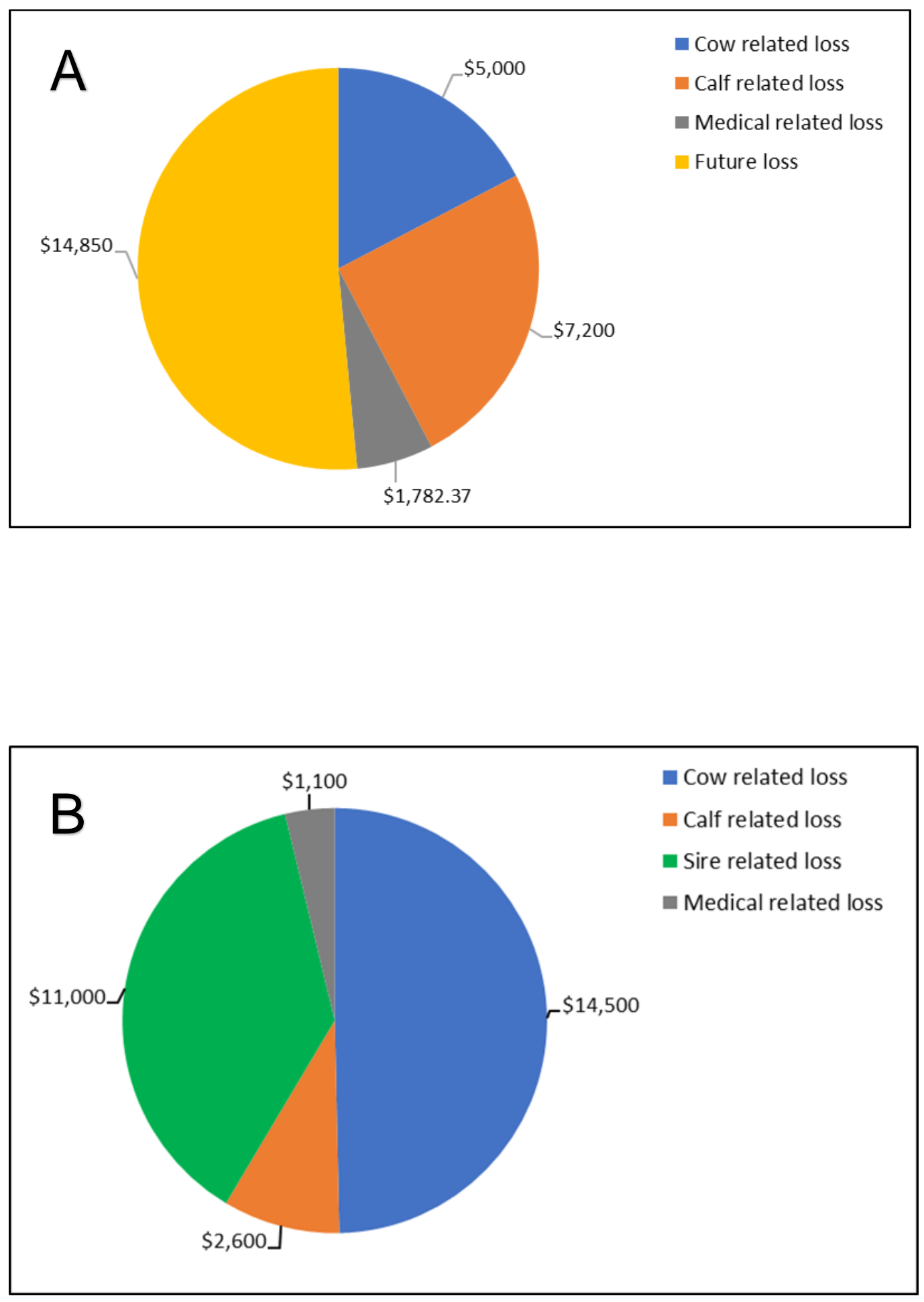

Figure 1.1 
Figure 1.1 Estimated economic loss. (A) Case of Oklahoma LOS. Cow related loss $=\$ 5000$ ( $4 \times \$ 1250$ to replace with open $6 \mathrm{y} / 0$ cows $)$. Calf related loss $=$ $\$ 7200$ (4 $\times \$ 1800$ for embryo calves). Medical related loss $=\$ 1782.37$ (Veterinary service etc.). Future loss $=\$ 14,850$ (4 cows $\times 4$ more calves per cow x 450lbs $x \$ 1.65$ ). (B) Case of Missouri LOS. Cow related loss (current + predicted) $=\$ 14,500$ (dam valued at $\$ 2600$, sold for salvage $\$ 500+$ value of next four calves as yearlings were expected $-\$ 12400)$. Calf related loss $(77 \mathrm{~kg})$ $=\$ 2600$ (average selling price of their yearling bulls). Sire related loss $=\$ 11,000$ (sire cost - had to sell to market after SLOS son). Medical related loss $=\$ 1,100$ (Veterinary services). 


\subsection{Ultrasonographic morphometry as a non-invasive method to identify LOS}

\subsubsection{Use of transrectal ultrasonography to identify fetal abnormalities}

Since 1953, it has been clear that ultrasonography can be useful for clinical purposes such as the identification of tumors (46) although this technology can be used for purposes beyond the identification of diseased tissue. Ultrasonography is the most convenient and economic non-invasive method to identify fetal developmental abnormalities during pregnancy. In humans, ultrasonography can detect various fetal abnormalities such as lethal muscle and skeletal disorders, spina-bifida, hydrocephalus, Down's syndrome, complex cardiac malformations, non-lethal dwarfing syndromes, anterior abdominal wall defects, diaphragmatic hernia, congenital myotonic dystrophy, haemoglobinopathy and many others (47). Although the overall accuracy of those detections was 55\%, it helped to decrease overall prevalence of those abnormalities up to $20 \%$ by terminating some of those pregnancies (47). Current advancements in ultrasonographic techniques have led to increased accuracy of detection of fetal developmental defects. For example, when various body malformations including macrocrania, cerebellar hypoplasia, enlarged kidneys and others were accessed through ultrasonography in three different trimesters, the overall accuracy of those structural anomalies were $93.73 \%, 94.43 \%$ and 93.95\% for first, second and third trimester of pregnancy, respectively (48). In addition, when comparison of various fetal fat body mass measurements between mothers with gestational diabetes and normal pregnant women, all 
ultrasonographic measurements such as anterior abdominal wall thickness, subscapular thickness, mid-upper arm and mid-thigh subcutaneous areas fat mass, were higher in fetuses of mothers with gestational diabetes (49). These data suggest that ultrasonography can be useful to identify the disproportionate development of human fetuses (49).

\subsubsection{Relationship between fetal development and fetal morphometry}

As in humans, ultrasonography is extensively used in cattle. Fetal age can be estimated in cattle by measuring fetal crown-rump length $(50,51)$ and fetal crown-nose length during the first trimester of pregnancy (51) with crownrump length being most precise for age estimation on gestation day 30 (50). However, other measurements such as uterine diameter, head, trunk and nose diameter can also be useful to estimate fetal age in cattle (50). Furthermore, transrectal ultrasonography of various organs and body parts of developing bovine fetuses during the first seven months of pregnancy showed that head, thorax, abdomen and pelvis regions can be readily accessible during the first four months of development, whereas, during five to seven months of gestation, thoracic, abdominal and pelvic regions is not easily accessible but fetal head can be accessible for ultrasonography in $80 \%$ of developing fetuses (52).

Furthermore, ultrasonography has also been used to better characterize variations of conceptus development in in vivo and in vitro derived bovine pregnancies based on fetal measurements (34). For instance, ultrasonographic 
examinations from gestation day 30 to term found that in vitro produced fetuses were smaller than in vivo ones during early pregnancy from day 37 to day 58 (34).

Since the main phenotype of LOS is giantism, there is a possibility that ultrasonography can help identify this fetal overgrowth in LOS cases during early pregnancy. In past, ultrasonography has been used to measure variations in growth in the developing fetuses. For example, weekly comparisons of fetal development from day 35 to day 108 days of gestation using fetal ultrasound dimensions such as biparietal diameter of the cranium (BPD) and cross-section of the abdomen at the insertion of the umbilical cord (CAU) between three different methods of embryo production (i.e. MOET, IVP co-culture or IVP SOF medium) have been done. Investigators found no differences between groups, thus, it was suggested that there is no difference in fetal growth in fetuses produced from the aforementioned techniques during early pregnancy (53). However, in that study, fetal growth was compared among three different procedures in which embryos are manipulated, not to an Al group, so it is not clear that ART produced fetuses follow the same fetal growth patterns as AI fetuses would or not. That question was answered by Bertolini et al (2002) who compared the fetal morphometry between IVP fetuses and in vivo produced fetuses from day 30 of gestation to term and found that fetal crown-rump length of in vivo produced fetuses at day 37 to day 58 of gestation was smaller than in vivo controls (34). Furthermore, in vitro produced calves were higher in their birth-weight compare to in vivo produced calves and researchers suggested that 
it may be due to the placenta trying to erase the effect of early growth retardation which led to aberrant placental development and compensatory fetal growth leading to LOS (34). Those authors suggested that IVP calves show biphasic growth, a period of growth retardation during early gestation followed by a placenta-driven growth overcompensation later in development (34). However, a SCNT study suggests that placental deficiencies in cloned fetuses during early pregnancy can lead to developmental retardation and increase in embryo mortality (54).

\subsection{Fetal-maternal communication and their influence on pregnancy associated markers}

\subsubsection{Fetal-maternal exchange}

The placenta transfers nutrients and oxygen to the developing fetus and removes the waste products from the fetus. There are four types of placenta in eutherian mammals which are defined on the basis of invasiveness of the fetal chorioallantois membranes to the maternal uterine tissue (55). Humans have hemochorial placenta which allow fetal chorioallantois membranes to be in direct contact with the maternal blood circulation (56). This type of placenta allow fetal DNA, RNA or other fetal products to easily pass to the maternal blood (57). The presence of fetal cell and other components in maternal blood is referred to as microchimerism (58).

Cattle have very distinct type of placenta, namely syndesmochorial, in which the trophoblast cells do not invade the maternal uterine tissue as deeply as 
occurs in hemochorial type placentas (59). In syndesmochorial placentas, degradation of the epithelium of the uterine caruncles occurs through several hormones and proteases secreted by the trophoblast cells at the preimplantation period, $(60,61)$ and subsequently, the trophectoderm adheres to caruncles and form a cotyledonary placenta. After successful implantation, uterine remodeling helps to restore the uterine epithelium. During this stage of pregnancy and even during later stage of pregnancies, trophoblast giant cells or binucleate cells, fuse with maternal endothelial cells and form the syn-endotheliochorial cells (62), which allows better transportation of nutrients to the fetus. These placental regions are called as syncytial regions and this placentation is called as "syn" epitheliochorial placenta.

Early on it was thought that syndesmochorial placentas do not allow the passage of any fetal contents into the maternal circulation. However, several studies have shown the presence of fetal DNA and other fetal factors in the maternal blood (63-65). Furthermore, when maternal blood of enhanced green fluorescent protein (eGFP) expressing transgenic bovine embryos was analyzed at day 60 of gestation, eGFP was detected in all pregnancies and testis-specific Y-encoded protein was also detected in male-specific pregnancies (66). Furthermore, eGFP protein and mRNA were also observed in the intercaruncular chorion and intercaruncular endometrium on day 60 of pregnancy (66). Thus, authors concluded that fetal DNA and protein can transfer to the maternal circulation. The exact mechanism for this microchimerism in cattle is still not clear but it was suggested that transfer of fetus derived molecules into maternal 
circulation may be possible through nonclassical protein secretion pathways, through transtrophoblastic-like channels and/or by placenta apoptotic processes (66).

\subsubsection{Blood Biomarkers}

Biomarkers are defined as "cellular, biochemical or molecular alterations that are measurable in biological media such as tissues, cells, or fluids" (67). Biomarkers can be used to diagnose diseases and can also be used to predict the cause and progression of disease as well as regression or outcome of treatment. In the past few decades, technological advancements in biomedical technologies have led to a better understanding of the pathogenic mechanism of multiple diseases that have allowed to access the risk associated with them through various biomarkers especially blood biomarkers. In support of that, earlier publications brought the concept on how these transcriptomic biosignatures of blood cells can be useful indicators of prognosis in the oncology field $(68,69)$. For example, detection of three carbohydrate antigens (CA) CA50, CA242 and CA199 in serum helped to increase accuracy and predictability of early stage pancreatic ductal adenocarcinoma in human (70). In addition, when gene expression analysis of approximately 13,000 unique genes of acute myeloid leukemia (AML) patients peripheral blood or bone marrow was done, unsupervised hierarchical clustering revealed 16 different clusters that helped to better classify AML (69). In the aforementioned study, gene expression was measured using GeneChips which was costly and time 
consuming. However, recent advancements in RNA biology associated technologies such as mRNA sequencing, make it easier and more economical to perform whole transcriptome analysis that identify transcript beyond known protein coding genes. For example, when whole transcriptome of the plasma RNA of patients with or without left ventricular (LV) remodeling after myocardial infarction (MI) was done, the long non-coding RNA (IncRNA) named Long noncoding cardiac associated RNA (LIPCAR) was found to be downregulated in the patients with LV remodeling one year after MI, whereas this gene became upregulated during the development of heart failure $(\mathrm{HF})$. In another study, the novel circular IncRNA, ANRIL (antisense non-coding RNA in the INK4 locus), which regulates gene expression of the INK4/ARF gene, was shown to be a useful biomarker to assess the risk of atherosclerotic vascular disease (71).

Throughout gestation, dynamic inflammatory changes occur in animals either by the animal's own hormones and/or under the influence of the fetus and some of them can be detected in blood. For example, in ruminants, interferontau secreted by the trophoblast cells of the developing conceptus (72), has been shown to induce various interferon associated genes such as interferon stimulated gene -15 (ISG-15) in maternal peripheral blood monocytes (PBMCs) at day 19 of gestation (73-76). Thus, leukocyte molecules can also be used as biomarkers for early diagnosis of pregnancy in cows (73-76). In addition, during fetal development, the placenta secretes pregnancy associated proteins (PAGs) into the maternal blood. Radioimmunoassay has been developed to identify PAGs in serum gestation day $28(77,78)$. This biotechnology is also useful for 
complicated pregnancies, for example, expression of ADAMTS2 in leucocytes is increase in women during spontaneous preterm labor when compared to same gestational aged non labor women which suggest that ADAMTS2 can be used as a marker of premature labor in human (79). Furthermore, in preeclamptic pregnancies, various genes such as $C O L 1 A 1, I K B K B, R B I$ are misregulated when compared to normal pregnant patients $(80)$.

Since various blood biomarkers has been shown to be useful to identify different states of health in both human and cattle, it can be hypothesized that blood biomarkers can also be useful to identify the LOS pregnancies in cattle. 


\section{Rationale for Thesis}

LOS is a syndrome in ruminants characterized by fetal overgrowth,

visceromegaly, and various placental abnormalities. Since some LOS calves can be oversized and this can lead to dystocia, sometimes cesarean section or assisted delivery is required. Dystocia can increase the chances of death of newborn calves and dams and increase the chances of having subsequent mastitis and lameness in dams. Furthermore, dystocia can decrease milk production and increase the calving to conception interval. These consequences of dystocia can have major adverse economic impact to producers. Thus, identification of LOS early during pregnancy would help producers minimize some of these losses by terminating the pregnancy or by preparing for a difficult parturition for LOS carrying dams.

Ultrasonography is a non-invasive method which is widely used in farm animals to detect pregnancy and fetal sex. Furthermore, ultrasonography has also been shown to be useful in the identification of various developmental abnormalities during pregnancy in humans, thus, one can hypothesize that ultrasonography can be useful to identify LOS fetuses during early pregnancy in cattle.

Pregnancy leads to dynamic changes in the body of animals and those changes can be detected in the blood as exemplified by the use of serum PAGs to identify the status of pregnancy in cattle. Furthermore, interferon stimulated genes such as ISG15 can also be detected in maternal blood leucocytes. In addition, complicated pregnancies such as preeclampsia in humans can also 
alter several gene expressions such as $C O L 1 A 1, I K B K B$ and $R B I$ in maternal blood leucocytes which can be used to identify preeclamptic pregnancies in pregnant women. Although it is possible that LOS can also alter gene expression of maternal blood leucocytes during pregnancy, no evidence is available to support this hypothesis.

The main goal of the current study is to determine the usefulness of fetal morphometry through ultrasonography and maternal blood to identify LOS prior to day 105 of gestation (pregnancy in cattle $=\sim 280$ days). For this, I hypothesize that ultrasound measurements of day 55 fetuses and maternal blood biomarkers on day 55 and day 105 of gestation will be useful to detect LOS. 


\section{Chapter 2 - Efforts to identify the large offspring syndrome during \\ pregnancy through ultrasonography and maternal blood transcriptome \\ analyses}

Note: this Chapter has been submitted to the Federation of American Societies for Experimental Biology for consideration of publication and will include the following people as authors:

Bhaumik Narendrabhai Patel ${ }^{1}$, Zhoulin Wu ${ }^{1,2}$, Darren Erich Hagen ${ }^{3}$, Edgar Joel Soto-Moreno ${ }^{1}$, Yahan Li ${ }^{1}$, Chris Kim ${ }^{1}$, Cliff Miller ${ }^{4}$, Anna Katherine Goldkamp ${ }^{3}$, Fred Williams III ${ }^{5}$, Elizabeth Jannaman ${ }^{6}$, Yao Xiao ${ }^{6}$, Paula Tribulo ${ }^{6,7}$, Eliab Estrada-Cortes ${ }^{6,8}$, Peter James Hansen ${ }^{6}$, Christine Marie Spinka ${ }^{9}$, Neal Martin ${ }^{10}$, Christine G. Elsik ${ }^{1,9}$, Astrid Roshealy Brau-Rodriguez ${ }^{1}$, Rocío Melissa Rivera ${ }^{1 *}$

${ }^{1}$ Division of Animal Sciences, University of Missouri, Columbia, MO, ${ }^{3}$ Department of Animal and Food Sciences, Oklahoma State University, ${ }^{4}$ Green Hills Veterinary Clinic, MO, ${ }^{5}$ Department of Veterinary Pathobiology, University of Missouri, Columbia, MO, ${ }^{6}$ Department of Animal Sciences, University of Florida, Gainesville, FL, ${ }^{9}$ Division of Plant Sciences, University of Missouri, Columbia, $\mathrm{MO},{ }^{10}$ Martin Veterinary Services, Centralia, MO.

Present Address: ${ }^{2}$ Key Lab of Meat Processing of Sichuan Province, Chengdu University, Chengdu, China, ${ }^{7}$ Instituto de Reproducción Animal, Córdoba, and CONICET, Córdoba, ARGENTINA X5000, ${ }^{8}$ Centro Altos de Jalisco INIFAP México, 


\subsection{Abstract:}

In vitro production of bovine embryos can result in large/abnormal offspring syndrome (LOS), a condition characterized by macrosomia, macroglossia, exomphalos and placental abnormalities. LOS can lead to the death of dam and calf. Currently, no test exists to identify LOS pregnancies. We hypothesized that ultrasonography and/or maternal blood markers are useful to identify LOS. Bovine fetuses were generated by artificial insemination (control) or produced in vitro. Fetal ultrasound measurements were taken on gestation day 55 (d55) and surgical fetal collections performed on d56 or d105. Maternal blood was collected on gestation d55 and d105. On d56 and d105, fetuses produced in vitro weighing $\geq 97$ percentiles of the Al weight were considered as LOS. D55 ultrasonographies were not useful to identify LOS on d56 fetuses, however for d105 fetuses, abdominal height and thoracic height were larger in LOS when compared to controls, and thoracic diameter and thoracic height were only larger in male fetuses. To determine whether maternal blood may be used to identify LOS on d55 and/or d105 of gestation, leukocyte mRNA from 23 pregnant females was isolated and sequenced using a short-read platform. Unsupervised clustering grouped 20 samples by animal ( $n=10$ heifers) rather than by stage of pregnancy. Leukocyte gene expression analyses revealed $>3,500$ differentially expressed genes in females carrying the two largest LOS fetuses. In summary, our study suggests that abdominal height and thoracic height from d55 fetal morphometry and transcript mount of ATF7IP from d105 maternal leukocytes may be useful to identify extreme cases of LOS. 
Keywords: Large offspring syndrome, abnormal offspring syndrome, assisted reproductive technologies, fetal morphometry, maternal blood biomarker.

\subsection{INTRODUCTION}

Large offspring syndrome (LOS) is an overgrowth condition observed in ruminant fetuses and neonates $(6,16)$. LOS was first reported in 1991 in a cloned calf produced via nuclear transfer (1). Later, in 1995, overgrowth was reported as a result of non-invasive assisted reproductive technology (ART) procedures (2). At that time, the overgrown animals were called "large calves" and the syndrome was called LOS (7). As the use of ART in ruminants increased during the next decade, so did the number of LOS report $(7,14,32$, 34, 81-83). The main characteristic of LOS is overgrowth, which in some instances can result in calves weighing twice the average birthweight of their breed (2). However, LOS in ruminants is a complex disorder with other phenotypes observed including visceromegaly, large tongue, increased incidence of hydro-allantois, abnormal limbs and spinal cord, ear malformation, hypoglycemia and umbilical hernia $(14,16,32,34,63,81,83,84)$. Because of these varied phenotypes, this syndrome is also known as abnormal offspring syndrome (AOS) (14).

Even though it is now clear that LOS/AOS is a multi-locus loss-ofimprinting (i.e. epigenetic) condition (19) it is still not known what triggers LOS and which ART (e.g. in vitro maturation of oocytes, in vitro fertilization, in vitro 
embryo culture and embryo transfer) is involved. Most reported cases of LOS in the literature were produced using serum supplementation during oocyte maturation and/or during embryo culture, which suggest that serum may be a factor promoting the syndrome $(16,19,20,30,85-88)$. Serum has been experimentally determined to cause LOS in sheep $(89,90)$ and a large portion of bovine calves derived from embryos cultured in serum containing medium can develop LOS (16). Even though published data demonstrates that serum supplementation promotes AOS in sheep (11), to date, no controlled study has been done in cattle to specifically answer this question. Further, co-culture of embryos with somatic cells as also been shown to promote LOS $(5,11)$. Of note, is that all studies in bovine in which LOS was associated with co-culture also used serum in their culture medium. Besides ART, particularly in sheep, asynchronous pregnancies and high urea diet during gestation have also led to fetal overgrowth $(36,37,40)$. In addition, the syndrome can also occur in fetuses and calves derived from embryos cultured without serum supplementation or coculture $(91,92)$ and more recently we have documented that this syndrome occurs spontaneously in cattle ( (93) and Rivera et al. in press). The latter is of interest as there is a similar loss-of-imprinting overgrowth syndrome in humans, namely Beckwith-Wiedemann syndrome, which occurs naturally and its incidence is increased in children conceived by ART (23).

$A R T$ is the method of choice in cattle when trying to improve genetic merit of the offspring (94) and is also used experimentally (95-97) including for the generation of genetically manipulated embryos (98). For obvious reasons, 
reports on the incidence of LOS in the industry are lacking, therefore its incidence is not known (99).

Due to its large size, LOS can cause dystocia and sometimes, cesarean section may be needed for delivery (100). Dystocia can also increase the risk of metritis after parturition (101). Even if the newborn calf survives the difficult birth, the enlarged tongue or extreme body weight make suckling difficult, thus increasing the chances of postnatal death (102). In addition, to the possible death of calves and cows, veterinary costs and the associated negative economic impact in terms of losses in milk, fat, and protein yields in the subsequent lactation are financial losses as a result of LOS $(41,103)$. For example, two independent LOS cases have been recently reported (Rivera et al., 2021 in press), one by an embryo transfer technician in which the embryos were produced by multiple ovulation embryo transfer and another a case of LOS following natural mating (i.e. spontaneous LOS). The total estimated losses from each of those LOS pregnancies were approximately $\$ 30,000$. These monetary losses could have been minimized, if the early identification of LOS was possible. To date, however, no test exists to predict LOS pregnancies in cattle; thus, it is of particular interest to find a biomarker to identify fetal overgrowth early during gestation to help producers prepare for a difficult birth or choose to terminate the pregnancy.

Ultrasound is a valuable non-invasive and repeatable tool that has been widely used in cattle to determine fetal growth $(34,104,105)$, fetal age $(50,52$, 106), fetal sex (107) and clinical pathologies such as mummified fetuses or 
endometritis (108). In humans, crown rump length, biparietal diameter and/or head circumference are used to determine gestational age $(109,110)$ and head circumference, abdominal circumference and forelimb length have been shown to be useful to estimate the fetal growth (111). Furthermore, the combination of various ultrasonographic measurements have proven useful to estimate birth weight (112-117) and to identify small-for-gestational-age and large-forgestational-age fetuses $(118,119)$.

Identification of blood biomarkers have also been successfully used as a non-invasive method to determine pregnancy status or risks associated with diseases (120). Such assays have depended on both cell-free compartments like plasma or serum and white blood cells $(121,122)$. For example, ISG-15 mRNA from pregnant cattle leukocytes $(123,124)$ and pregnancy associated glycoproteins (PAGs) from bovine maternal blood serum are useful markers of early pregnancy $(77,78,125,126)$. Since technological developments have overcome methodological constraints inherent to assessment of global RNA abundance, it is now possible to identify both coding and non-coding RNAs in human blood (127-133). Whether maternal blood components can be used to identify LOS early in pregnancy is not known.

For our study, we hypothesized that LOS can be identified during pregnancy in cattle by use of day 55 ultrasonography and/or maternal blood leukocyte mRNA biomarkers. The approach was to generate embryos by in vitro procedures previously shown to generate fetuses susceptible to LOS (16) and to 
perform morphometric analysis of those fetuses at day 55 of gestation and transcriptome analysis of maternal blood leukocytes of gestation days 55 and 105.

\subsection{MATERIALS AND METHODS}

\section{Heifers}

All animal procedures were conducted in accordance with the Guide for the Care and Use of Agricultural Animals in Research and Teaching and approved by the Institutional Animal Care and Use Committee of the University of Missouri (Protocol \#9455). All animals were kept at the University of Missouri South Farm Research Center in Columbia. All heifers were purchased from two herds in October of 2018 and ranged in age from 17-19 months of age.

\section{Estrus synchronization and selection of animals}

For these experiments, fetuses were collected on three occasions. Day 56 fetuses were collected in February (Exp IA) and May 2019 (Exp IB) whereas day 105 fetuses were collected in July 2019 (Exp II)].

\section{Experiment I: (day 56 fetal collections)}

Angus crossbred heifers of approximately $18-20$ months of age were synchronized and selected for breeding using the 14-day controlled internal drug release $(\mathrm{CIDR} \circledast$, Zoetis, Kalamazoo, $\mathrm{MI})$ prostaglandin $(\mathrm{PG})$ \& timed artificial insemination (TAI) protocol (Figure 2.1). Briefly, CIDRs were placed in the 
heifers (denoted as day 0 ) and removed 14 days later. Sixteen days after CIDR removal, $25 \mathrm{mg}$ of prostaglandin F2 alpha (PGF2a, (Lutalyze); Zoetis, NJ) was administered intramuscularly (i.m.). Concurrent with the PGF $2 \alpha$ administration, a breeding indicator patch (Estrotect, Genex, Shawano, WI) was applied to each animal across the backbone as per the instructions of the Estrotect patches. Estrus was checked three times per day $(7: 00 \mathrm{~h}, 12: 00 \mathrm{~h}$ and 16:00 h/17:00 h) for three days and only animals with a heat score above two (Exp IA) or $2.5(\operatorname{Exp} I B)$ at the time of $\mathrm{Al}(13: 00 \mathrm{~h})$ were selected for artificial insemination (Al) or embryo transfer $(\mathrm{ET})$. The breeding indicators were scored $0-4$, with a score of 0 indicating no patch activation; a score of 1 signifying $<25 \%$ patch activation; a score of 2 signifying $>25$ to $<50 \%$ patch activation; a score of 3 signifying $>50$ to $<75 \%$ patch activation; and a score of 4 signifying $>75 \%$ patch activation.

Regardless of group, all animals were injected with $100 \mathrm{mcg}$ of gonadotropin releasing hormone $(\mathrm{GnRH})$ i.m. (Factrel, Zoetis) at the time of corresponding to $\mathrm{Al}$ in the Al group (Figure 2.1).

In order to collect the number of fetuses required for the experiments, two sets of estrus synchronizations were performed. The first group of 120 heifers (Exp IA) were synchronized starting November 2018 and the second group of 164 heifers (Exp IB - some of these were used in Exp II) were synchronized starting February 2019.

\section{Experiment II: (day 105 fetal collections)}


For this collection, Angus heifers ( $n=164$; some of these were used in Exp 1B) were synchronized as described above and assigned randomly to Al or ET (Figure 2.1).

\section{In vitro and in vivo production of embryos and embryo transfer}

Media and procedures were as previously described by us $(16,134)$. Briefly, B. t. taurus (Angus/Angus-Crossbred) ovaries were collected at an abattoir and transported to Stillwater Oklahoma (Oklahoma State University; OSU) for oocyte collection. Oocytes were placed in $\mathrm{CO}_{2}$ equilibrated maturation medium and shipped overnight at $38.5^{\circ} \mathrm{C}$ to the University of Missouri (MU) or the University of Florida (UF). In addition, B. t. taurus oocytes were also purchased from DeSoto Biosciences (Seymour, TN, USA) and processed at MU. All media for embryo production were prepared at MU by a single technician and shipped overnight to the pertinent location prior to each procedure. Two sources of oocytes and two in vitro production (IVP) locations were used to ensure sufficient embryos for transfer in the case of technical difficulties. Oocytes were removed from maturation medium after $\sim 21 \mathrm{~h}$ of culture and inseminated with semen from one B. $t$. indicus male (Brahman breed [JDH MR MANSO 7960958 154BR599 11200 EBS/INC CSS 2]). Putative zygotes were stripped of cumulus cells by vigorous vortexing at approximately $18 \mathrm{~h}$ after insemination and cultured in KSOM supplemented with amino acids in a humidified atmosphere containing $5 \% \mathrm{O}_{2}, 5 \% \mathrm{CO}_{2}$, and $90 \% \mathrm{~N}_{2}$. On day five after insemination, the culture medium was supplemented with $10 \%(\mathrm{v} / \mathrm{v})$ estrus cow serum (collected and prepared in house and previously used in (16)) and embryos returned to the incubator. Day 
6 embryos produced at UF were shipped overnight at $38.5^{\circ} \mathrm{C}$ in culture medium to $\mathrm{MU}$. On day seven after insemination, blastocyst-stage embryos were selected, washed in BioLife Holding \& Transfer Medium (AgTech; Manhattan), and loaded in groups of two into $0.25 \mathrm{cc}$ yellow, direct transfer and irradiated straws (AgTech) and kept in a Styrofoam box until ET. Blastocysts were transferred to 52 and 106 synchronized recipient females for Exp I and II, respectively, on day 7 after $\mathrm{GnRH}$ injection (Figure 2.1).

\section{Pregnancy detection and allocation to treatment}

For Exp IA, pregnancy was confirmed using a breeding indicator patch. Briefly, 16 days after Al, all animals were patched and checked for heat score once daily for 11 days and scores below 1.5 were considered pregnant (Figure 2.1). Confirmation of pregnancy was not accurate when the breeding indicator patch was used because some patches became activated due to normal animal activity. Therefore, subsequent pregnancy determinations (Exp IB and Exp II) were performed on day 36 by transrectal ultrasonography (Figure 2.1).

\section{Day 55 and day 77 fetal ultrasound morphometry}

At day 55 of pregnancy, presumed pregnant animals (Exp IA - $n=39$; Exp IB $-n=23$; Exp II $-n=66$ ) were checked for presence of a fetus by transrectal ultrasonography using a SonoSite EDGE ultrasound machine equipped with a L52 10.0-5.0 MHz linear-array transducer (Figure 2.1). Images acquired by the ultrasound were analyzed using software resident on the machine. Ultrasound measurements taken were abdominal height, abdominal diameter, trunk 
diameter, thoracic height, crown rump length, head length and biparietal diameter (Figure 2.2.A1-A7).

Fetal sex and number of fetuses were also determined by ultrasonography on day 77 of gestation (Exp II $n=55$ ) (Figure 2.1). Furthermore, a subset of 18 animals (6 Al and $12 \mathrm{ART}$ animals) were checked for fetal morphometry. Ultrasound measurements taken were abdominal height, abdominal diameter, trunk diameter, thoracic height, crown rump length, head length and biparietal diameter.

\section{Surgical fetal collections of day 56 and day 105 fetuses}

Heifers ( $n=51$ for day $56 ; n=48$ for day 105) were fasted at least $12 h$ prior to surgery. Fetuses were surgically retrieved to preserve nucleic acid integrity. All surgical procedures were performed by a licensed veterinarian. Preparation of the surgical site was done by clipping hairs from the paralumber fossa with \#50 clipper blade. All other organic debris was removed by scrubbing a minimum of three times alternatively with chlorhexidine and $70 \%$ ethanol. For restless animals, 20 mg xylazine, i.m., was administered. All caesarean sections were performed under epidural anesthesia ( $5 \mathrm{ml}$ of $2 \%$ lidocaine) by either an inverted $L$ block or a distal paravertebral nerve block. The incision was made vertically in the middle of the paralumbar fossa, starting approximately 10 $\mathrm{cm}$ ventral to the transverse processes of the lumbar vertebrae and continued ventrally, far enough to allow removal of the fetuses. Linear incision was performed into the gravid uterine horn and digital manipulation was used to 
remove the conceptus. Closure of the uterus and abdominal wall was done with an absorbable suture whereas closure of skin was performed with ford interlocking non-absorbable suture.

\section{Collection of fetal tissues and fetal measurements of day 56 and day 105 fetuses}

Collected fetuses and their fetal membranes were weighed and then fetal morphometry was assessed, and abnormal phenotypes noted. Measurements included crown-rump length, heart girth, forelimb length, biparietal length, abdominal height, head length and thoracic height. Subsequently, all tissues were dissected and divided in two and immediately frozen in liquid nitrogen. For all experiments, the same person measured and weighed all fetuses and fetal membranes, and another person dissected all the tissues. The average time from excision of the fetus from the uterus to when all tissues were frozen in liquid nitrogen was approximately $18 \mathrm{~min}$. All tissues were stored at $-86^{\circ} \mathrm{C}$ until further use.

\section{Morphometric analysis of crown rump length and umbilicus diameter in day 105 fetuses}

Measurement of day 105 fetuses' crown rump length (from the top of the head to base of the tail) and size of the umbilicus (cross section at the junction between the umbilicus and the body) were measured using the ImageJ's

(ImageJ, NIH) freehand line function using a lateral side picture of the day 105 fetuses. The surface where the fetuses laid was squared (each square $=2.54$ 
$\mathrm{cm}$ ) and was used to convert all measurements to $\mathrm{cm}$, and then a ratio of umbilicus diameter to crown rump length was taken (Supplementary table S2.1).

\section{Maternal blood collection and blood processing}

Maternal blood was collected via tail venipuncture on days 13, 19, 28, 55 and 105 of pregnancy into K3 EDTA tubes (BD, Franklin Lakes) and serum blood collection tubes (BD) (Figure 2.1). Blood processing was done as described earlier in (136). Briefly, both types of blood collection tubes were centrifuged at $1200 \mathrm{x} \mathrm{g}$ for $20 \mathrm{~min}$ at $4^{\circ} \mathrm{C}$ and plasma and serum were aspirated and temporarily stored at $4^{\circ} \mathrm{C}$ for 6 to $18 \mathrm{~h}$ prior to storing them at $-20^{\circ} \mathrm{C}$. The buffy coat from the K3 EDTA tubes were transferred to $15 \mathrm{ml}$ centrifuge tubes containing $12 \mathrm{ml}$ of red blood cell lysis buffer (150 mM NH4Cl, $10 \mathrm{mM} \mathrm{NaHCO}$, 1 mM EDTA, pH 7.0). White blood cells (WBC) containing tubes were briefly vortexed and then incubated at room temperature for $5 \mathrm{~min}$ and later centrifuged at $300 \times \mathrm{g}$ for $10 \mathrm{~min}$ at $4^{\circ} \mathrm{C}$. After discarding the supernatant, the WBC pellet was washed once in $5 \mathrm{ml}$ red blood cell lysis buffer and then with $5 \mathrm{ml}$ ice-cold 1 x Dulbecco's phosphate buffered saline (DPBS), with centrifugation at $300 \mathrm{xg}$ at $4^{\circ} \mathrm{C}$ for $5 \mathrm{~min}$, at each wash. After discarding the supernatant, the WBC pellet containing tubes were placed immediately on dry ice and then stored at $-86^{\circ} \mathrm{C}$.

\section{Selection of samples for RNA sequencing (RNAseq)}

The WBC samples of 23 day 105 pregnant cows were selected for RNAseq on the basis of their group (i.e., Al or ART-normal, ART-LOS) and fetal sex. The breakdown of the samples was: $8 \mathrm{Al}$ (fetuses $=4$ males and 4 
females), 6 ART-normal (fetuses $=3$ males and 3 females), 9 ART-LOS (fetuses $=4$ males and 5 females). In addition, the day 55 WBC samples of the same 23 females were also used for transcriptome analyses.

\section{RNA isolation}

Total RNA was isolated using Trizol ${ }^{\mathrm{TM}}$ reagent (Invitrogen, Carlsbad, CA) according to the manufacturer's instructions and stored at $-86^{\circ} \mathrm{C}$ until use.

\section{Library preparation and transcriptome sequencing}

Three micrograms of RNA samples were submitted to BGI Americas Corporation (San Diego, CA) for library preparation and quantitative RNAseq. In brief, RNA quality and concentration were determined by Agilent 2100 analyzer. $\mathrm{RNa}$ quality for each sample is summarized in Supplementary table S2.2A and S2.2B. Libraries were sequenced using the DNBSEQ-G400 platform to generate 20 million 100bp paired end (100PE) reads.

\section{RNAseq data analysis}

The quality of reads of each sample were checked by FastQC (137) and MultiQC (138). All raw reads were subjected to quality trimming using the DynamicTrim and LengthSort function of SolexaQA++ (139). For a read to be included in the analyses, the phred score of at least 60 bases needed to be $>19$. Lastly, read quality was confirmed by FastQC and MultiQC and finally aligned to the bovine reference genome assembly ARS-UCD1.2 (140). HISAT2 v2.1.0 (141) was used to align trimmed reads to the bovine reference genome assembly ARS-UCD1.2. To minimize mismatching, --mp 6, 6 -score of HISAT2 v2.1.0 
were used and paired end reads that aligned to the genome for each sample were kept for subsequent analysis. The percentage of aligned reads for each sample is summarized in Supplementary table S2.2A and S2.2B. Total read counts for each gene was calculated by using HTseq-count's default unioncounting mode (142) using NCBI (GCF_002263795.1_ARS-UCD1.2) and Ensembl gtf files (GCA_002263795.2). Bioconductor packages EdgeR (145) and DESeq2 (146) were used for differential gene expression analyses. Analysis groups were: 1) Al+ART-Normal vs. ART-LOS, and 2) all animals vs. the two females carrying the two largest LOS (i.e., 604 and 664). In addition, transcript abundance analysis was done with all pregnancies and then repeated excluding pregnancies with two fetuses. Similar analyses were done for the day 55 samples.

\section{Unsupervised hierarchical clustering}

The unsupervised hierarchical clustering analysis was done using all 46 de-identified blood RNA samples using the $\mathrm{R}$ language hierarchical clustering function.

\section{cDNA synthesis and quantitative RT-PCR}

Total RNA was treated with DNase (Fischer Scientific, Waltham, MA) before cDNA synthesis. DNase treated $6++++$ was used as template to synthesize cDNA in a $20 \mu \mathrm{l}$ reaction with: $10 \mathrm{mM}$ DTT (Invitrogen, Carlsbad, CA), $4 \times$ Superscript IV buffer (Invitrogen), 50 ng random primer (Promega, Madison, WI), $1 \mathrm{mM}$ dNTPs (Invitrogen), then incubated at $65^{\circ} \mathrm{C}$ for 5 minutes before 
adding $200 \mathrm{U}$ SuperScript ${ }^{\mathrm{TM}}$ IV reverse transcriptase (Invitrogen) and $40 \mathrm{U}$ ribonuclease inhibitor (Invitrogen). The samples were incubated at $23^{\circ} \mathrm{C}$ for 10 $\min , 52.5^{\circ} \mathrm{C}$ for $10 \mathrm{~min}, 80^{\circ} \mathrm{C}$ for $10 \mathrm{~min}$ and stored at $-20^{\circ} \mathrm{C}$ until use.

In order to ensure that transcript predictions would be useful to other herds and breeds, blood from three day 104/105 pregnant Holstein females were collected at Foremost Dairy Farm at the University of Missouri. WBC collection and RNA/cDNA processing were as described above.

\section{Selection of the endogenous normalizers and test genes for qRT-PCR}

Genes whose false discovery rate (FDR) from EdgeR analysis was above 0.9 and padj value from DESeq2 analysis was above 0.85 , consistent across both day 55 and day 105 RNA samples, were selected (Supplementary table S2.3A). Subsequently, the coefficient of variation (CV) was calculated for each gene across all samples and three genes, SURF4, NECAP1 and SMG7 were selected to be used as endogenous normalizers for qRT-PCR analysis. Standard deviation and $\mathrm{CV}$ values of those genes can be found in Supplementary table S2.3B. A subset of genes was chosen to corroborate expression levels of DEGs identified by deep sequencing based on differences between treatments, CV, and availability of intron-spanning TaqMan probes ( $\mathrm{BBI}$, Foster City, $\mathrm{CA})$. The genes chosen were BRD4 (Bt07108257_m1), NCOR1(Bt04314790_m1), ATF7IP (Bt03277239_m1), RSG14 (Bt04296838_m1), GPR84 (Bt03222335_m1), and UPP1 (Bt03262341_m1). The RNAseq CV for all transcripts analyzed by qRTPCR was $<12$. 


\section{Day 19 ISG15 gene expression}

Interferon-tau induces the expression of interferon stimulated gene 15 (ISG-15) in maternal leukocytes at day 19 of pregnancy and has been suggested as a pregnancy marker in bovine (76). To see if pregnancies with overgrown fetuses can affect the ISG-15 expression in maternal leukocytes, ISG-15 (BM_ISG15NM_174366BNP1) was analyzed using IDT PrimeTime® Std qPCR assay for the 23 maternal WBC RNA samples on gestation day 19 as well as 8 WBS RNA samples of females that had lost their fetuses by day 36 gestation. We used ActinB (BM_ACTB_NM_173979BNP1) as normalizer for this qPCR experiment.

\section{Statistical analyses}

The morphometric data were analyzed by analysis of variance (ANOVA) using the general linear model procedure (SAS Institute, Cary, NC). Here, the dependent variables were all fetal measurements, and the independent variable was the group (AI, ART-Normal, ART-LOS).

Statistical analyses for the RNAseq data were implemented with $\mathrm{R}$ (http://www.r-project.org/) using DESeq2 and EdgeR. For the differential gene expression analysis, DESeq2 and EdgeR both are based on negative binomial regression model. For EdgeR differential gene expression tesing was performed using quasi likelihood $\mathrm{F}$ test (QLF) ratio test using a generalized linear model (GLM). 
The mRNA levels of the target genes for the pregnant females carrying ART-LOS and the two largest LOS fetuses (604 and 664) relative to the combined Al and ART-normal groups, and control population (i.e. Holstein pregnant cows) was calculated using the comparative cycle threshold $\left(\mathrm{C}_{\mathrm{T}}\right)$ method. Briefly, the $\mathrm{C}_{\mathrm{T}}$ for each sample was normalized to the geometric mean of the endogenous reference genes. The average $\mathrm{C}_{\mathrm{T}}$ for a given group was calculated by averaging the $\mathrm{C}_{\mathrm{\tau}}$ of all the independent samples. These averages were then compared with the average $\mathrm{C}_{\top}$ of the control by the comparative $\mathrm{C}_{\mathrm{T}}$ method $\left(\Delta \Delta \mathrm{C}_{\mathrm{T}}\right)$. The $\Delta \mathrm{C}_{\mathrm{T}}$ values were used for statistical analysis.

\section{Data Availability}

The raw FASTQ files are publicly available at Gene Expression Omnibus (accession number pending).

\subsection{RESULTS}

\section{Synchronization and pregnancy results}

Estrus synchronization information can be found in Supplementary table S2.4A and S2.4B. In Exp 1A, day 55 transrectal ultrasonography identified that pregnancy rates were $52.9 \%$ and $26.9 \%$ for $\mathrm{Al}$ and $\mathrm{ART}$, respectively. For Exp IB and Exp II pregnancy rates using transrectal ultrasonography on day 36 were $67.6 \%$ and $56.6 \%$ and on day 55 were $60.4 \%$ and $50.9 \%$ for the Al and ART groups, respectively. 


\section{Fetal collections and LOS determination}

Fetal overgrowth is the defining phenotype of LOS $(7,37)$, and weight at surgical collection was used to define LOS using criteria described earlier by us (16). A fetus was categorized as overgrown if its weight was greater than the $97^{\text {th }}$ percentile weight of the Al. For day 56 fetuses, the average weight of the Al was $9.46 \pm 1.5 \mathrm{~g}$ for male and $8.1 \pm 1.08 \mathrm{~g}$ for females. In total, we collected $20 \mathrm{ART}$ males (weight range $=6.94-13.77 \mathrm{~g}$ ) and $22 \mathrm{ART}$ female fetuses (weight range $=5.55-10.31 \mathrm{~g})$. A total of eight ART males and one ART female fetus weighed $>97^{\text {th }}$ percentile weight of $\mathrm{Al}$ (i.e., male $\geq 10.18 \mathrm{~g}$ and female $\geq 10.16 \mathrm{~g}$; Figure 2.3A). The range in weight of the ART-LOS fetuses was $10.23-13.77 \mathrm{~g}$ for males and the largest female weighed $10.31 \mathrm{~g}$ (Figure 2.3B). All day 56 ART fetuses weighing $\leq 97^{\text {th }}$ percentile weight of controls were considered as ARTnormal weight (referred to as "ART-normal"). In addition, several ART fetuses also showed focal hemorrhage on the brain and one fetus had abdominal wall defects (Figure 2.3C and Table 2.1).

For day 105 fetuses, the average weight of the Al was $494.3 \pm 44 \mathrm{~g}$ for males $(n=8)$ and $416.5 \pm 36 \mathrm{~g}$ for females $(n=4)$. Thus, ART-males weighing $>$ $548.92 \mathrm{~g}$ and ART-females weighing $>463.16 \mathrm{~g}$ on day 105 of gestation were considered LOS (Figure 2.4A). A total of 8 male fetuses with LOS (weight range $=552-1080 \mathrm{~g}$ ) and 9 female fetuses with LOS (weight range $=468-986 \mathrm{~g}$ ) were collected. The two largest day 105 LOS fetuses (male (664): $1080 \mathrm{~g}$; female (604B): $986 \mathrm{~g}$ ) were more than twice the weight of the average Al fetal weight (Figure 2.4B). There were 25 males (442 - $542 \mathrm{~g}$ ) and 4 females (318 - 
$448 \mathrm{~g}$ ) ART-normal fetuses. In addition to oversize, various abnormal phenotypes were observed in the ART-LOS group, including protruding tongue, large umbilicus (Figure 2.4B.3 and Table 2.1), gelatinous material in the peritoneal cavity and organs and skull asymmetry (Figure 2.4C and Table 2.1).

\section{Day 56 Fetuses}

\section{Fetal measurements at collection}

In the Al group, there were 14 singleton pregnancies. For the ART group, 19 were singletons and 12 had two conceptuses. When fetal measurements of day 56 were compared between AI, ART-normal and ART-LOS, crown rump length tended to be greater in ART-LOS when compared to ART-normal $(p=$ 0.051), whereas heart girth tended to be larger in AI and ART-LOS than ARTnormal $(p<0.04)($ Figure 2.5A). However, when male specific analyses were done, biparietal diameter was higher in ART-LOS compared to Al and ARTnormal ( $p=0.063$ and $p<0.02$, respectively). In addition, forelimb length tended to be smaller in ART compared to $\mathrm{Al}(\mathrm{p}=0.08)$, whereas heart girth tended to be greater in ART-LOS when compared to ART-normal ( $p=0.07$ ) (Figure 2.5B). When female ART group were compared to female Al, heart girth was smaller in the ART group ( $p=0.053$ ) (Figure 2.5C). Female specific analysis was not done to compare Al and ART-normal vs ART-LOS as only one female's weight was greater than the $97 \%$ threshold used to ascribe ART-LOS. 


\section{Day 55 fetal ultrasonographies}

When day 55 ultrasonographic measurements of day 56 fetuses were analyzed, thoracic height tended to be greater $(p=0.066)$ in the ART-LOS group compared to the ART-normal group (Figure 2.6A). Similarly, when the male specific analysis was done, thoracic height was higher $(p<0.02)$ in ART-LOS when compared to the ART-normal group. However, when female ART and female Al were compared, none of the ultrasonographic measurements were different between them (Figure 2.6B). Female specific analysis was not done to compare Al and ART-normal vs. ART-LOS as only one female in the ART group weighed more than the $97 \%$ threshold used to ascribe ART-LOS (Figure 2.6C).

The ratio of day 55 ultrasound measurements (biparietal diameter and crown -rump length) to their reciprocal day 56 fetal measurements was $\sim 0.8$ (Figure 2.7A). We did not identify any differences in biparietal diameter, crownrump length and heart-girth were compared among four groups (Al, ART-normal, ART-LOS, and the group comprised of the four largest ART-LOS fetuses) (Figure 2.7A).

\section{Day 105 Fetuses}

At day 77 of gestation, sex verification of fetuses of 55 pregnancies (single- $n=44$ : twin $-n=11$ ) was done using ultrasonography. Out of them, 26 fetuses were female, and 37 fetuses were male, two could not be sexed due to positioning and one fetus was no longer viable. An attempt was made to 
determine fetal morphometry on day 77 of pregnancy, however this was not possible or reliable for many of the samples (Supplementary table S2.5).

\section{Fetal measurements at collection}

In the Al group, there were 12 singleton pregnancies. For the ART group, 26 were singletons and 10 had two conceptuses. Abdominal height, abdominal diameter, trunk diameter, thoracic height, crown rump length and biparietal diameter were larger $(p<0.05)$ when compared to ART-normal and AI counterparts, whereas head length was shorter $(p<0.05)$ in ART-LOS when compared to ART-normal counterparts (Figure 2.4D). However, when sex specific comparisons were done, males and females followed different patterns. For males, abdominal height, abdominal diameter, thoracic diameter, thoracic height, crown rump length, heart girth and biparietal diameter were larger $(\mathrm{p}<$ 0.05), in ART-LOS when compared to ART-normal and Al counterparts (Figure 8A). In females, abdominal height, thoracic height and crown rump length were larger in ART-LOS than other two groups $(p<0.05)$ and biparietal diameter was smaller in ART-normal than ART-LOS $(p<0.05)$, but there was no statistical difference in forelimb length, heart girth and head length measurements among any of these three groups (Figure 2.8B). In gross examination during collection of LOS fetuses, two of the day 105 ART-LOS fetuses had a noticeably large umbilicus (Figure 2.4B.3 and Table 2.1). However, when the ratio of the umbilicus to the crown rump length of the 4 largest day 105 fetuses were 
compared to the controls using image analysis, no statistical difference was detected (Figure 2.9).

\section{Day 55 ultrasonographies}

Abdominal height and thoracic height were significantly greater in ARTLOS than AI ( $p<0.02$ and 0.08 , respectively) and ART-normal $(p<0.002$ and $<0.08$ ), whereas biparietal diameter and crown rump length tended to be smaller in the ART-normal group when compared to the Al controls $(p=0.066$ and $p=0.08$, respectively). Furthermore, abdominal diameter $(p<0.03)$ and trunk diameter $(p=0.05)$ were greater in ART-LOS when compared to ART-normal (Figure 2.2B). However, when analyzed on a sex-specific basis, trunk diameter and thoracic height were greater in ART-LOS male fetuses when compared to AI ( $p=0.069$ and $p<0.05$, respectively) and ART-normal $(p<0.03$ and $p=0.055$, respectively; Figure 2.2C), a difference not seen in females (Figure 2.2D). Furthermore, ARTLOS males tended to have higher abdominal height $(p=0.09)$ than ART-normal males (Figure 2.2C) but there was no difference in females (Figure 2.2D). On the other hand, biparietal diameter was smaller in ART-normal females when compared to $\mathrm{Al}(\mathrm{p}<0.04$; Figure 2.2D), but no difference was observed in males (Figure 2.2C).

The ratio of day 55 ultrasound measurements to their reciprocal day 105 fetal measurements showed that crown rump length was greater in the Al group than the ART-LOS and the group comprised of the four largest ART-LOS fetuses 
$(p<0.002$ and $p<0.002)$, whereas crown rump length of the four largest LOS fetuses was smaller than ART-normal $(p<0.03)$ and ART-LOS tended to be smaller than ART-normal ( $p=0.07$; Figure 2.7B). Abdominal height of ART-LOS was smaller than Al and ART-normal (both were $p=0.06$; Figure 2.7B). Biparietal diameter of the four largest ART-LOS was smaller than Al and ARTnormal $(p<0.01)$ and biparietal diameter of ART-LOS was smaller than Al and ART-normal $(p<0.01$; Figure 2.7B). Furthermore, heart girth of the four largest ART-LOS was smaller than AI, ART-LOS and ART-normal $(p<0.05)$, whereas heart girth of Al was higher than ART-normal and ART-LOS $(p<0.08$; Figure 2.7B).

When both ultrasound data sets were combined (Day 56 and Day 105) we found that abdominal height and abdominal diameter as well as thoracic height were on average larger $(\mathrm{P}<0.04)$ in ART-LOS when compared to the Al and ART-normal groups (Figure 2.10). In addition, the abdominal height and the thoracic height for the largest LOS in each day (i.e., Day 56 - $13.77 \mathrm{~g}$ and Day $105-1080 \mathrm{~g}$ ) were larger than all other fetuses (Figure 2.10).

\section{Maternal blood transcriptome analysis}

Only reads which aligned to known genes were used in the present study.

\section{Unsupervised hierarchical clustering of RNAseq reads}

Unsupervised hierarchical clustering of the raw reads counts after alignment to the bovine genome showed that out of 46 samples, 20 samples clustered together by animal. In addition, the RNAseq results of the females 
carrying the two largest ART-LOS fetuses (604 and 664) separated from the rest of the animals (Figure 2.11).

\section{Maternal white blood cells transcriptome analyses of gestation day 55}

No genes were identified as differentially expressed (i.e. - EdgeR, FDR $<0.05$ and DESeq2, padj <0.05) between day 55 WBC RNA for AI, ART-normal and ART-LOS using NCBI and Ensembl Bos taurus gene sets. However, when analyses excluded pregnancies with two fetuses, DESeq2 identified LOC101903301 (Ensembl ID = ENSBTAG00000040367) as one DEG between ART-LOS and the combination of the other two groups. When the RNA of the two largest ART-LOS carrying heifers was compared to the rest of the samples, EdgeR and DESeq2 tools with Ensembl gene sets revealed 5 DEGs (ENSBTAG00000015149, ENSBTAG00000025385, ENSBTAG00000006383, ENSBTAG00000002937 and ENSBTAG00000034185) and 4 (ENSBTAG00000015149, ENSBTAG00000025385, ENSBTAG00000006383 and ENSBTAG00000002937), respectively, whereas DESeq2 tool with NCBI gene set revealed 2 DEGs (ADGRE3 and ADAM11).

\section{Maternal white blood cells transcriptome analyses of gestation day 105}

When day 105 ART-LOS WBC RNA was compared to ART-normal and Al groups together, DESeq2 revealed 9 genes and 31 genes as DEGs with the Ensembl and NCBI gene set, respectively (Supplementary table S2.6A and S2.6B)., whereas EdgeR, didn't identify any DEGs. 
However, when similar analyses were done excluding pregnancies with two fetuses, DESeq2 revealed 1 (ENSBTAG00000040367) and 2 (LOC101903301 and LOC107131224) genes as DEG for Ensembl and NCBI gene set, respectively, whereas EdgeR, did not identify any DEGs as all together data.

When the WBC RNA of the two largest ART-LOS carrying cows was compared to the rest of the samples, EdgeR and DESeq2 tools with Ensembl gene set revealed 4354 and 3845 genes (note: available upon request) as DEG, respectively (Supplementary table S2.6C and S2.6D), whereas EdgeR and DESeq2 tools with NCBI gene set revealed 4271 and 3678 genes as DEG, respectively (Supplementary table S2.6E and S2.6F).

\section{Corroboration of RNAseq DE genes by qRT-PCR}

None of the genes selected for corroboration showed differences between groups (i.e. Al, ART-normal, ART-LOS and Holstein controls) when analyzed by real time RT-PCR analysis (Figure 2.12A). Upon closer examination of the data, we noticed that there is great variation in expressions within a group. One gene, ATF7IP, however, was consistently downregulated (both in RNAseq differential gene expression analysis and qRT-PCR results) in WBC RNA of the female carrying the largest LOS fetus when compared to all other females (Figure 2.12B). 


\section{Day 19 ISG-15 gene expression by qRT-PCR}

When the ISG15 gene expression were compared between the AI, ARTnormal, ART-LOS and ART-dead (pregnancies lost before day 36), we found that ART-dead were downregulated when compared to ART-LOS $(p<0.06)$ and AI ( $p$ $<0.004$ ) groups but not with ART-normal group (Supplementary figure S2.1).

\subsection{DISCUSSION}

The goal of the present study was to determine the usefulness of day 55 fetal morphometry and maternal white blood cell transcriptome at day 55 and day 105 of gestation for the identification of fetal overgrowth during pregnancy. The current study revealed that day 55 fetal ultrasound abdominal height and thoracic height measurements may be an indicator of male LOS fetuses, whereas differential gene expression analysis of maternal blood revealed that ATF7IP may serve as an indicator for the largest LOS fetuses ( $>2 X$ the average weight of controls) at day 105 of pregnancy. In addition, we identified that LOS fetuses had a different growth pattern (in relation to fetal weight) from Al and ART-normal fetuses after day 55 of gestation and that LOS fetuses had several developmental abnormalities such as hemihyperplasia (asymmetric growth), enlarged tongues, brain hemorrhage, enlarged umbilical cord, abdominal ascites and abdominal wall defect. In total, $36.9 \%$ of the day 105 collected ART fetuses were considered LOS (> 97 percentile weight of Al on a sex specific basis). 
Collection of fetuses was done on day 56 of gestation, since organogenesis has been shown to be completed before this day in cattle (147). The reason behind this decision was to answer other aspects of the project (beyond the scope of the current study) such as questions regarding organ formation and epigenetic mechanisms associated with LOS; information that will be used to identify etiologies of fetal overgrowth in cattle and human $(16,19,20$, 148-151). Furthermore, in the current study, fetuses were also collected on day 105 of gestation as we have previously shown that fetal overgrowth is evident at this stage of gestation (16). In humans, $97 \%$ percentile criteria is used to describe macrosomia in newborn babies (152). Since macrosomia is the main characteristic of LOS, we used this weight to ascribe LOS in the present study, similar to what we have done previously (16).

Larger than normal umbilicus and presence of large amounts of fluidgelatinous material in the abdominal cavity were observed in largest day 105 ART-LOS fetuses. This is similar, to what Constant et al revealed in somatic cell nuclear transfer (SCNT) LOS fetuses collected at day 220 of gestation (17). In that study, the authors also suggested that a large umbilical cord and abdominal ascites were the consequences of placental dysfunction which led to placental overgrowth, rather than fetal overgrowth (17). However, several other studies had shown association of early placental defects with loss of fetuses during early pregnancy $(18,153)$. These investigators also suggested that the angiogenesis and allantoic placental defects in the first trimester of pregnancy might have resulted in growth retardation and eventually death of ART fetuses $(18,153)$. 
Fetuses with severe placental defects may be lost during early pregnancy and if those fetuses having placental defects survive, it can be speculated that they could have higher placental and fetal growth at later stages of pregnancy through compensatory mechanisms. In the current study, the conceptuses were surgically collected to allow rapid collection of tissues in order to preserve nucleic acid integrity, for other aspect of the project, therefore even though we collected the placentas, we were not able to take proper measurements. However, no other obvious placental abnormalities were evident in the collected tissues.

Enlarged tongue was also observed in day 105 ART-LOS which is similar to previous findings in our laboratory (16) and comparable to what has been observed in a similar congenital overgrowth condition in humans, namely Beckwith-Wiedemann Syndrome (BWS; Choufani et al., 2010; Weksberg et al., 2010; Brioude et al., 2018; Wang et al., 2020). Large tongues can lead to difficulty in suckling and increase the chances of prenatal death (102). In addition, the largest day 105 ART-LOS fetus showed brachycephaly and asymmetrical growth of the cranium, an interesting finding given that one characteristic of BWS is hemihyperplasia (157-160). These similarities suggest that these overgrowth syndromes share similar misregulated developmental mechanisms associated with asymmetrical growth.

A greater than two-times increase in fetal weight was observed in day 105 ART-LOS fetuses in the current study, an observation also reported by others ( 2 , $6,100)$, suggesting that if those fetuses were followed up to term, dystocia would be probable and assisted delivery or caesarean section would be required (15). 
Dystocia as a result of LOS can lead to neonatal death (2) and/or death of cows. Further, dystocia has been associated with stillbirth (43), is a major contributor to perinatal mortality in cattle (161) and has also been shown to increase the chances of metritis (101) and lameness (41). Furthermore, dystocia can have an adverse impact on milk production (44) and increase the calving to conception interval in dairy cows (45). Thus, overgrown fetuses can have negative economic consequences to the producers (Rivera 2021, in press) and identification of those large calves during pregnancy would help overcome these problems.

In the current study, we captured fetal ultrasonographic measurements at day 55 for fetuses that were collected on day 56 or day 105 of gestation. In the past, it has been shown that fetometric ultrasonographic measurement such as crown rump length can be useful for the determination of fetal age $(51,162)$ and also to understand fetal growth patterns in cattle $(17,34,53)$. In addition, it has also been shown that after day 57 of gestation, all important body structures including forelimb and hindlimb are prominently visible in cattle through ultrasonography (104). Since ultrasonography has been improved in the last couple of decades, several researchers are able to have accurate fetal measurements even by day 50 of gestation $(34,163)$. We found that the ratio of day 55 ultrasound measurements to day 56 fetal measurements was $\sim 0.8$ which suggests that fetometric growth parameters such as crown-rump length and biparietal diameter give accurate estimation of fetal developmental status at that age. In addition, the ratio was the same between groups which indicates no 
difference for LOS fetuses at this stage for those measurements. Therefore, our data suggest that the 97 percentile Al weight criteria used to ascribe a fetus as being LOS on day 56 is not useful.

As expected, the ratio was smaller $(0.14-0.43)$ when these comparisons were made between day 55 ultrasonographies and day 105 fetal measurement. However, we identified that the ratio of crown rump length, biparietal diameter, and heart girth was decreased in the LOS fetuses which were $>1.5 \mathrm{X}$ the weight of the $\mathrm{Al}$, which indicates disproportionate allometric growth in these fetuses after day 56 of gestation and previously reported for sheep LOS (11). In accordance with our findings, past studies have shown that smaller in vitro or SCNT fetuses in the first trimester resulted in heavier fetuses at term $(34,163)$. Bertolini and coinvestigators also suggested that in vitro produced fetuses show early growth retardation and then follow acceleration in fetal growth at later stages of gestation, showing biphasic growth pattern (34). Further, the ratio of day 55 ultrasound and day 105 fetal measurements of crown rump length and biparietal diameter showed that the normal weighing ART fetuses had a different growth pattern than the ART-LOS group.

Individual measurements of abdominal height and thoracic height of the largest day 56 and day 105 ART-LOS fetuses were greater when compared to all other fetuses. To our knowledge, this has not been reported before and may be two measurements to consider when trying to identify LOS by ultrasonography, at least for the extremely heavy fetuses. Previous research reported larger biparietal diameter value at day 63 of gestation in cloned LOS fetuses (163) and 
smaller crown rump length value at day 58 of pregnancy in in vitro produced LOS fetuses (34) were shown to be associated with LOS pregnancies. However, they were not found as an indicator for LOS in our current study. Possibilities for the discrepancies in our findings, are 1) different definition of LOS (we used $>97 \%$ weight of the Al fetuses while Bertolini used fetuses that were $33 \%$ heavier than controls for comparisons), 2) improvement in ultrasonography technology allowing for more accurate measurement, and 3) number of observations (113 fetuses in our study vs. 26 fetuses in (163))

Research has shown that male and female fetuses followed different fetal growth patterns after day 100 of gestation; males tend to be heavier than female fetuses (164). We also observed this in the current study at day 105, in which Al females were $\sim 15.3 \%$ smaller than male Al. Sex-specific analyses of ultrasound measurements show that thoracic diameter and thoracic height can be indicators for male LOS pregnancies at day 105 of gestation whereas, for female LOS, we didn't find any measurements useful to identify LOS.

When we tried to do fetometry at day 77 of gestation, we were only able to measure head length with some accuracy. All other measurements were not reliable, suggesting that day 77 ultrasonography might be too late to try to accurately identify LOS. Given the allometric growth that occurs after day 56 and the fact that day 77 is too late to predict LOS by ultrasonography, and that fetal sex is also accurately predicted starting at approximately day 70 of gestation, we suggest that day $\sim 65$ may be a good target day to measure for LOS in a sex- 
specific manner as it has been shown that fetuses can be measured at day 62 of gestation (163).

In our study, we also had the objective of determining if maternal blood could be used as a biomarker to identify LOS on day 55 and/or 105 of pregnancy. For this, we analyzed the WBC transcriptome of 23 females carrying day $105 \mathrm{AI}$, ART-normal and ART-LOS fetuses. We also analyzed the WBC transcriptomes of the same females on gestation day 55. Our initial approach was to do an unsupervised hierarchical clustering of de-identified samples to determine if obvious difference existed between the females carrying the largest fetuses when compared to the other two groups. To our surprise, the transcriptome of 20/46 samples clustered together by animal regardless of pregnancy stage (i.e. day 55 and day 105). Another interesting point is that the experiment was done over three seasons (Autumn, Spring and Summer with a range in temperature of $-30^{\circ} \mathrm{C}$ to $43^{\circ} \mathrm{C}$ ) which was not detected in the transcriptome given the clustering by individual. Further, some of the differential gene expression captured in our study could be explained by the number of fetuses in the uterus (one vs two). Taken together, our unexpected observations suggest that leukocyte gene expression is dependent on the individual animal and number of fetuses, rather than their environment or stage of pregnancy, at least for the days studied here. We could not find published works addressing this point but propose that these data should act as a cautionary tale when transcriptome of various gestation stage are compared in cattle. 
To verify that the LOS maternal blood biomarker is consistent across all breeds, WBC from day 105 pregnant Holstein cows were also included in qRTPCR corroborations. On the basis of fold change difference from Al, RSG14, and GPR84 appeared to be downregulated in the WBC of females carrying the two biggest LOS fetuses. However, when cycle threshold was checked for each individual sample the variation among them is large even within treatment, especially for RSG14 and GPR84, indicating that these genes are not appropriate for the identification of LOS in the maternal WBC RNA. Holstein controls have similar level of ATF7IP expression than the average of the females carrying the two largest LOS fetuses, however, when samples were analyzed individually, the maternal WBC of the female carrying the largest LOS has reduced transcript amounts of this gene. Perhaps this gene may be useful to identify the largest LOS fetuses at day 105 of gestation, although more samples would be needed to reach this conclusion. Alternatively, the combined use of low levels of day 105 ATF7IP together with increased day 55 ultrasound abdominal height and thoracic height measurements could more accurately predict LOS.

Concentrations of maternal PAG genes can be higher in the serum of the pregnancies carrying cloned fetuses that become overgrown when compared to controls (combined ART and Al groups) between day 36 to day 50 of pregnancy (163). It was suggested that the higher PAG in serum could be due to fewer smaller placentomes (163). In ruminants, interferon-tau is secreted by the trophoblast cells of the developing conceptus (72) and has been shown to induce various interferon associated genes such as interferon stimulated gene - 
15 (ISG-15) in maternal peripheral blood WBC at day 19 of gestation (73-76). Thus, ISG-15 has been suggested as a biomarker for early diagnosis of pregnancy in cows (73-76). Since in our study, we identified fetal and placental abnormalities, we decided to determine ISG-15 concentrations in WBC of gestational stage day 19 of the 23 females selected for RNAseq. In addition, a group of WBCs of females carrying ART fetuses which died before day 36 (ARTdead) was also included to assess possible errors in placental development of these fetuses. However, we found that there was no difference between the ART-LOS, ART-normal and Al groups, but ART-dead was down regulated compared to ART-LOS and Al but not with ART-normal. Our limited data suggest that the trophoblast cells of fetuses destined to become LOS are not affected in their interferon-tau secretion.

In summary, here we document initial efforts to identify LOS during the first trimester of pregnancy in cattle. Data suggest that abdominal height and thoracic height may be useful to identify male ART-LOS fetuses at day 55 of gestation, whereas ATF7IP may be indicator for extreme fetal weight at day 105 of gestation. Here, we only tested six genes by quantitative RT-PCR which were differentially expressed by transcriptome comparisons. It should be noted that we only tested genes whose TaqMan probes were readily available, which were not necessarily the top differentially expressed genes as per transcriptome analysis. Published work shows that fetal growth varies among different breeds and that size difference can be noticeable as early as 3 months of gestation (165), therefore it is possible that fetal growth patterns may vary as early as day 
55 of gestation among different breeds. This could be one of the limitations of our study since we only used Angus/Angus-Crossbred heifers; however, there is lack of published data showing that on day 55 of gestation fetuses from different breeds differ in size. Future research would have to address this question. Here, we also did sex-specific analyses for all our variables, including for ultrasonographic measurements. Since in our experiment, number of male fetuses (both in Al and ART groups) was higher ( 61\% male (day $56 \sim 51 \%$ and day $105 \sim 71 \%$ ) our analysis might be skewed, which could be another limitation of this study. Finally, and importantly, it should be noted that we only used the known-mostly coding group of bovine transcripts for this study and that the noncoding and novel transcript portion of the transcriptome remains unexplored. Future work will focus on these types of transcripts.

\subsection{Acknowledgements}

We would like to thank Drs. Dave Patterson, Jordan Thomas, Martha Sofia Ortega, and Mike Smith for their help during estrous synchronization and technical assistance through the project and Kenneth Ladyman and Reinhard Van Zyl for farm management and related help. We would also like to thank Cooper Stansberry and Michael Campbell for their help during oocyte collection and Dr. Ky Pohler for facilitating the donation of Brahman semen used in the project. We would also like to thank Drs. Cliff Miller and Neal Martin's veterinary technicians Sarah K., Carolyn W. and Chase H for veterinary medical assistance. The following grant supported this work: USDA 2018-67015-27598. 


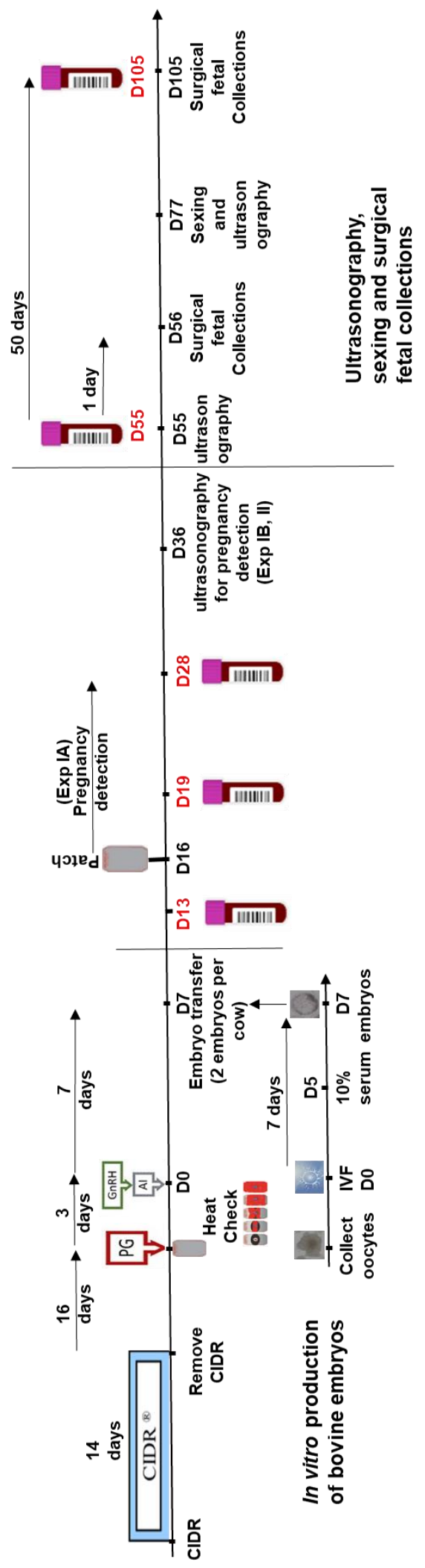

Figure 2.1 
Figure 2.1. Experimental design. Production of day 56 and day 105 fetuses (Exp IA, IB and Exp II). Estrus synchronization and selection of animals for Exp. IA - 120 animals were divided into 3 groups and the 14-day CIDR $^{\circledR}$ - PG \& TAI protocol was followed. Estrus synchronization and selection of animals for Exp IB and II - 164 animals were divided into 3 groups and the 14-day CIDR ${ }^{\circledR}$ - PG \& TAI protocol was followed except those animals were followed up to the last day of Al. Maternal blood was collected on D13, D19, D28, D55 \& D105. CIDR: controlled internal drug release, an intravaginal progesterone releasing device. PG: prostaglandin. GnRH: gonadotropin releasing hormone. Al: artificial insemination. D0: day of AI. IVF: in vitro fertilization. D5, D7, D13, D16, D19, D28, D36, D55, D56, D77, D105: Day 5, 7, 13, 16, 19, 28, 36, 55, 56, 77, 105 after AI. ART: assisted reproductive technologies. 


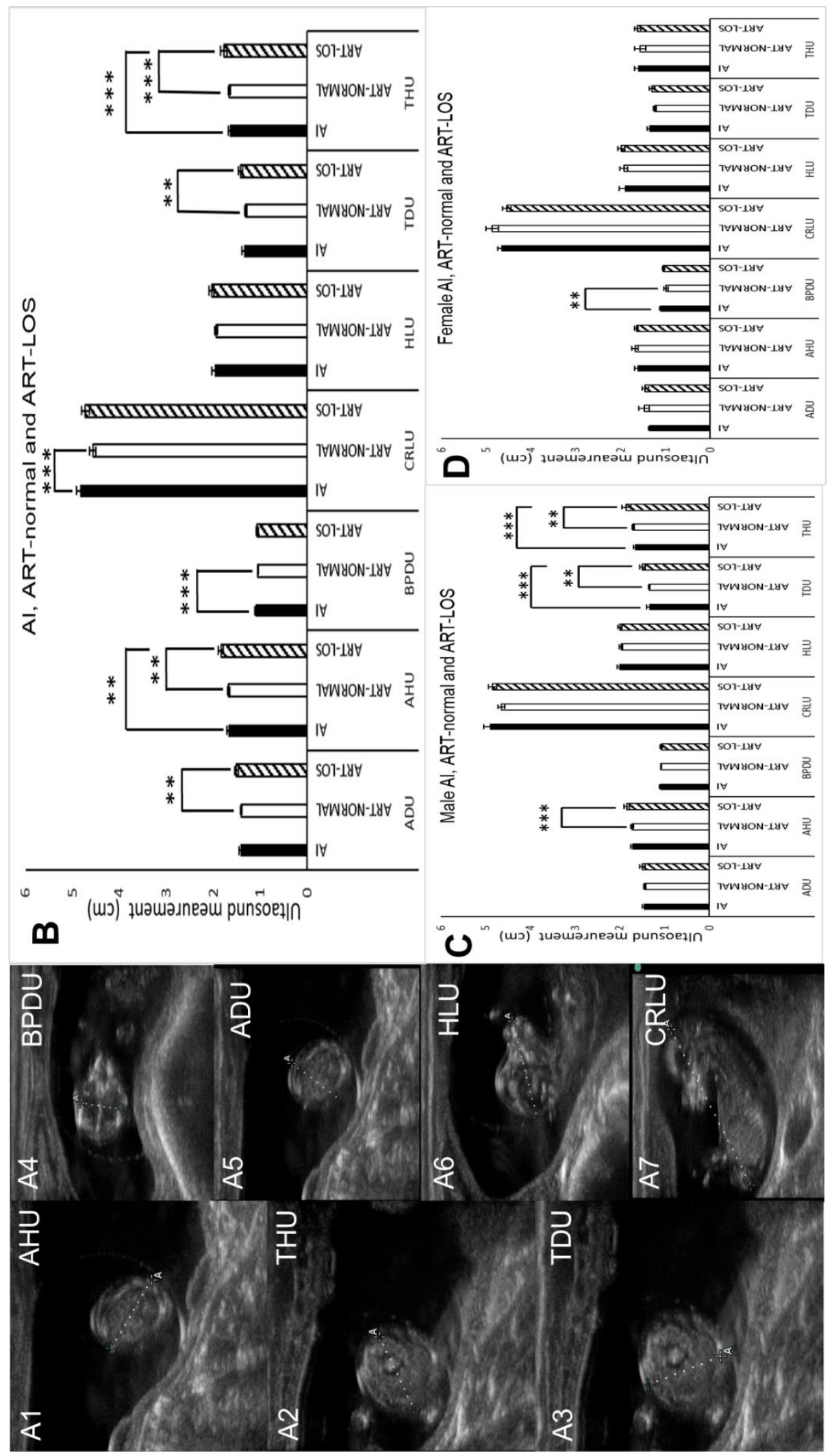

Figure 2.2 
Figure 2.2. Fetal morphometry of fetuses collected on day 105 gestation. (A1) to (A7) sagittal views of the ultrasound images taken on day 55 of gestation. $\mathrm{U}$ : ultrasound. AH: abdominal height. AD: abdominal diameter. BPD: biparietal diameter. CRL: crown rump length. HL: head length. TD: thoracic diameter. TH: thoracic height. (B) Comparison of ultrasound measurements between AI, ARTnormal and ART-LOS without considering sex of fetuses. (C) \& (D) Comparison of ultrasound measurements between Al, ART-normal and ART-LOS, males and females, respectively. (B), (C) \& (D) Al: artificial insemination. ART: assisted reproductive technologies. ${ }^{*}$ indicates $p<0.01 .{ }^{* *}$ indicates $p<0.05 .{ }^{* * *}$ indicates $p<0.1$. Note: sample sizes are not equal and thus there is less statistical significance for some comparisons when compared to other ones. 
A

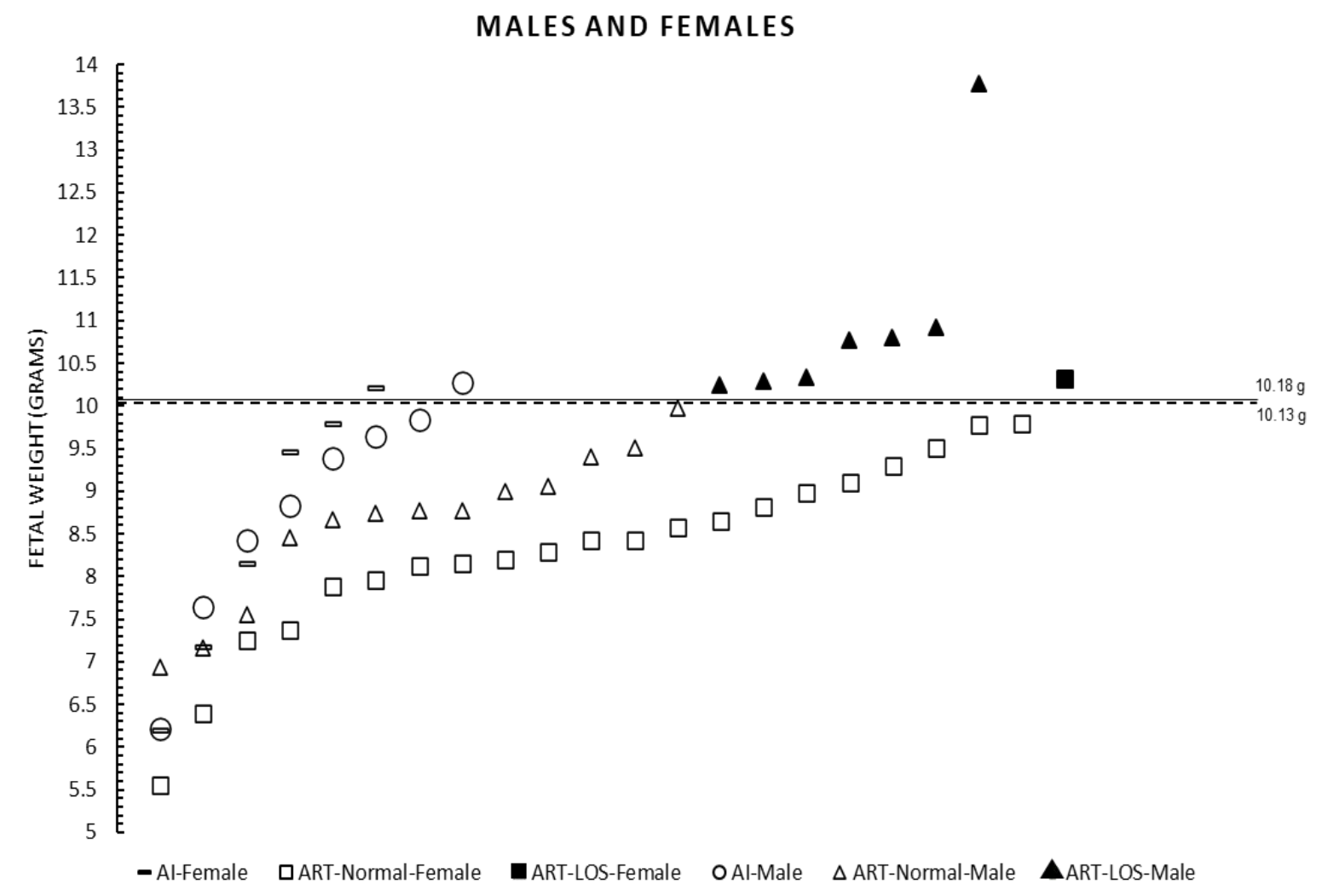

B

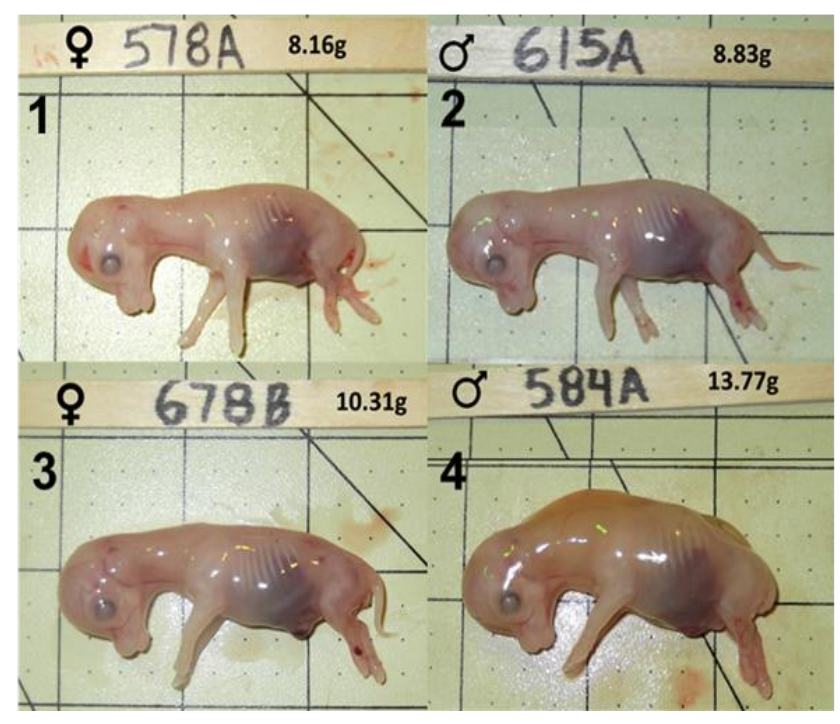

C

\section{$1584 \mathrm{~A}$}

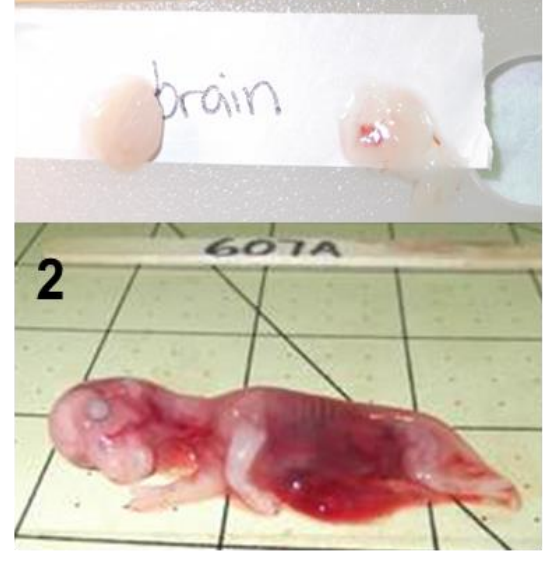

Figure 2.3 
Figure 2.3. Day 56 fetal collections. (A) Fetal weight at day 56 of gestation. The $\mathrm{X}$ axis has no actual implication and is used to scatter the spots representing each fetus for ease of visualization. The sex of the fetuses and the way they generated is shown at the bottom. The bold line represents the $97^{\text {th }}$ percentile of Al day 56 fetal weight (i.e., male -10.18 grams, female- 10.13 grams). (B) Overgrowth primary feature of LOS. B1 = Al-578A (control female weighing 8.16 $\mathrm{g}$ which is approximate average weight of female control fetuses). B2 $=\mathrm{Al}-615 \mathrm{~A}$ (control male weighing $8.83 \mathrm{~g}$ which is the approximate average weight of male control fetuses). B3 and B4 show largest LOS fetuses with macrosomia (ARTLOS 678B: female weighing $10.31 \mathrm{~g}$ and ART-LOS 584A: male weighing 13.77 g). Each square on the background $=2.54$ square $\mathrm{cm}$. (C) Secondary phenotype observed in day 56 LOS fetus - focal hemorrhage on the brain (C1) and abdominal wall defects (C2). LOS: large offspring syndrome. Al: artificial insemination. ART: assisted reproductive technologies. 

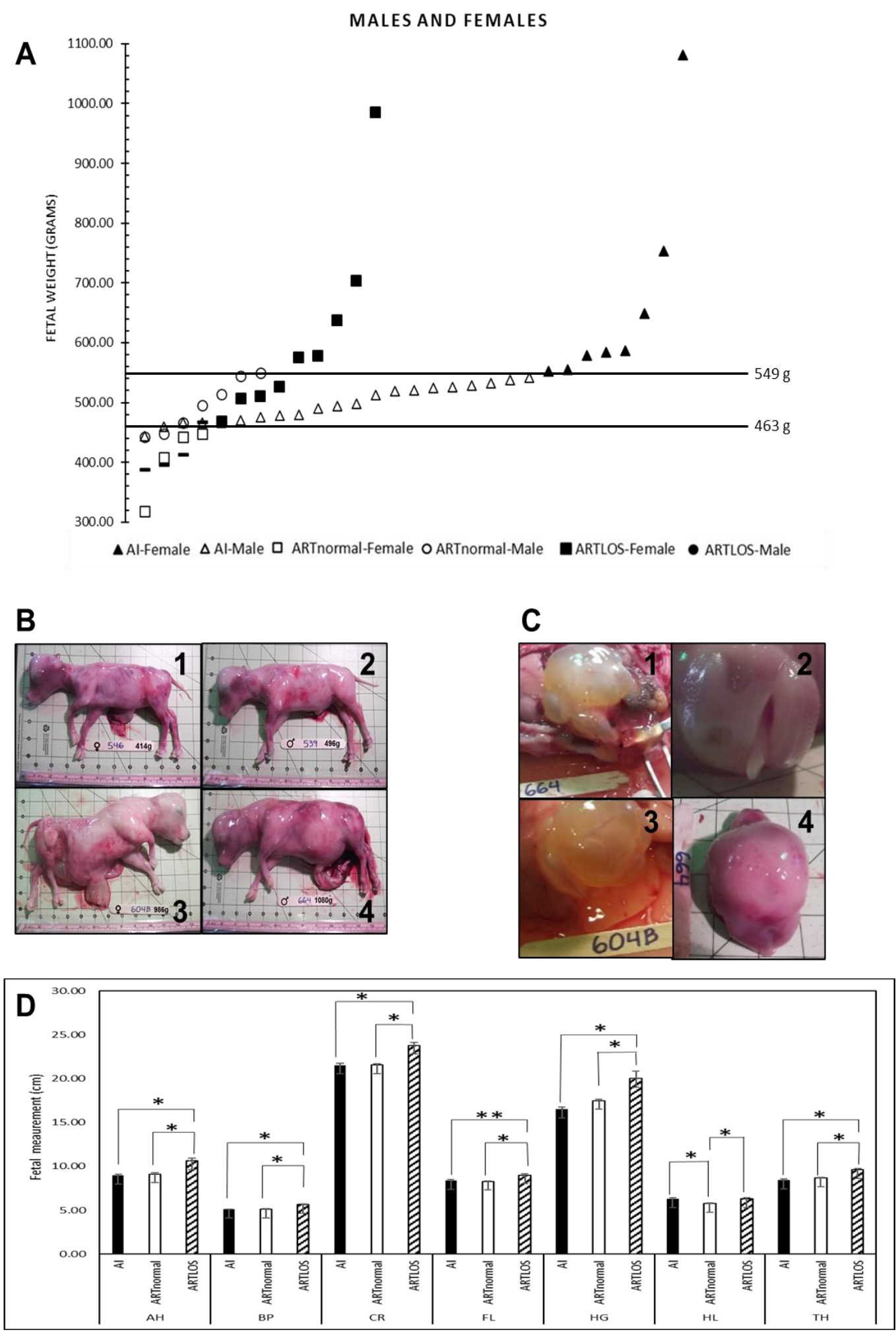

Figure 2.4 
Figure 2.4. Day 105 fetal collections. (A) Fetal weight at gestation day 105. The $\mathrm{X}$ axis has no actual implication and is used to scatter the spots representing each fetus for ease of visualization. The sex of the fetuses and the way they generated is shown at the bottom. The bold line represents the $97^{\text {th }}$ percentile of Al day 105 fetal weight (i.e. male $-548.92 \mathrm{~g}$, female- $463.16 \mathrm{~g}$ ). (B) Overgrowth primary feature of LOS. B1 $=\mathrm{Al}-546$ (control female weighing $414 \mathrm{~g}$ which is approximate average weight of female control fetuses) and B2 = Al-539 (control male weighing $496 \mathrm{~g}$ which is the approximate average weight of male control fetuses). B3 and B4 show largest LOS fetuses with macrosomia (ART-LOS 604B: female weighing $986 \mathrm{~g}$ and ART-LOS 664: male weighing $1080 \mathrm{~g})$. They also have larger umbilicus. Each square on the background $=2.54$ square $\mathrm{cm}$. (C) Secondary phenotypes observed in day 105 LOS fetuses: gelatinous material present around stomach and abdomen (C1), large tongue (C2), gelatinous material around the liver (C3) and asymmetrical head (C4). (D) Fetus measurements of day 105 fetus groups without considering sex of fetuses. $\mathrm{Al}=$

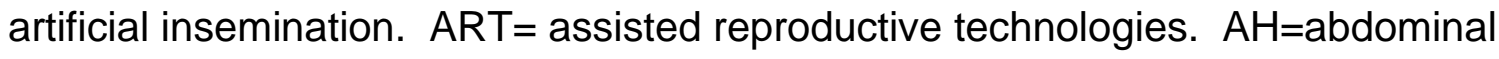
height. $F L=$ forelimb length. $B P=$ biparietal diameter. $C R=$ crown rump length. $H L=$ head length. $\mathrm{HG}=$ heart girth. $\mathrm{TH}=$ thoracic height. $\mathrm{LOS}=$ large offspring syndrome. $\mathrm{Al}=$ artificial insemination. $\mathrm{ART}=$ assisted reproductive technologies. * indicates $p<0.01 .{ }^{* *}$ indicates $p<0.05$ 


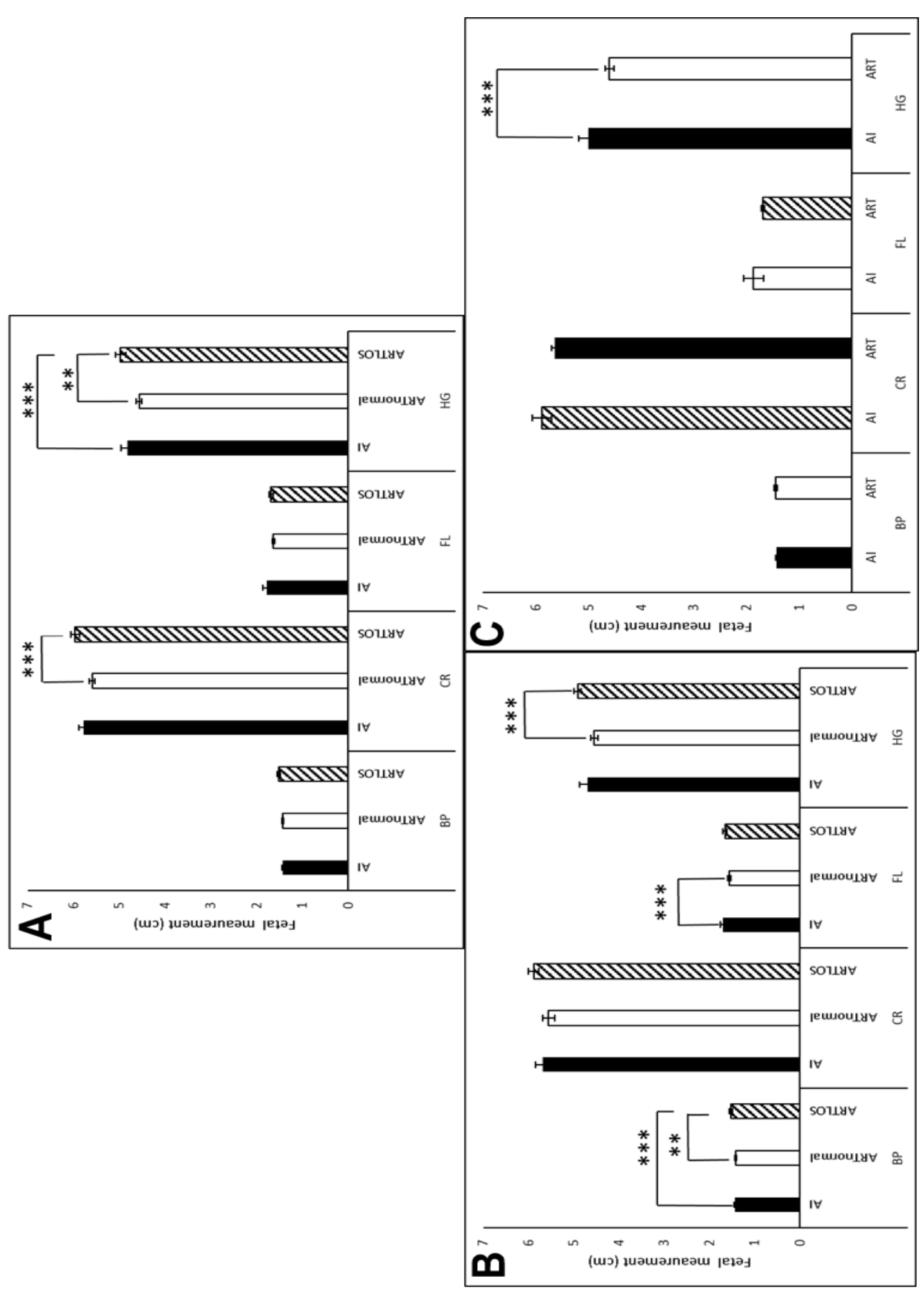

Figure 2.5 
Figure 2.5. Fetal measurements of fetuses collected on day 56 of gestation. (A) Comparison of fetal measurements between day $56 \mathrm{Al}$, ART-normal and ART-LOS fetuses without considering sex of fetuses. (B) Comparison of fetal measurements between day $56 \mathrm{Al}$, ART-normal and ART-LOS, males only. (C) Comparison of fetal measurements between two groups of day 56 female $\mathrm{Al}$, ART. Al: artificial insemination. ART: assisted reproductive technologies. FL: forelimb length. BP: biparietal diameter. CR: crown rump length. HG: heart girth. ${ }^{* *}$ indicates $\mathrm{p}<0.05 .{ }^{* * *}$ indicates $\mathrm{p}<0.1$. 


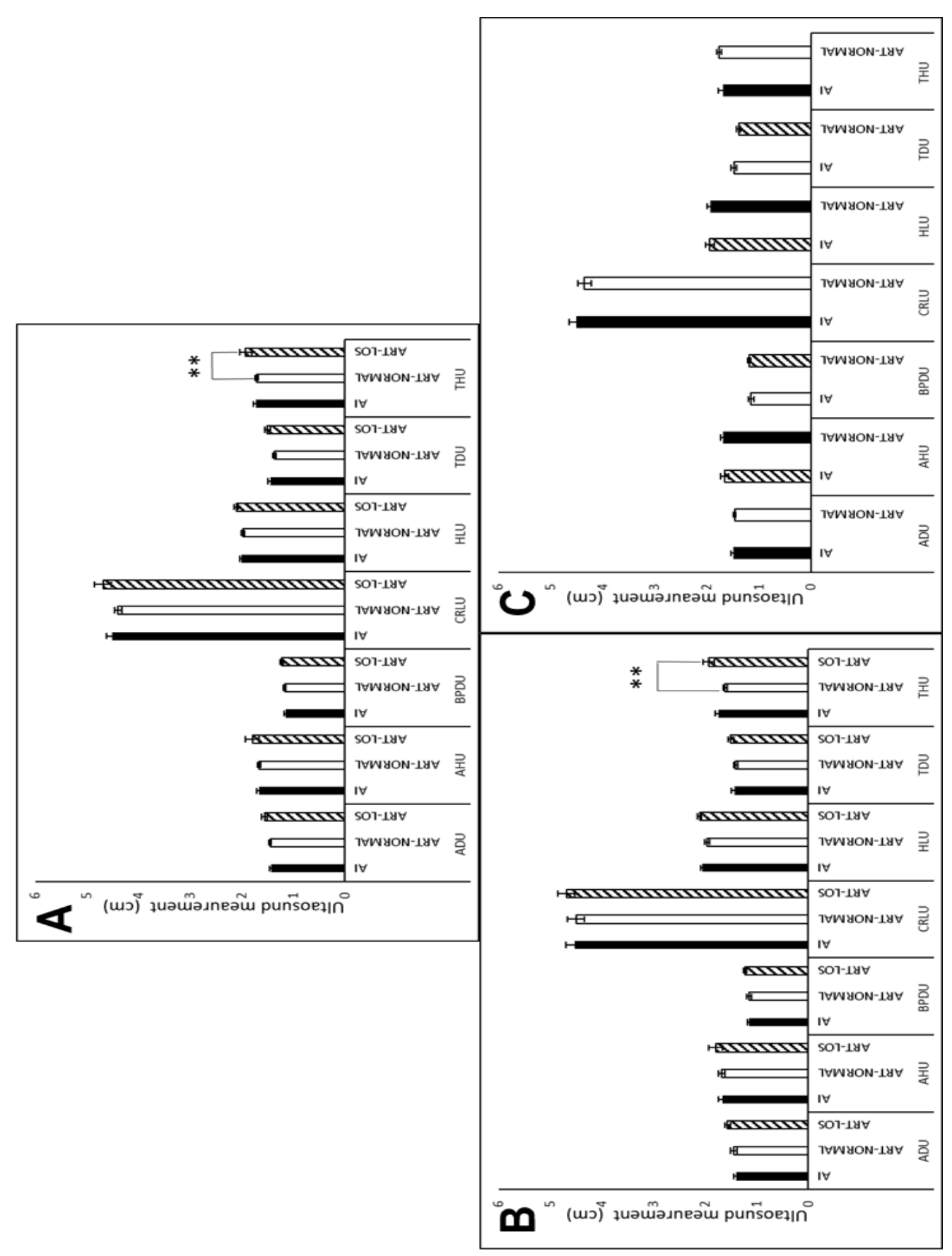

Figure 2.6 
Figure 2.6. Day 55 fetal morphometry of fetuses collected on day 56 of gestation. (A) Comparison of ultrasound measurements between AI, ARTnormal and ART-LOS without considering sex of fetuses. (B) Comparison of ultrasound measurements between male AI, ART-normal and ART-LOS. (C) Comparison of ultrasound measurements between female Al and ART. Al: artificial insemination. ART: assisted reproductive technologies. LOS: large offspring syndrome. U: ultrasound. AH: abdominal height. FL: forelimb length. BP: biparietal diameter; CR: crown rump length. HL: head length. HG: heart girth. $\mathrm{TH}$ : thoracic height. ${ }^{*}$ indicates $\mathrm{p}<0.05$. 


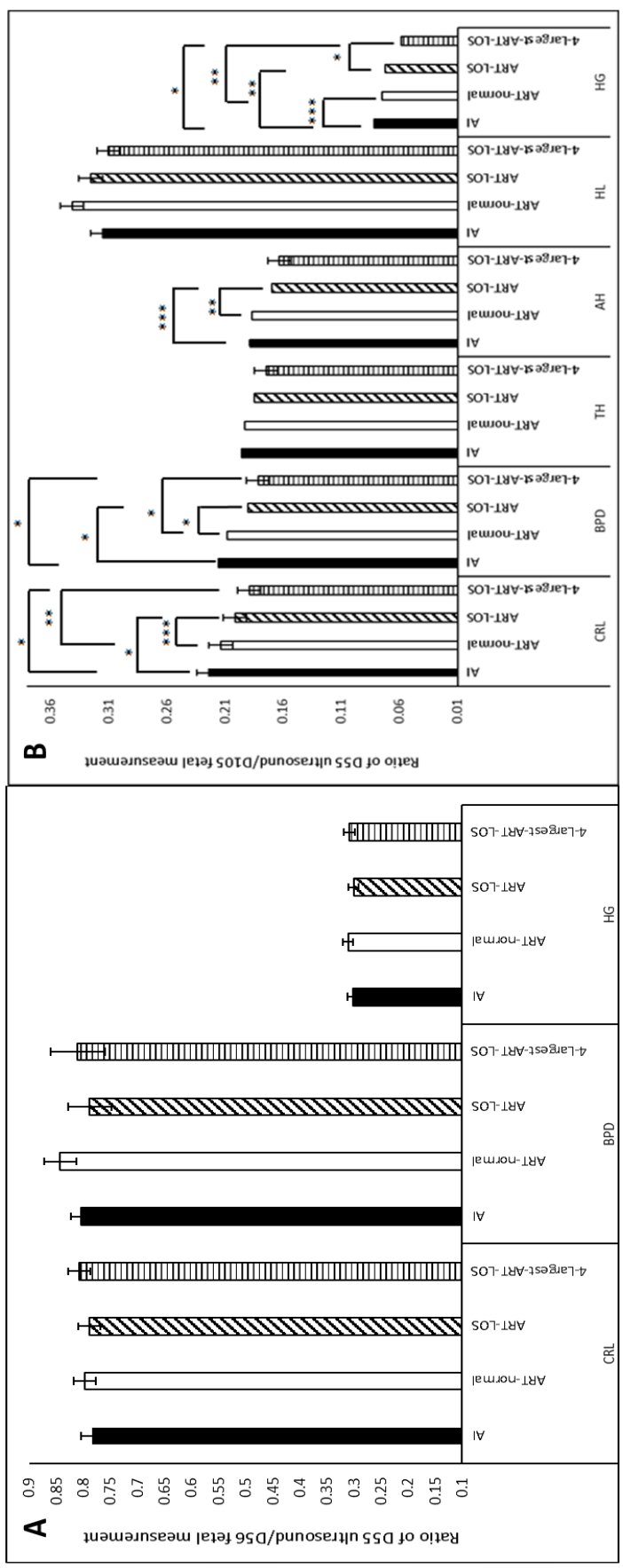

Figure 2.7 
Figure 2.7. Ultrasound/collection ratio. (A) Ratio of gestation day 55

ultrasound measurements to collection day 56 measurements. CRL, BPD among all four groups were $\sim 0.8$. (B) Ratio of gestation day 55 ultrasound measurements to collection day 105 measurements. CRL, BPD and HG of the 4 largest LOS fetuses were smaller than AI and ART-normal group whereas CRL, $\mathrm{BPD}, \mathrm{AH}$ and $\mathrm{HG}$ of ART-LOS was smaller than Al. Al = artificial insemination. $A R T=$ assisted reproductive technologies. $L O S=$ large offspring syndrome. $A H=$ abdominal height. $\mathrm{BPD}=$ biparietal diameter. $\mathrm{CRL}=$ crown rump length. $\mathrm{HL}=$ head length. $\mathrm{HG}=$ heart girth. $\mathrm{TH}=$ thoracic height. ${ }^{*}$ indicates $\mathrm{p}<0.01 .{ }^{* *}$ indicates $p<0.05 .^{* * *}$ indicates $p<0.1$ 


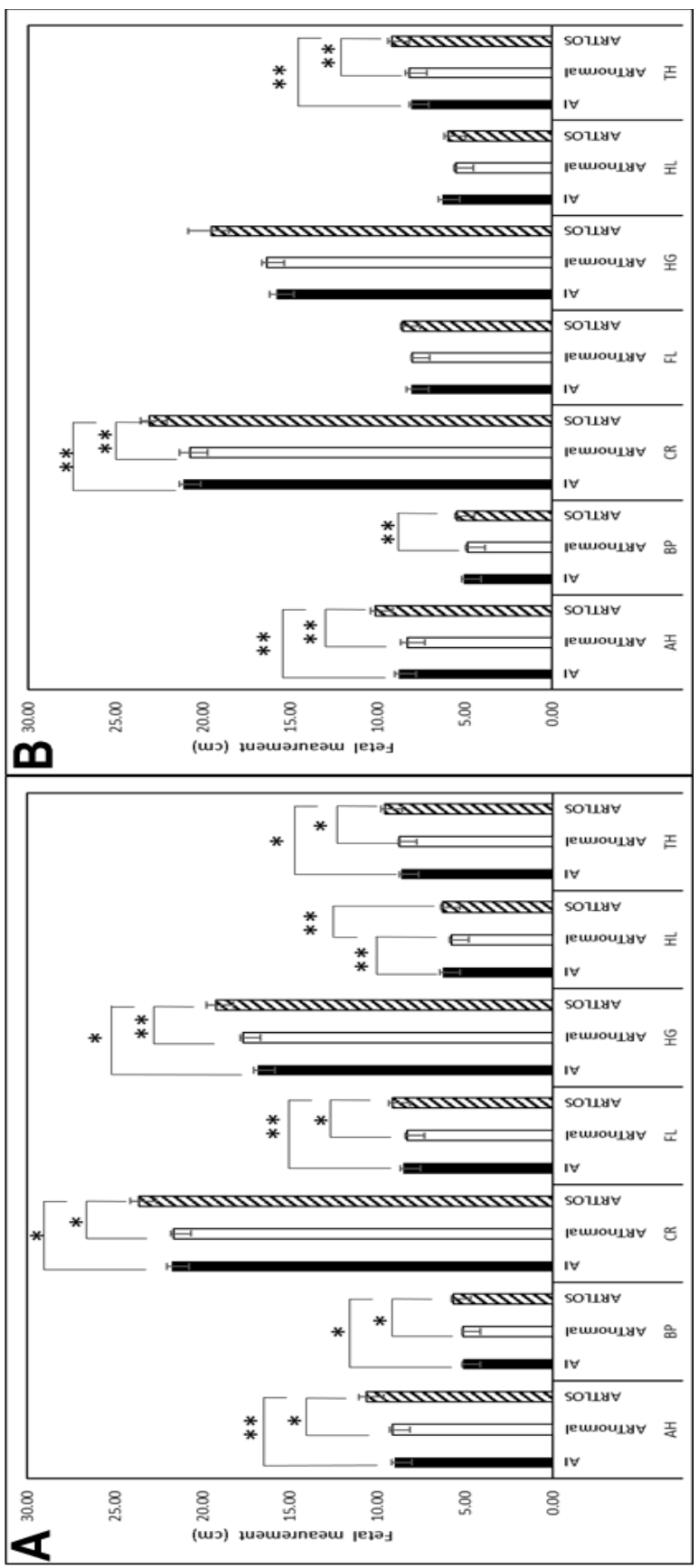

Figure 2.8 
Figure 2.8. Fetal measurements of fetuses collected on day 105 of gestation. Comparison of fetal measurements between day $105 \mathrm{Al}$, ART-normal and ART-LOS, males (A) and females (B) respectively. Al: artificial insemination. ART: assisted reproductive technologies. AH: abdominal height. FL: forelimb length. BP: biparietal diameter. CR: crown rump length. HL: head length. HG: heart girth. TH: thoracic height. ${ }^{*}$ indicates $\mathrm{p}<0.01 .{ }^{* *}$ indicates $\mathrm{p}<0.05$. 


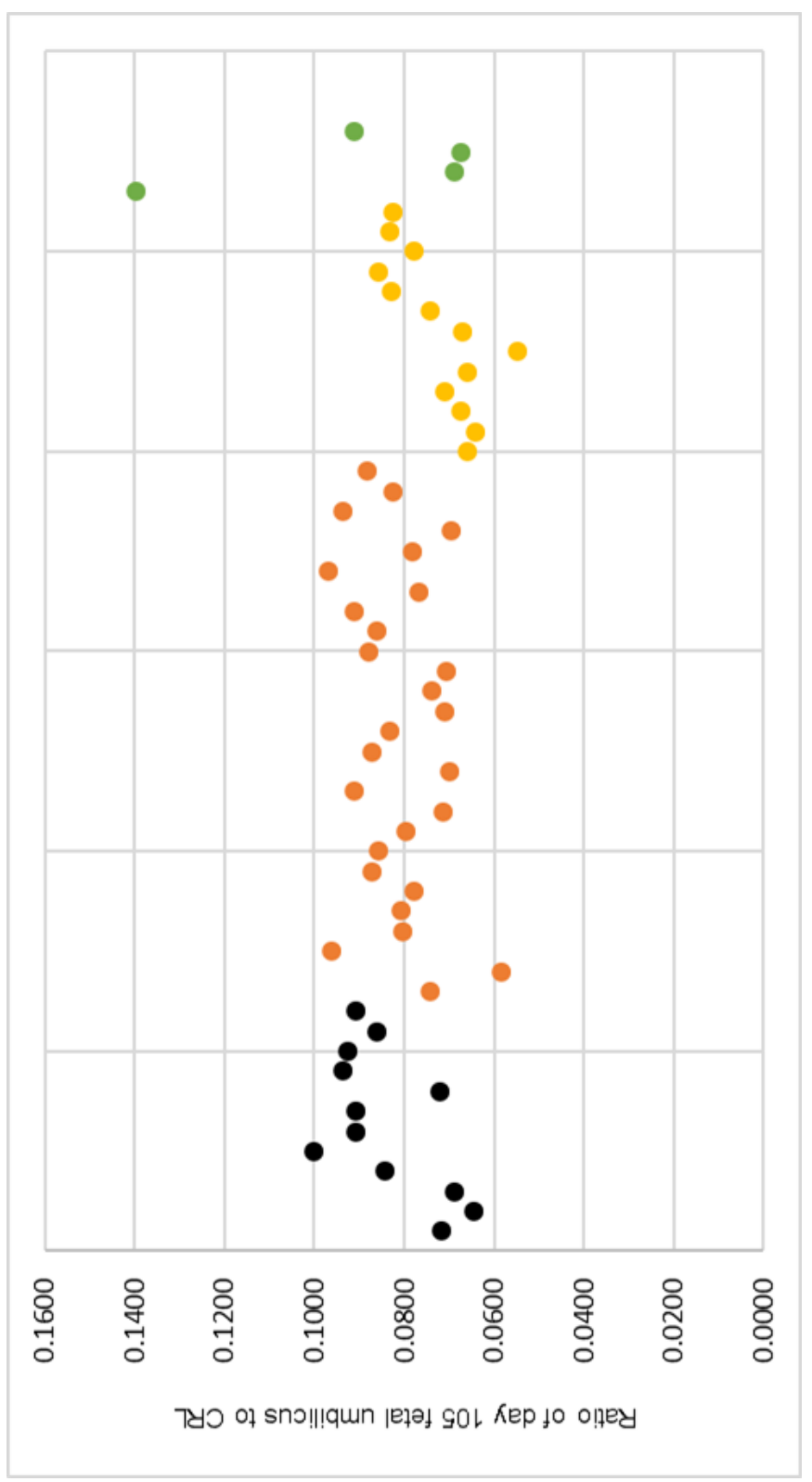

Figure 2.9 
Figure 2.9. Ratio of gestation day 105 umbilicus to CRL. Fetal pictures were used to determine the umbilicus/CRL ratio using image $\mathrm{J}$. The umbilicus was measured at the base. Black circle shows Al fetus ratio, orange circle shows the ART-normal fetus's ratio, yellow circle shows ART-LOS fetus's ratio and green circle shows 4 biggest ART-LOS fetuses' ratio. CRL: crown rump length. LOS: large offspring syndrome. ART: assisted reproductive technologies. 


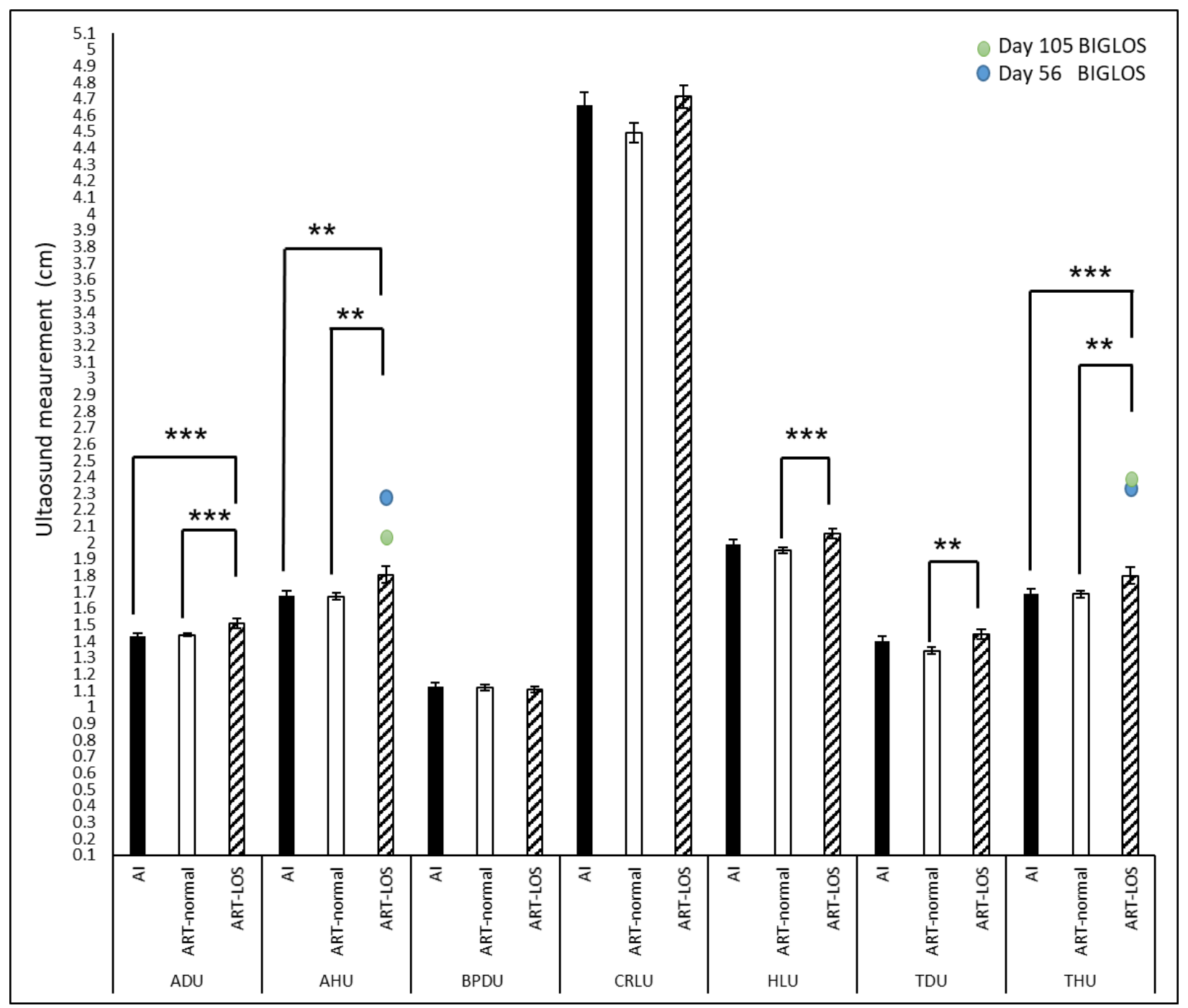

Figure 2.10 
Figure 2.10. Combined Day 55 fetal morphometry of fetuses collected on day 56 and day 105 of gestation. Comparison of ultrasound between Al, ARTnormal and ART-LOS without considering sex of fetuses. Al: artificial insemination. ART: assisted reproductive technologies. LOS: large offspring syndrome. U: ultrasound. AH: abdominal height. FL: forelimb length. BP: biparietal diameter; CR: crown rump length. HL: head length. HG: heart girth. TH: thoracic height. ${ }^{* *}$ indicates $p<0.05 .{ }^{* *}$ indicates $p<0.1$. Green dot and blue dot represent largest day 105 and day 56 fetus's fetal measurement at day 55 of gestation, respectively. 


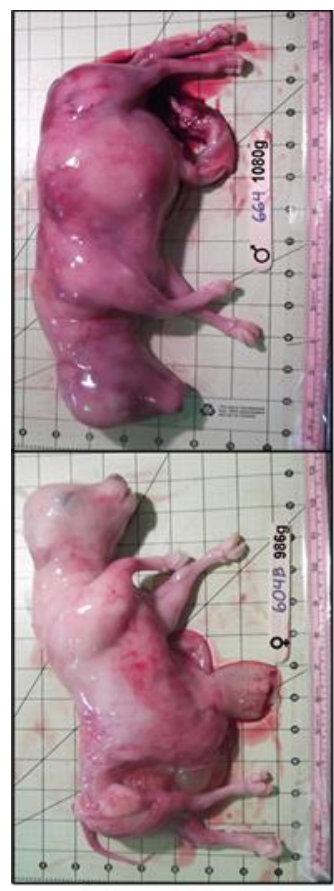

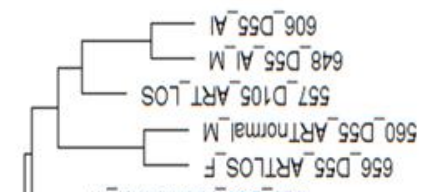

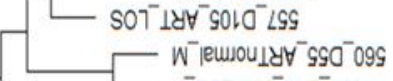

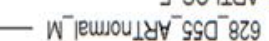

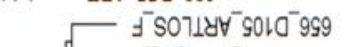

$$
\begin{aligned}
& W^{-1}-H^{-} 9010^{-} 8+9
\end{aligned}
$$
- W'iemoulaty solo"ogs

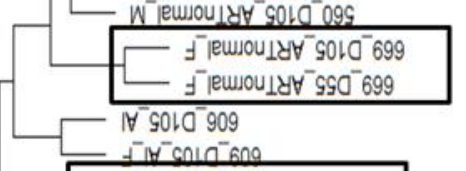

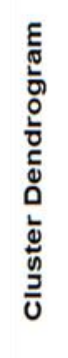

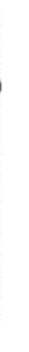
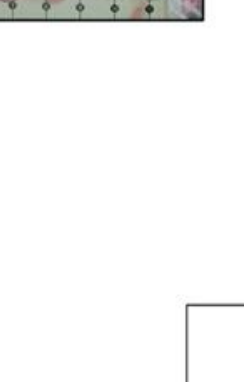
Figure 2.11. Unsupervised hierarchical clustering of white blood cells transcriptome in day $\mathbf{5 5}$ and day $\mathbf{1 0 5}$ of pregnancy. Red oval denotes females (604 and 664) carrying the two largest LOS fetuses on day 105 of pregnancy. Black squares denote 10 out of 23 animals that clustered based on animal and not stage of pregnancy. 


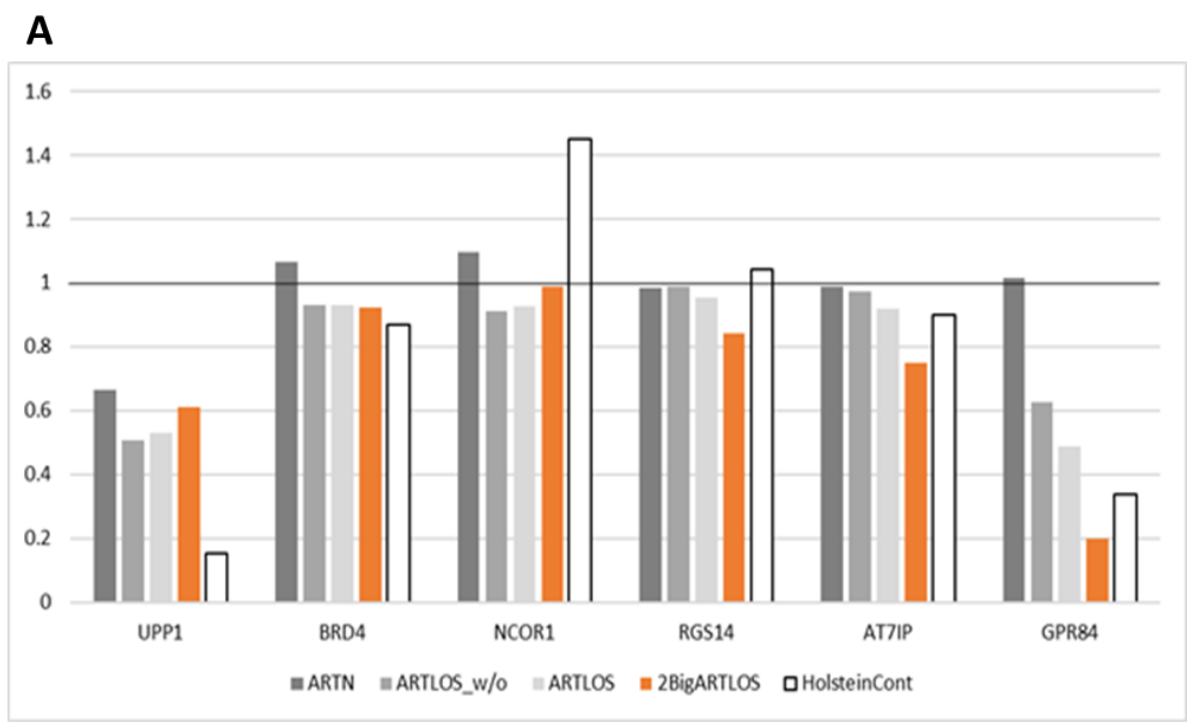

ATF7IP

B

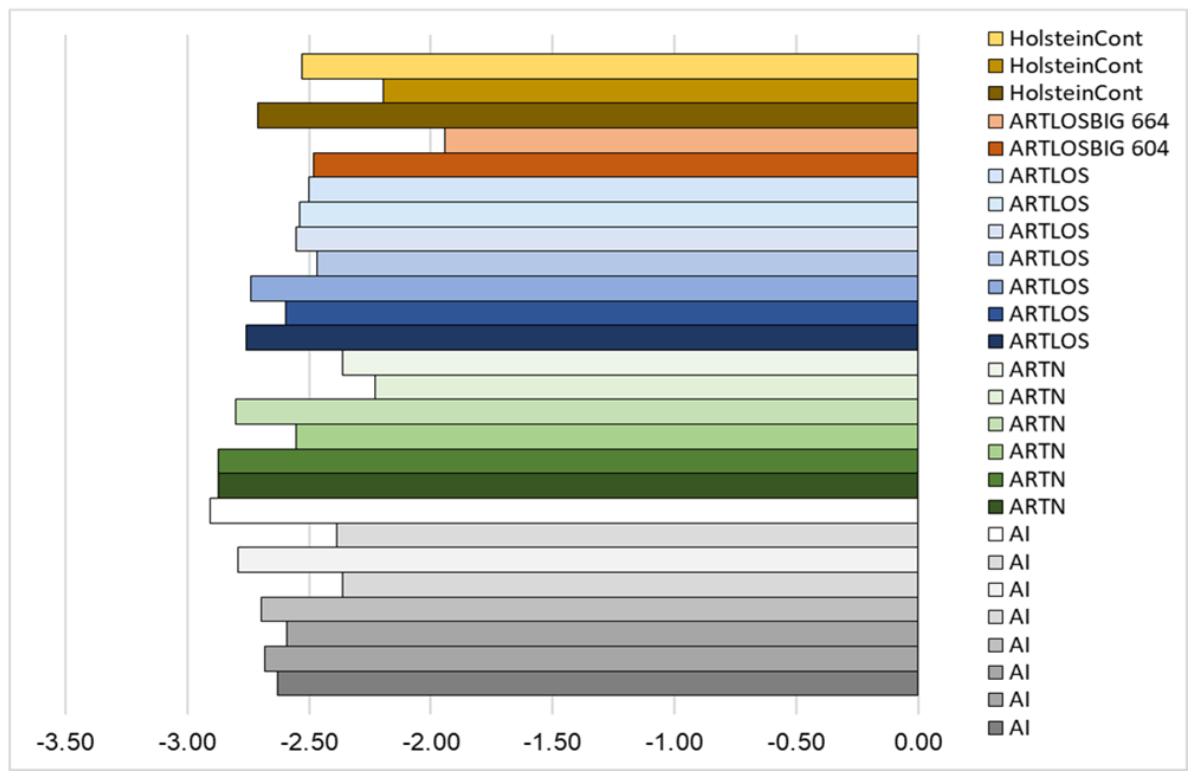

Figure 2.12 
Figure 2.12. Quantitative RT-PCR corroborations of genes identified as differentially expressed by RNAseq in maternal white blood cells. (A) Fold

difference from Al (line at 1). (B) Quantitative RT-PCR corroborations of ATF7IP in maternal white blood cells. The figure shows the variability in transcript amount within treatment groups. The $\mathrm{X}$ axis denotes cycle threshold $(\Delta \mathrm{Ct})$. A negative $\Delta \mathrm{Ct}$ means that the target gene amplifies sooner than the endogenous controls signifying that there is more transcript. A positive $\Delta \mathrm{Ct}$ means that the target gene amplifies later than the endogenous controls signifying that there is less transcript. $\mathrm{Al}=$ Artificial insemination. $\mathrm{ARTN}=\mathrm{ART}$ normal weight group. ARTLOS = ART LOS group, BigARTLOS = represent the females carrying the two largest LOS fetuses (604 and 664). HolsteinCont $=$ Holstein females collected on day 105 of pregnancy to serve as control for the experiment. 


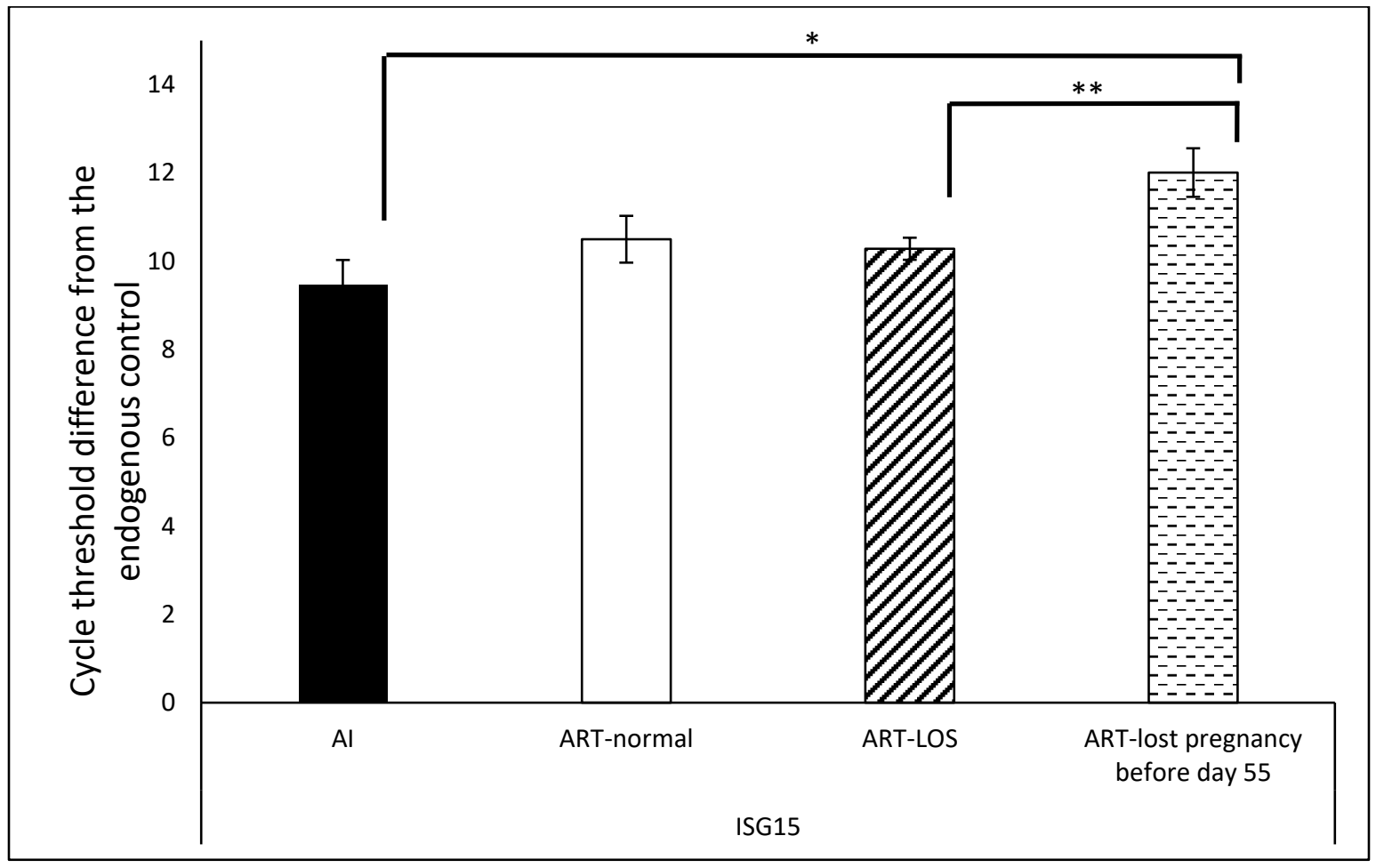

Supplementary Figure S2.1 
Supplementary Figure S2.1. Day 19 ISG15 gene expression. $\mathrm{Al}=$ artificial insemination. ART= assisted reproductive technologies. LOS = large offspring syndrome. ** indicates $p<0.05 .{ }^{* *}$ indicates $p<0.1$. 
Table 2.1. LOS phenotypes observed at fetal collection.

\begin{tabular}{|c|c|c|c|}
\hline \multirow[b]{3}{*}{ Gross observations day 56} & \multicolumn{3}{|c|}{ Day 56 Fetus ID and Weight } \\
\hline & $584(13.77 \mathrm{~g})$ & $591 \mathrm{~A}(10.27 \mathrm{~g})$ & $607 \mathrm{~A}(6.39 \mathrm{~g})$ \\
\hline & & & \\
\hline Abdominal wall defects & & & $\mathbf{x}$ \\
\hline \multirow[t]{3}{*}{ Focal hemorrhage on brain } & $\mathbf{X}$ & $\mathbf{X}$ & \\
\hline & \multicolumn{3}{|c|}{ Day 105 Fetus ID and Weight } \\
\hline & $664(1080 \mathrm{~g})$ & 604B (986 g) & $656(704 \mathrm{~g})$ \\
\hline \multicolumn{4}{|l|}{ Gross observations day 105} \\
\hline Macroglossia & $\mathbf{x}$ & & \\
\hline Large heart & $\mathbf{x}$ & $\mathbf{X}$ & $\mathbf{x}$ \\
\hline Large kidney & & $x$ & \\
\hline Large lung & $\mathbf{x}$ & & $\mathbf{x}$ \\
\hline Large pancreas & & $\mathbf{x}$ & \\
\hline Large umbilicus & & $x$ & $\mathbf{x}$ \\
\hline Abdominal ascites & $\mathbf{x}$ & $\mathbf{x}$ & \\
\hline Asymmetrical head & $\mathbf{x}$ & & \\
\hline Hemorrhage on head & & $\mathbf{x}$ & \\
\hline Hepatic cyst & $\mathbf{X}$ & & \\
\hline
\end{tabular}




\section{Supplementary Table S2.1 Ratio of day 105 umbilicus and CRL.}

\begin{tabular}{|c|c|c|c|c|c|}
\hline Group & Sex & Fetus ID & $\begin{array}{c}\text { Um bilicus length } \\
(\mathrm{cm})\end{array}$ & CRL $(\mathrm{cm})$ & $\begin{array}{c}\text { Ratio_of_umbili } \\
\text { cus_to_CRL }\end{array}$ \\
\hline Al & Female & $533 A$ & 1.647409848 & 22.99363 & 0.0716 \\
\hline $\mathrm{Al}$ & Female & $546 \mathrm{~A}$ & 1.469593963 & 22.81375 & 0.0644 \\
\hline $\mathrm{Al}$ & Female & $609 \mathrm{~A}$ & 1.651100979 & 23.99733 & 0.0688 \\
\hline Al & Female & $647 A$ & 1.886701166 & 22.41406 & 0.0842 \\
\hline $\mathrm{Al}$ & Male & $517 A$ & 2.433474009 & 24.35207 & 0.0999 \\
\hline $\mathrm{Al}$ & Male & $524 \mathrm{~A}$ & 2.064478438 & 22.76822 & 0.0907 \\
\hline $\mathrm{Al}$ & Male & $527 \mathrm{~A}$ & 2.255912203 & 24.89788 & 0.0906 \\
\hline $\mathrm{Al}$ & Male & $539 A$ & 1.721119514 & 23.90435 & 0.072 \\
\hline $\mathrm{Al}$ & Male & $590 \mathrm{~A}$ & 2.335772769 & 25.02224 & 0.0933 \\
\hline $\mathrm{Al}$ & Male & $606 \mathrm{~A}$ & 2.321687014 & 25.15312 & 0.0923 \\
\hline Al & Male & $640 \mathrm{~A}$ & 2.01646857 & 23.42875 & 0.0861 \\
\hline $\mathrm{Al}$ & Male & $648 \mathrm{~A}$ & 2.143930221 & 23.68326 & 0.0905 \\
\hline ART_normal & Female & $519 A$ & 1.752429418 & 23.66431 & 0.0741 \\
\hline ART_normal & Female & $522 B$ & 1.257532271 & 21.65827 & 0.0581 \\
\hline ART_normal & Female & $688 \mathrm{~A}$ & 2.318355917 & 24.17182 & 0.0959 \\
\hline ART_normal & Male & $522 \mathrm{~A}$ & 1.909835544 & 23.83783 & 0.0801 \\
\hline ART_normal & Male & $530 \mathrm{~B}$ & 1.894014823 & 23.55227 & 0.0804 \\
\hline ART_normal & Male & $532 \mathrm{~A}$ & 2.002957516 & 25.8395 & 0.0775 \\
\hline ART_normal & Male & $540 \mathrm{~A}$ & 2.153794627 & 24.70058 & 0.0872 \\
\hline ART_normal & Male & $542 B$ & 2.121772067 & 24.80472 & 0.0855 \\
\hline ART_normal & Male & $547 \mathrm{~A}$ & 2.02796143 & 25.52157 & 0.0795 \\
\hline ART_normal & Male & $547 \mathrm{~B}$ & 1.754966818 & 24.60583 & 0.0713 \\
\hline ART_normal & Male & $557 A$ & 2.311441526 & 25.37462 & 0.0911 \\
\hline ART_normal & Male & $559 A$ & 1.8056005 & 25.8542 & 0.0698 \\
\hline ART_normal & Male & $560 \mathrm{~A}$ & 2.143620117 & 24.60551 & 0.0871 \\
\hline ART_normal & Male & $576 \mathrm{~A}$ & 2.107447707 & 25.36457 & 0.0831 \\
\hline ART_normal & Male & $580 \mathrm{~A}$ & 1.658963247 & 23.4185 & 0.0708 \\
\hline ART_normal & Male & $585 A$ & 1.772628658 & 24.07664 & 0.0736 \\
\hline ART_normal & Male & $585 B$ & 1.821990087 & 25.90078 & 0.0703 \\
\hline ART_normal & Male & $605 \mathrm{~A}$ & 2.215869509 & 25.30408 & 0.0876 \\
\hline ART_normal & Male & $611 \mathrm{~A}$ & 2.147271214 & 24.95087 & 0.0861 \\
\hline ART_normal & Male & $624 \mathrm{~A}$ & 2.043172027 & 22.43629 & 0.0911 \\
\hline ART_normal & Male & $628 A$ & 1.974585573 & 25.81613 & 0.0765 \\
\hline ART_normal & Male & $628 \mathrm{~B}$ & 2.218822173 & 22.92348 & 0.0968 \\
\hline ART_normal & Male & $631 \mathrm{~A}$ & 1.965815906 & 25.23815 & 0.0779 \\
\hline ART_normal & Male & $633 A$ & 1.546369034 & 22.34727 & 0.0692 \\
\hline ART_normal & Male & $652 A$ & 2.204591851 & 23.58467 & 0.0935 \\
\hline ART_normal & Male & $666 \mathrm{~A}$ & 2.12116012 & 25.7349 & 0.0824 \\
\hline ART_normal & Male & $688 \mathrm{~B}$ & 2.084167891 & 23.65453 & 0.0881 \\
\hline ART_LOS & Female & $530 \mathrm{~A}$ & 1.529894939 & 23.21044 & 0.0659 \\
\hline
\end{tabular}




\begin{tabular}{|c|c|c|c|c|c|}
\hline ART_LOS & Female & $543 \mathrm{~A}$ & 1.582656073 & 24.75685 & 0.0639 \\
\hline ART_LOS & Female & $557 \mathrm{~B}$ & 1.656715 & 24.64175 & 0.0672 \\
\hline ART_LOS & Female & $616 \mathrm{~A}$ & 1.883895039 & 26.55188 & 0.071 \\
\hline ART_LOS & Female & $620 \mathrm{~A}$ & 1.661029531 & 25.26923 & 0.0657 \\
\hline ART_LOS & Female & $663 \mathrm{~A}$ & 1.400483681 & 25.59089 & 0.0547 \\
\hline ART_LOS & Female & $683 \mathrm{~A}$ & 1.682977702 & 25.22005 & 0.0667 \\
\hline ART_LOS & Male & $512 \mathrm{~A}$ & 2.041310414 & 27.56333 & 0.0741 \\
\hline ART_LOS & Male & $535 \mathrm{~A}$ & 2.140202372 & 25.92357 & 0.0826 \\
\hline ART_LOS & Male & $542 \mathrm{~A}$ & 2.204518303 & 25.72483 & 0.0857 \\
\hline ART_LOS & Male & $604 \mathrm{~A}$ & 2.039006599 & 26.25729 & 0.0777 \\
\hline ART_LOS & Male & $637 \mathrm{~A}$ & 2.152399533 & 25.92039 & 0.083 \\
\hline ART_LOS & Male & $680 \mathrm{~A}$ & 2.061112991 & 24.98187 & 0.0825 \\
\hline 4_Biggest_ART-LOS & Female & $604 \mathrm{~B}$ & 3.900653823 & 27.93119 & 0.1397 \\
\hline 4_Biggest_ART-LOS & Male & $664 \mathrm{~A}$ & 2.011625351 & 29.25045 & 0.0688 \\
\hline 4_Biggest_ART-LOS & Female & $656 \mathrm{~A}$ & 1.795230756 & 26.77361 & 0.0671 \\
\hline 4_Biggest_ART-LOS & Male & $602 \mathrm{~A}$ & 2.606172687 & 28.70276 & 0.0908 \\
\hline
\end{tabular}

Both umbilicus and CRL were measured in centimeters from fetus pictures using ImageJ. CRL- crown-rump length. 


\section{Supplementary Table S2.2A. Gestation day 55 and day 105 maternal leucocyte RNAseq summary using NCBI Bos taurus assembly ARS- UCD 1.2.}

\begin{tabular}{|c|c|c|c|c|c|c|c|c|c|c|}
\hline $\begin{array}{c}\text { Cow } \\
\text { ID }\end{array}$ & $\begin{array}{l}\text { Single } \\
\text { (S) or } \\
\text { tw in(T) }\end{array}$ & Group & $\begin{array}{c}\text { Fetal } \\
\text { w eight } \\
\text { (g) }\end{array}$ & $\begin{array}{c}\text { Sex } \\
\text { of } \\
\text { fetus }\end{array}$ & $\begin{array}{c}\text { Day of } \\
\text { pregnancy }\end{array}$ & RIN & $\begin{array}{l}\text { \#reads } \\
\text { before } \\
\text { quality } \\
\text { trimming }\end{array}$ & $\begin{array}{l}\text { \#reads } \\
\text { after } \\
\text { quality } \\
\text { trimming }\end{array}$ & 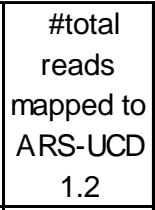 & $\begin{array}{l}\text { \%total } \\
\text { reads } \\
\text { mapped }\end{array}$ \\
\hline 533 & S & Al1 & 388 & $\mathrm{~F}$ & 105 & 9 & 70494496 & 70486246 & 67374165 & 95.58 \\
\hline 647 & $S$ & $\mathrm{Al} 2$ & 396 & $\mathrm{~F}$ & 105 & 8.7 & 71909588 & 71900968 & 68621986 & 95.44 \\
\hline 546 & $\mathrm{~S}$ & $A \mid 3$ & 414 & $\mathrm{~F}$ & 105 & 9.4 & 70369796 & 70361006 & 67410500 & 95.81 \\
\hline 609 & $S$ & A14 & 468 & $F$ & 105 & 9 & 70317570 & 70308802 & 67279128 & 95.69 \\
\hline 517 & $S$ & A15 & 442 & $M$ & 105 & 7 & 73996408 & 73987048 & 70654713 & 95.5 \\
\hline 648 & $S$ & Al6 & 466 & $M$ & 105 & 9.1 & 70403586 & 70395346 & 67291416 & 95.59 \\
\hline 590 & $S$ & $\mathrm{Al} 7$ & 544 & $M$ & 105 & 8.6 & 72009340 & 72000680 & 68727952 & 95.45 \\
\hline 606 & $S$ & $A 18$ & 550 & $M$ & 105 & 9 & 70077598 & 70068666 & 67018077 & 95.65 \\
\hline 519 & $S$ & ART-N1 & 408 & $\mathrm{~F}$ & 105 & 9.3 & 70125516 & 70118094 & 67332714 & 96.03 \\
\hline 669 & $S$ & ART-N2 & 442 & $\mathrm{~F}$ & 105 & 8.2 & 70173446 & 70165196 & 66962773 & 95.44 \\
\hline 688 & $T$ & ART-N3 & 448 & $\mathrm{~F}$ & 105 & 9.3 & 72435786 & 72427334 & 69233239 & 95.59 \\
\hline 628 & $\mathrm{~T}$ & ART-N4 & 434 & $M$ & 105 & 6.7 & 72180888 & 72172240 & 69107584 & 95.75 \\
\hline 560 & $\mathrm{~S}$ & ART-N5 & 480 & M & 105 & 9 & 72488602 & 72479812 & 69522148 & 95.92 \\
\hline 633 & $S$ & ART-N6 & 538 & M & 105 & 7.5 & 71979464 & 71969898 & 68651442 & 95.39 \\
\hline 557 & $T$ & ART-LOS1 & 506 & $\mathrm{~F}$ & 105 & 6.7 & 72106928 & 72097896 & 68845783 & 95.49 \\
\hline 663 & S & ART-LOS2 & 578 & $\mathrm{~F}$ & 105 & 9.2 & 74636094 & 74627328 & 71438695 & 95.73 \\
\hline 616 & $S$ & ART-LOS3 & 638 & $\mathrm{~F}$ & 105 & 9.2 & 70201060 & 70192856 & 66924731 & 95.34 \\
\hline 656 & $\mathrm{~S}$ & ART-LOS4 & 704 & $\mathrm{~F}$ & 105 & 9.2 & 70190938 & 70182738 & 67164003 & 95.7 \\
\hline 604 & $\mathrm{~T}$ & ART-LOS5 & 986 & $\mathrm{~F}$ & 105 & 4.4 & 70307484 & 70299560 & 67518407 & 96.04 \\
\hline 637 & s & ART-LOS6 & 586 & M & 105 & 9.4 & 70258108 & 70249844 & 67207308 & 95.67 \\
\hline 512 & $S$ & ART-LOS7 & 648 & $M$ & 105 & 7.8 & 72169974 & 72161132 & 68719383 & 95.23 \\
\hline 602 & $S$ & ART-LOS8 & 752 & $M$ & 105 & 8 & 72386718 & 72377778 & 69236360 & 95.66 \\
\hline 664 & $S$ & ART-LOS9 & 1080 & $M$ & 105 & 3.6 & 72131696 & 72123546 & 68971848 & 95.63 \\
\hline 533 & $\mathrm{~S}$ & Al1 & 388 & $\mathrm{~F}$ & 55 & 8.2 & 72435692 & \begin{tabular}{|l|}
72426782 \\
\end{tabular} & 69075419 & 95.37 \\
\hline 647 & $S$ & Al2 & 396 & $\mathrm{~F}$ & 55 & 8.5 & 72334552 & 72325372 & 69250131 & 95.75 \\
\hline 546 & $S$ & $A B$ & 414 & $\mathrm{~F}$ & 55 & 8.9 & 72224428 & 72215094 & 69189369 & 95.81 \\
\hline 609 & $\mathrm{~S}$ & $\mathrm{Al} 4$ & 468 & $\mathrm{~F}$ & 55 & 9.4 & 72283066 & 72274632 & 69098021 & 95.6 \\
\hline 517 & $\mathrm{~S}$ & Al5 & 442 & $M$ & 55 & 8 & 70438806 & 70430230 & 67539053 & 95.89 \\
\hline 648 & $S$ & Al6 & 466 & $M$ & 55 & 8 & 71483452 & 71474136 & 68146852 & 95.34 \\
\hline
\end{tabular}




\begin{tabular}{|c|c|c|c|c|c|c|c|c|c|c|}
\hline 590 & $\mathrm{~S}$ & $\mathrm{Al7}$ & 544 & $\mathrm{M}$ & 55 & 9.4 & 70376660 & 70368418 & 67541465 & 95.98 \\
\hline 606 & $\mathrm{~S}$ & $\mathrm{Al}$ & 550 & $\mathrm{M}$ & 55 & 7.4 & 74550210 & 74541104 & 71435024 & 95.83 \\
\hline 519 & $\mathrm{~S}$ & ART-N1 & 408 & $\mathrm{~F}$ & 55 & 9.3 & 72088426 & 72079870 & 69078701 & 95.84 \\
\hline 669 & $\mathrm{~S}$ & ART-N2 & 442 & $\mathrm{~F}$ & 55 & 9.1 & 70243932 & 70235580 & 67247887 & 95.75 \\
\hline 688 & $\mathrm{~T}$ & ART-N3 & 448 & $\mathrm{~F}$ & 55 & 9.5 & 72259626 & 72250856 & 69281300 & 95.89 \\
\hline 628 & $\mathrm{~T}$ & ART-N4 & 434 & $\mathrm{M}$ & 55 & 6.6 & 74568930 & 74559826 & 71493744 & 95.89 \\
\hline 560 & $\mathrm{~S}$ & ART-N5 & 480 & $\mathrm{M}$ & 55 & 9.1 & 72379562 & 72371058 & 69396367 & 95.89 \\
\hline 633 & $\mathrm{~S}$ & ART-N6 & 538 & $\mathrm{M}$ & 55 & 9.5 & 72332390 & 72325026 & 69270783 & 95.78 \\
\hline 557 & $\mathrm{~T}$ & ART-LOS1 & 506 & $\mathrm{~F}$ & 55 & 9.5 & 72214470 & 72207666 & 69042385 & 95.62 \\
\hline 663 & $\mathrm{~S}$ & ART-LOS2 & 578 & $\mathrm{~F}$ & 55 & 8.9 & 70076982 & 70068416 & 67115997 & 95.79 \\
\hline 616 & $\mathrm{~S}$ & ART-LOS3 & 638 & $\mathrm{~F}$ & 55 & 9.3 & 70176532 & 70168294 & 67030106 & 95.53 \\
\hline 656 & $\mathrm{~S}$ & ART-LOS4 & 704 & $\mathrm{~F}$ & 55 & 9.3 & 72806926 & 72797466 & 69820059 & 95.91 \\
\hline 604 & $\mathrm{~T}$ & ART-LOS5 & 986 & $\mathrm{~F}$ & 55 & 9.6 & 71861400 & 71852960 & 68708083 & 95.62 \\
\hline 637 & $\mathrm{~S}$ & ART-LOS6 & 586 & $\mathrm{M}$ & 55 & 9.4 & 70106712 & 70098050 & 67152024 & 95.8 \\
\hline 512 & $\mathrm{~S}$ & ART-LOS7 & 648 & $\mathrm{M}$ & 55 & 8.7 & 74688290 & 74679108 & 71451930 & 95.68 \\
\hline 602 & $\mathrm{~S}$ & ART-LOS8 & 752 & $\mathrm{M}$ & 55 & 7.9 & 70144948 & 70136178 & 67258032 & 95.9 \\
\hline 664 & $\mathrm{~S}$ & ART-LOS9 & 1080 & $\mathrm{M}$ & 55 & 9.6 & 70174478 & 70165974 & 67298708 & 95.91 \\
\hline
\end{tabular}

$\mathrm{bp}=$ base pairs. RIN = RNA integrity number. $\mathrm{LOS}=$ large offspring syndrome. $\mathrm{Al}=$ artificial insemination. $A R T=$ assisted reproductive technologies. $F=$ female. $M=$ male. 


\section{Supplementary Table S2.2B. Gestation day 55 and day 105 maternal leucocyte RNAseq summary using Ensembl Bos taurus assembly ARS- UCD 1.2}

\begin{tabular}{|c|c|c|c|c|c|c|c|c|c|c|}
\hline $\begin{array}{c}\text { Cow } \\
\text { ID }\end{array}$ & $\begin{array}{l}\text { Single } \\
\text { (S) or } \\
\text { tw in(T) }\end{array}$ & Group & $\begin{array}{c}\text { Fetal } \\
\text { w eight } \\
(\mathrm{g})\end{array}$ & $\begin{array}{c}\text { Sex } \\
\text { of } \\
\text { fetus }\end{array}$ & $\begin{array}{c}\text { Day of } \\
\text { pregnancy }\end{array}$ & RIN & $\begin{array}{l}\text { \#reads } \\
\text { before } \\
\text { quality } \\
\text { trimming }\end{array}$ & $\begin{array}{l}\text { \#reads } \\
\text { after } \\
\text { quality } \\
\text { trimming }\end{array}$ & $\begin{array}{c}\text { \#total reads } \\
\text { mapped to } \\
\text { ARS-UCD } 1.2\end{array}$ & $\begin{array}{l}\text { \%total } \\
\text { reads } \\
\text { mapped }\end{array}$ \\
\hline 533 & $S$ & Al1 & 388 & $\mathrm{~F}$ & 105 & 9 & 70494496 & 70486246 & 67358493 & 95.56 \\
\hline 647 & $S$ & $A 12$ & 396 & $\mathrm{~F}$ & 105 & 8.7 & 71909588 & 71900968 & 68606903 & 95.42 \\
\hline 546 & $S$ & $A B$ & 414 & $\mathrm{~F}$ & 105 & 9.4 & 70369796 & 70361006 & 67394667 & 95.78 \\
\hline 609 & $S$ & $A 14$ & 468 & $F$ & 105 & 9 & 70317570 & 70308802 & 67264081 & 95.67 \\
\hline 517 & $S$ & Al5 & 442 & $M$ & 105 & 7 & 73996408 & 73987048 & 70642124 & 95.48 \\
\hline 648 & $S$ & Al6 & 466 & $M$ & 105 & 9.1 & 70403586 & 70395346 & 67274662 & 95.57 \\
\hline 590 & $S$ & Al7 & 544 & M & 105 & 8.6 & 72009340 & 72000680 & 68713538 & 95.43 \\
\hline 606 & $S$ & $A 18$ & 550 & $M$ & 105 & 9 & 70077598 & 70068666 & 67003185 & 95.63 \\
\hline 519 & $S$ & ART-N1 & 408 & $\mathrm{~F}$ & 105 & 9.3 & 70125516 & 70118094 & 67317812 & 96.01 \\
\hline 669 & $S$ & ART-N2 & 442 & $F$ & 105 & 8.2 & 70173446 & 70165196 & 66947644 & 95.41 \\
\hline 688 & $T$ & ART-N3 & 448 & $F$ & 105 & 9.3 & 72435786 & 72427334 & 69219589 & 95.57 \\
\hline 628 & $\mathrm{~T}$ & ART-N4 & 434 & $M$ & 105 & 6.7 & 72180888 & 72172240 & 69094450 & 95.74 \\
\hline 560 & $S$ & ART-N5 & 480 & $M$ & 105 & 9 & 72488602 & 72479812 & 69506630 & 95.9 \\
\hline 633 & $S$ & ART-N6 & 538 & $M$ & 105 & 7.5 & 71979464 & 71969898 & 68638621 & 95.37 \\
\hline 557 & $\mathrm{~T}$ & ART-LOS1 & 506 & $\mathrm{~F}$ & 105 & 6.7 & 72106928 & 72097896 & 68832768 & 95.47 \\
\hline 663 & $S$ & ART-LOS2 & 578 & $F$ & 105 & 9.2 & 74636094 & 74627328 & 71420288 & 95.7 \\
\hline 616 & $S$ & ART-LOS3 & 638 & $F$ & 105 & 9.2 & 70201060 & 70192856 & 66907474 & 95.32 \\
\hline 656 & $S$ & ART-LOS4 & 704 & $F$ & 105 & 9.2 & 70190938 & 70182738 & 67147700 & 95.68 \\
\hline 604 & $T$ & ART-LOS5 & 986 & $\mathrm{~F}$ & 105 & 4.4 & 70307484 & 70299560 & 67505767 & 96.03 \\
\hline 637 & $S$ & ART-LOS6 & 586 & $M$ & 105 & 9.4 & 70258108 & 70249844 & 67190457 & 95.64 \\
\hline 512 & $S$ & ART-LOS7 & 648 & $M$ & 105 & 7.8 & 72169974 & 72161132 & 68703633 & 95.21 \\
\hline 602 & $S$ & ART-LOS8 & 752 & $M$ & 105 & 8 & 72386718 & 72377778 & 69219151 & 95.64 \\
\hline 664 & $S$ & ART-LOS9 & 1080 & $M$ & 105 & 3.6 & 72131696 & 72123546 & 68958743 & 95.61 \\
\hline 533 & $S$ & Al1 & 388 & $F$ & 55 & 8.2 & 72435692 & 72426782 & 69060642 & 95.35 \\
\hline 647 & $S$ & $A L$ & 396 & $F$ & 55 & 8.5 & 72334552 & 72325372 & 69232796 & 95.72 \\
\hline 546 & $S$ & $A \mid 3$ & 414 & $F$ & 55 & 8.9 & 72224428 & 72215094 & 69172091 & 95.79 \\
\hline 609 & $S$ & Al4 & 468 & $F$ & 55 & 9.4 & 72283066 & 72274632 & 69084757 & 95.59 \\
\hline 517 & $S$ & Al5 & 442 & $M$ & 55 & 8 & 70438806 & 70430230 & 67525397 & 95.88 \\
\hline 648 & $S$ & Al6 & 466 & $M$ & 55 & 8 & 71483452 & 71474136 & 68131827 & 95.32 \\
\hline
\end{tabular}




\begin{tabular}{|c|c|c|c|c|c|c|c|c|c|c|}
\hline 590 & $\mathrm{~S}$ & $\mathrm{Al}$ & 544 & $\mathrm{M}$ & 55 & 9.4 & 70376660 & 70368418 & 67527200 & 95.96 \\
\hline 606 & $\mathrm{~S}$ & $\mathrm{Al}$ & 550 & $\mathrm{M}$ & 55 & 7.4 & 74550210 & 74541104 & 71421842 & 95.82 \\
\hline 519 & $\mathrm{~S}$ & $\mathrm{ART}-\mathrm{N} 1$ & 408 & $\mathrm{~F}$ & 55 & 9.3 & 72088426 & 72079870 & 69061153 & 95.81 \\
\hline 669 & $\mathrm{~S}$ & ART-N2 & 442 & $\mathrm{~F}$ & 55 & 9.1 & 70243932 & 70235580 & 67232175 & 95.72 \\
\hline 688 & $\mathrm{~T}$ & ART-N3 & 448 & $\mathrm{~F}$ & 55 & 9.5 & 72259626 & 72250856 & 69266448 & 95.87 \\
\hline 628 & $\mathrm{~T}$ & ART-N4 & 434 & $\mathrm{M}$ & 55 & 6.6 & 74568930 & 74559826 & 71480204 & 95.87 \\
\hline 560 & $\mathrm{~S}$ & ART-N5 & 480 & $\mathrm{M}$ & 55 & 9.1 & 72379562 & 72371058 & 69381685 & 95.87 \\
\hline 633 & $\mathrm{~S}$ & ART-N6 & 538 & $\mathrm{M}$ & 55 & 9.5 & 72332390 & 72325026 & 69254472 & 95.75 \\
\hline 557 & $\mathrm{~T}$ & ART-LOS1 & 506 & $\mathrm{~F}$ & 55 & 9.5 & 72214470 & 72207666 & 69025723 & 95.59 \\
\hline 663 & $\mathrm{~S}$ & ART-LOS2 & 578 & $\mathrm{~F}$ & 55 & 8.9 & 70076982 & 70068416 & 67101535 & 95.77 \\
\hline 616 & $\mathrm{~S}$ & ART-LOS3 & 638 & $\mathrm{~F}$ & 55 & 9.3 & 70176532 & 70168294 & 67013207 & 95.5 \\
\hline 656 & $\mathrm{~S}$ & ART-LOS4 & 704 & $\mathrm{~F}$ & 55 & 9.3 & 72806926 & 72797466 & 69804481 & 95.89 \\
\hline 604 & $\mathrm{~T}$ & ART-LOS5 & 986 & $\mathrm{~F}$ & 55 & 9.6 & 71861400 & 71852960 & 68689763 & 95.6 \\
\hline 637 & $\mathrm{~S}$ & ART-LOS6 & 586 & $\mathrm{M}$ & 55 & 9.4 & 70106712 & 70098050 & 67136174 & 95.77 \\
\hline 512 & $\mathrm{~S}$ & ART-LOS7 & 648 & $\mathrm{M}$ & 55 & 8.7 & 74688290 & 74679108 & 71433702 & 95.65 \\
\hline 602 & $\mathrm{~S}$ & ART-LOS8 & 752 & $\mathrm{M}$ & 55 & 7.9 & 70144948 & 70136178 & 67242662 & 95.87 \\
\hline 664 & $\mathrm{~S}$ & ART-LOS9 & 1080 & $\mathrm{M}$ & 55 & 9.6 & 70174478 & 70165974 & 67281245 & 95.89 \\
\hline
\end{tabular}

$b p=$ base pairs. RIN = RNA integrity number. $L O S=$ large offspring syndrome. $A I=$ artificial insemination. $\mathrm{ART}=$ assisted reproductive technoloaies. $\mathrm{F}=$ female. $\mathrm{M}=$ male. 


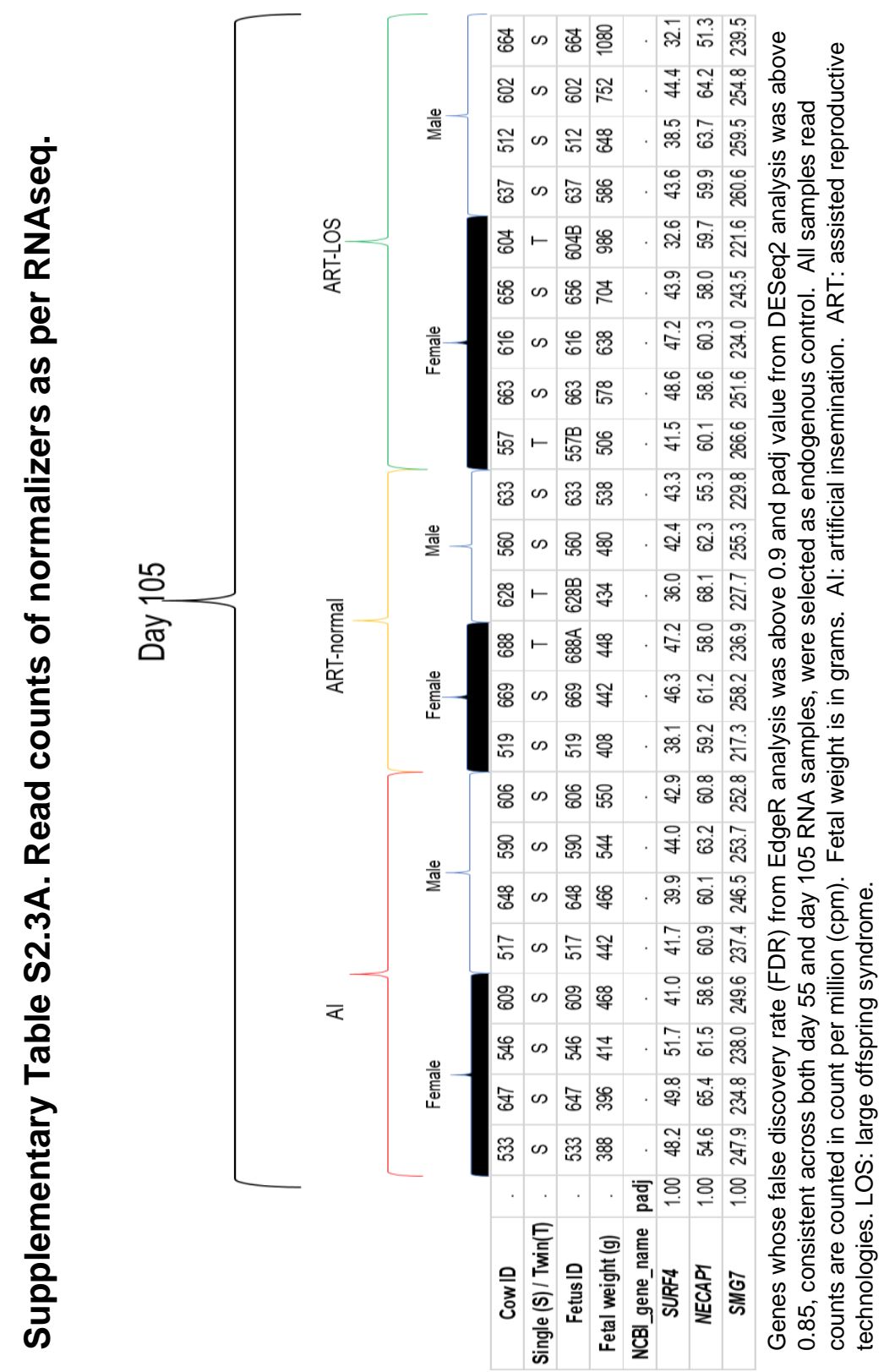




\section{Supplementary Table S2.3B. Selection of normalizers for RT-PCR.}

\begin{tabular}{|c|c|c|c|c|c|c|}
\hline $\begin{array}{c}\text { Day of } \\
\text { pregnancy }\end{array}$ & Ensembl_Gene_ID & padj & FDR & $\begin{array}{l}\text { Average } \\
\text { read counts }\end{array}$ & SD & $\mathrm{CV} \%$ \\
\hline & ENSBTAG00000051352 & 1 & 1 & 97.97 & 9.13 & 9.31 \\
\hline \multirow[t]{3}{*}{105} & ENSBTAG00000020237 & 1 & 1 & 61.78 & 5.92 & 9.58 \\
\hline & ENSBTAG00000008003 & 1 & 1 & 253.42 & 24.09 & 9.51 \\
\hline & ENSBTAG00000051352 & 0.94 & 0.89 & 107.16 & 7.86 & 7.34 \\
\hline \multirow[t]{2}{*}{55} & ENSBTAG00000020237 & 0.93 & 0.85 & 64.54 & 3.78 & 5.86 \\
\hline & ENSBTAG00000008003 & 0.97 & 0.95 & 258.96 & 16.05 & 6.2 \\
\hline \multirow[t]{2}{*}{$\begin{array}{c}\text { Day of } \\
\text { pregnancy }\end{array}$} & NCBI_Gene_name & padj & FDR & $\begin{array}{l}\text { Average } \\
\text { read counts } \\
(\mathrm{CPM})\end{array}$ & SD & CV\% \\
\hline & SURF4 & 1 & 0.88 & 42.82 & 4.97 & 11.6 \\
\hline \multirow[t]{3}{*}{105} & NECAP1 & 1 & 0.96 & 60.22 & 3.52 & 5.85 \\
\hline & SMG7 & 1 & 0.91 & 244.25 & 12.81 & 5.24 \\
\hline & SURF4 & 0.96 & 0.87 & 48.39 & 5.09 & 10.51 \\
\hline \multirow[t]{2}{*}{55} & NECAP1 & 0.95 & 0.88 & 61.87 & 4.29 & 6.94 \\
\hline & SMG7 & 0.98 & 0.98 & 244.97 & 12.91 & 5.27 \\
\hline
\end{tabular}

False discovery rate (FDR), padj value, average count per million (cpm), standard deviation (SD) coefficient of variation (CV) was calculated for all annotated genes across all samples and analyses and three genes named SURF4, NECAP1 and SMG7 were selected to be used as endogenous normalizers for qRT-PCR analysis. 


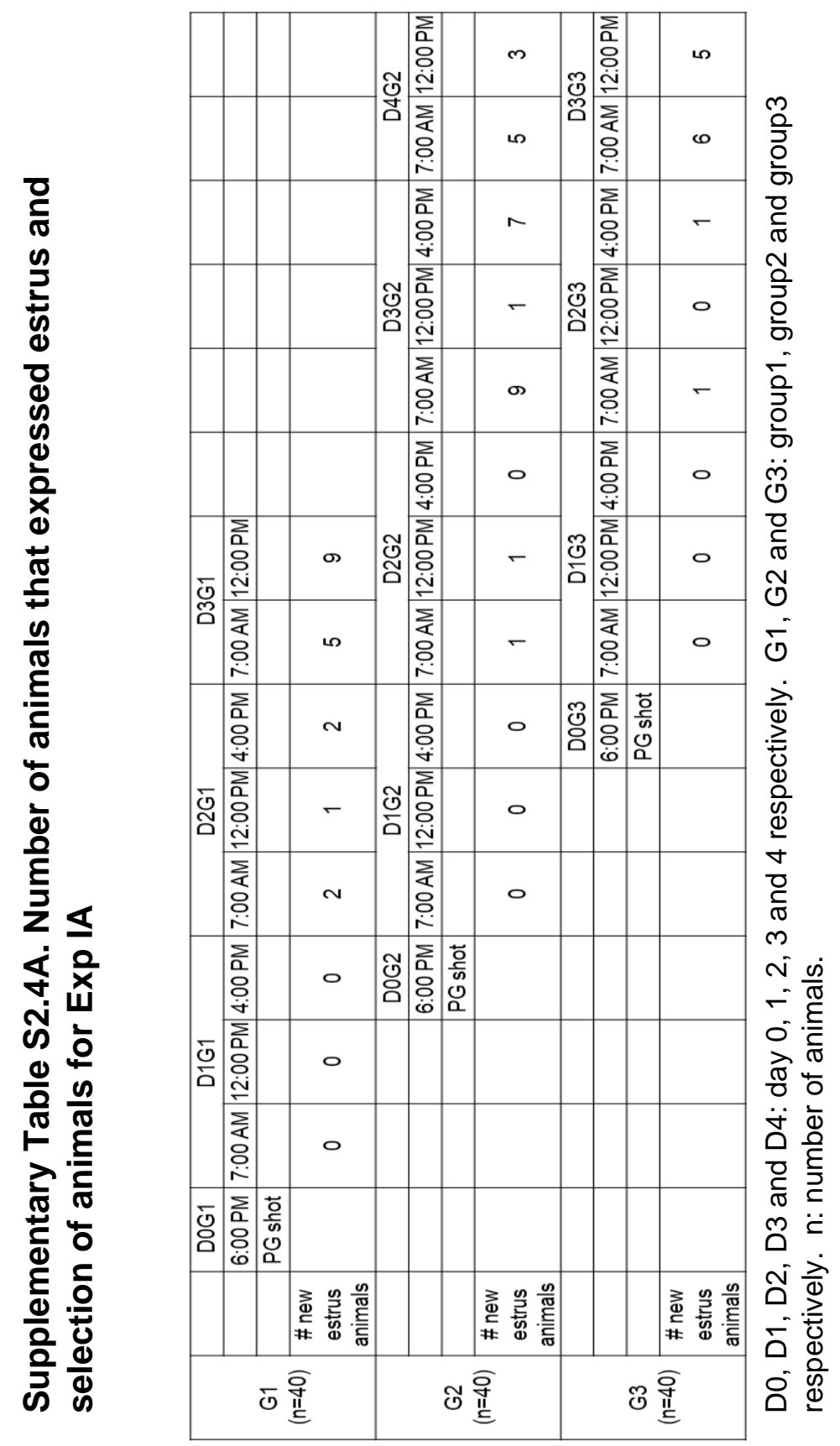




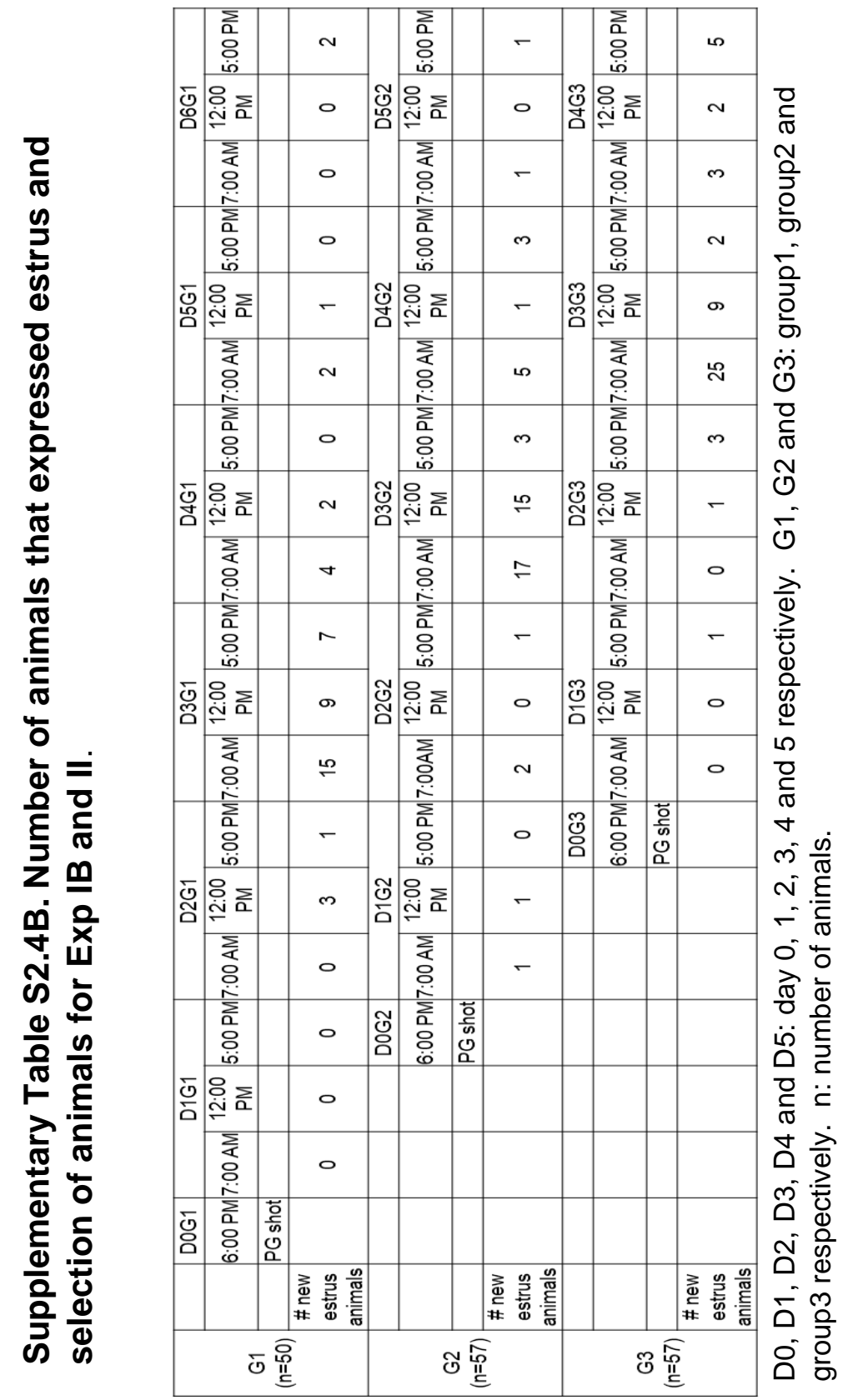


Supplementary Table S2.5. Day 77 ultrasonography.

\begin{tabular}{|c|c|c|c|c|c|c|c|c|}
\hline Cow ID & AT/ART & \begin{tabular}{|c|} 
Single(S) $/$ \\
Tw in (T) \\
\end{tabular} & BPDU & THU & TDU & AHU & ADU & HLU \\
\hline 517 & $\mathrm{Al}$ & $S$ & 1.97 & 2.72 & 2.33 & 3.18 & 2.81 & 4.15 \\
\hline 537 & $\mathrm{Al}$ & $S$ & 1.98 & * & * & 3.44 & 3.08 & 3.94 \\
\hline 539 & $\mathrm{Al}$ & $S$ & 2.25 & 3.44 & 2.06 & 3.17 & 3.08 & 3.86 \\
\hline 603 & $\mathrm{Al}$ & $S$ & 1.97 & 2.64 & 1.84 & 2.63 & 2.23 & 3.88 \\
\hline 650 & $\mathrm{Al}$ & $S$ & 2.03 & 2.8 & 1.86 & 3.12 & 3.02 & 3.91 \\
\hline 677 & $\mathrm{Al}$ & $S$ & 2.02 & 2.71 & 2.46 & 2.64 & 2.61 & 4.37 \\
\hline 519 & ART & $S$ & 2.16 & 3.02 & 2.36 & 2.62 & 2.84 & 3.88 \\
\hline \multirow[t]{2}{*}{522} & ART & $\mathrm{T}$ & 2.06 & 2.46 & 2.27 & 2.9 & 2.62 & 3.64 \\
\hline & ART & & 2.02 & 4.23 & * & * & * & * \\
\hline 530 & ART & $\mathrm{T}$ & * & * & * & * & * & * \\
\hline \multirow[t]{2}{*}{542} & ART & $\mathrm{T}$ & 1.94 & * & * & * & * & 4.17 \\
\hline & ART & & 2.21 & * & * & * & * & 4.44 \\
\hline 559 & ART & $S$ & 1.99 & 3.56 & 2.52 & 3.26 & 2.77 & 4.39 \\
\hline \multirow[t]{2}{*}{585} & ART & $T$ & * & * & * & * & * & 3.78 \\
\hline & ART & & * & * & * & * & * & 4.08 \\
\hline 616 & ART & $S$ & * & * & * & 2.91 & 3.17 & 4.21 \\
\hline \multirow[t]{2}{*}{624} & ART & $T$ & * & * & * & * & * & 4.27 \\
\hline & ART & & * & * & * & * & * & 4.22 \\
\hline \multirow[t]{2}{*}{628} & ART & $T$ & * & 2.96 & 2.75 & 3.15 & 3.29 & 4.2 \\
\hline & ART & & * & 2.99 & 2.52 & 3.48 & 2.96 & 3.53 \\
\hline 669 & ART & $\mathrm{S}$ & 1.96 & 3.29 & 2.02 & 3.41 & 2.86 & 4.13 \\
\hline 680 & ART & $S$ & 1.98 & 3.09 & 2.39 & 3.17 & 2.73 & 3.93 \\
\hline 683 & ART & $S$ & 2.1 & 4.01 & 2.55 & 3.48 & 3.09 & 4 \\
\hline
\end{tabular}

All ultrasound measurements are in centimeter. $\mathrm{U}=u$ ultrasound. Al: artificial insemination. ART: assisted reproductive technologies. $\mathrm{AH}$ : abdominal height. FL: forelimb length. BP: biparietal diameter. CR: crown rump length. HL: head length. HG: heart girth. TH: thoracic height. ${ }^{*}$ indicates measurements were not possible. 


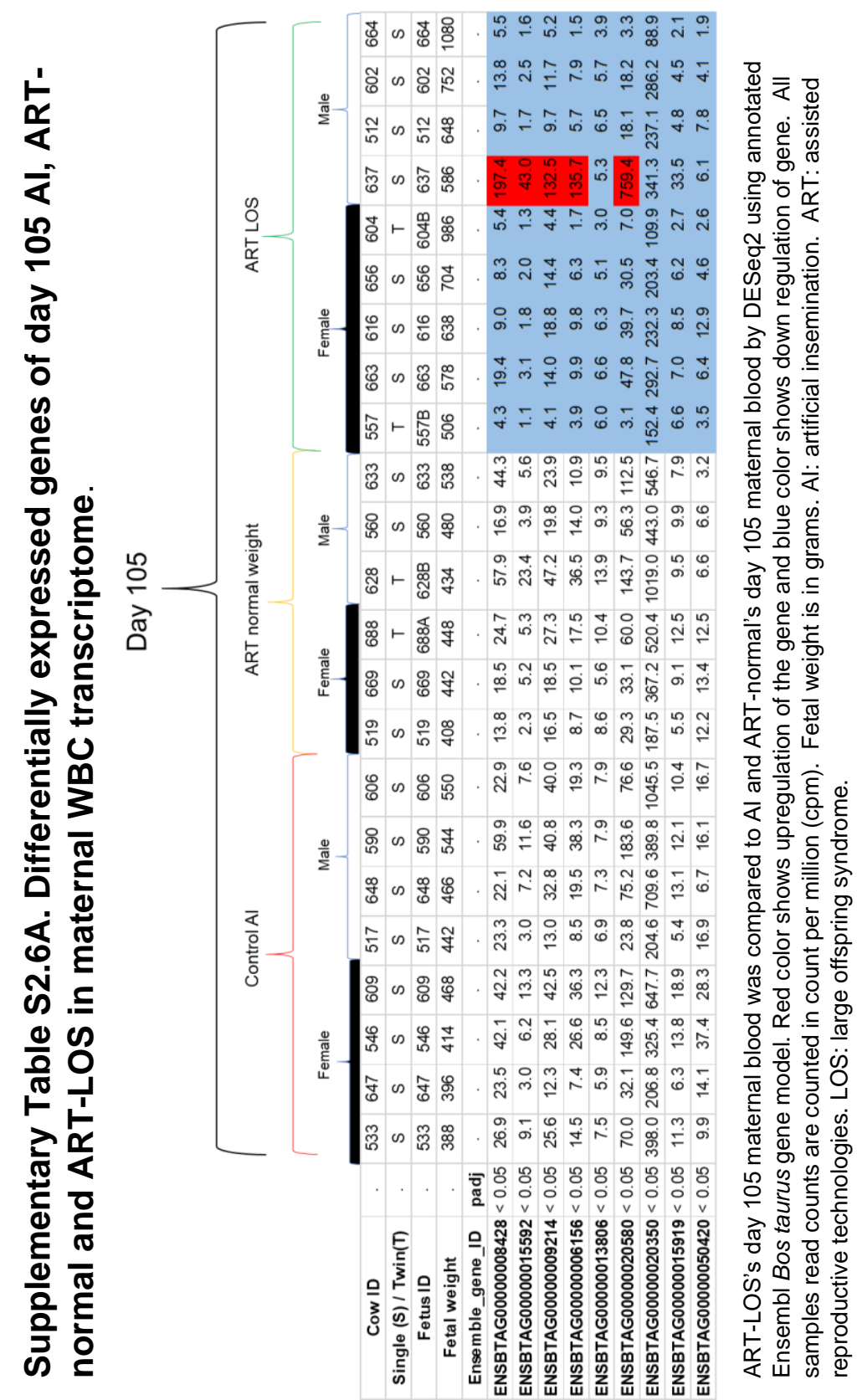




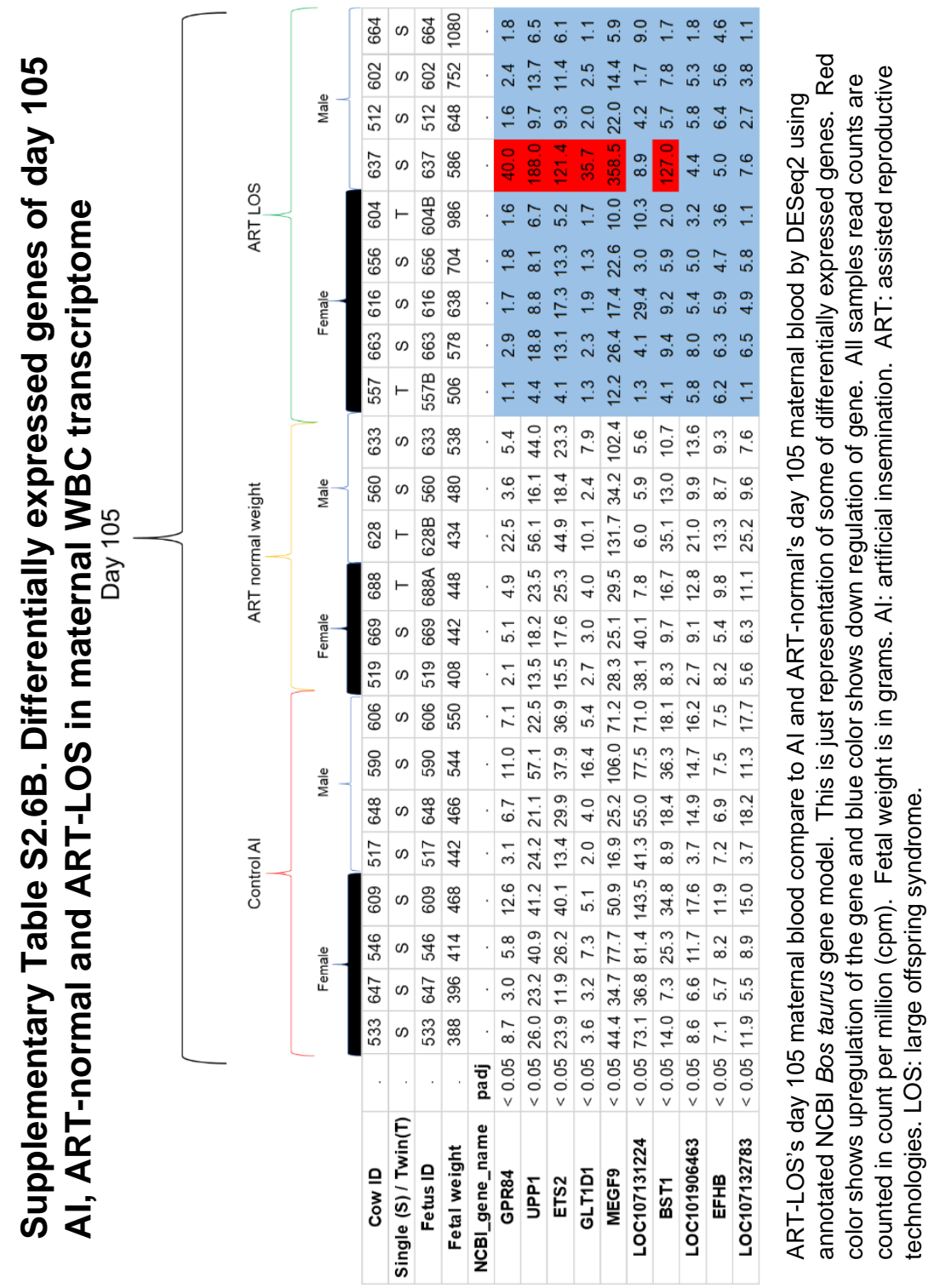




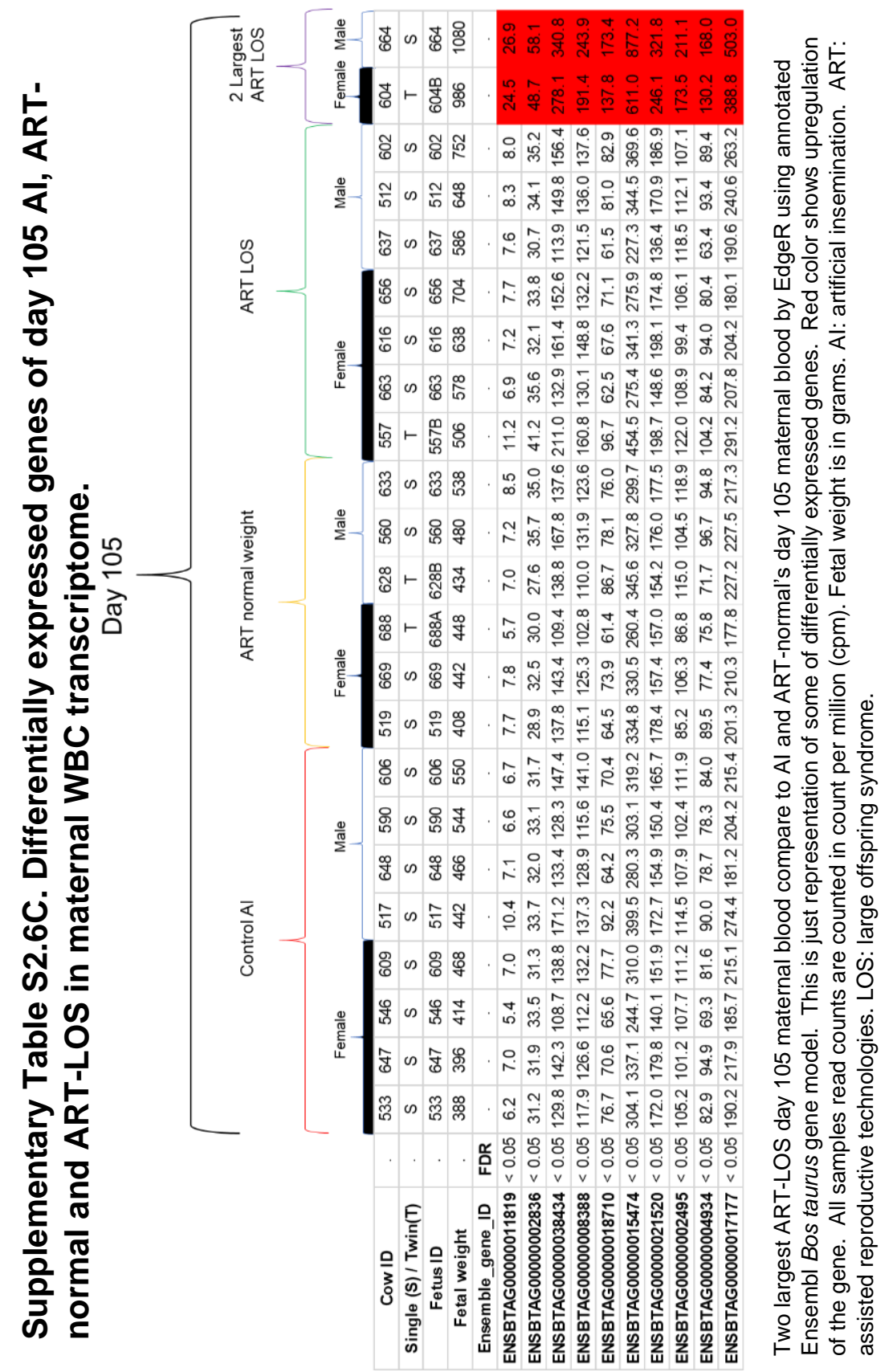




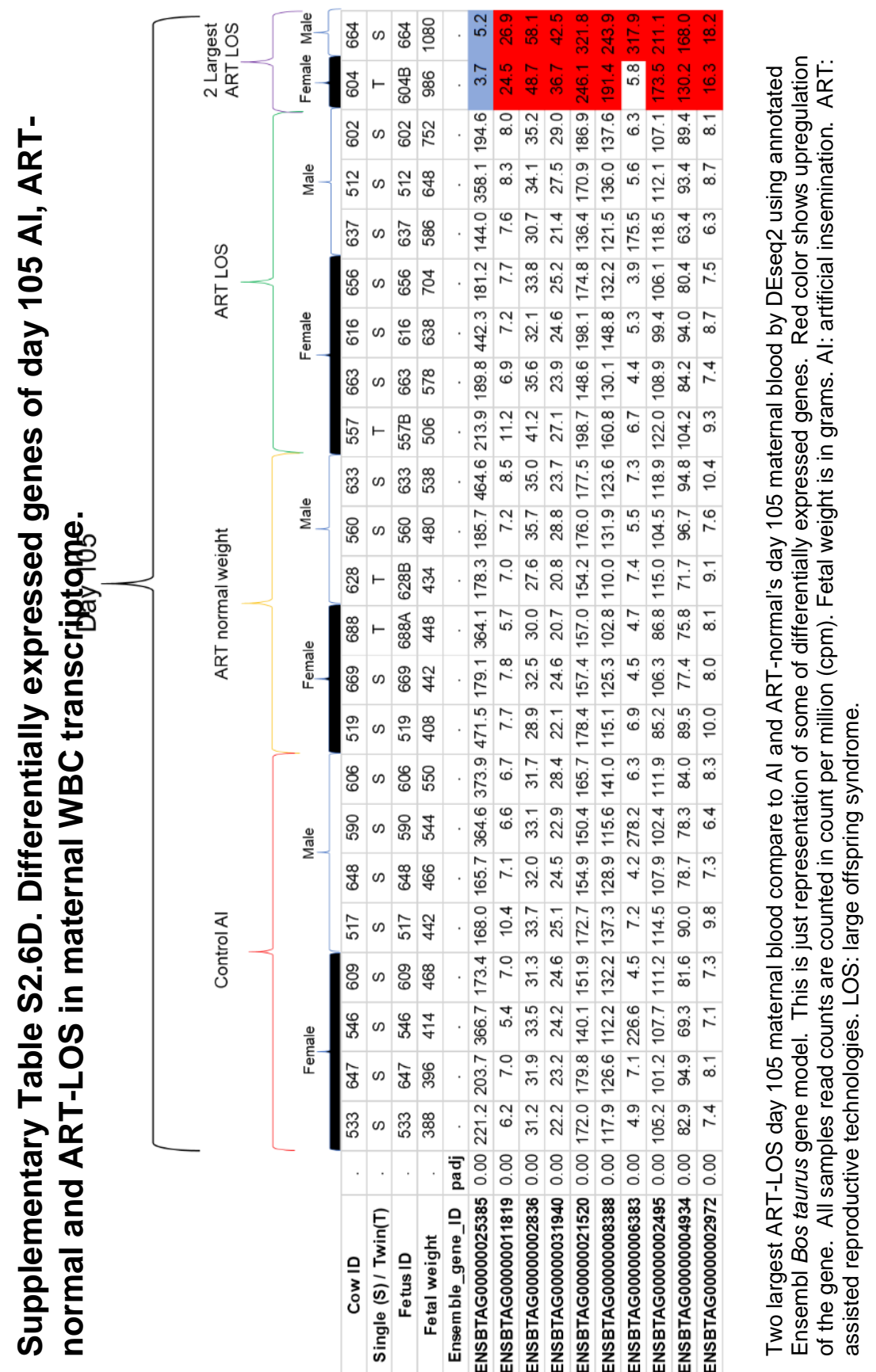




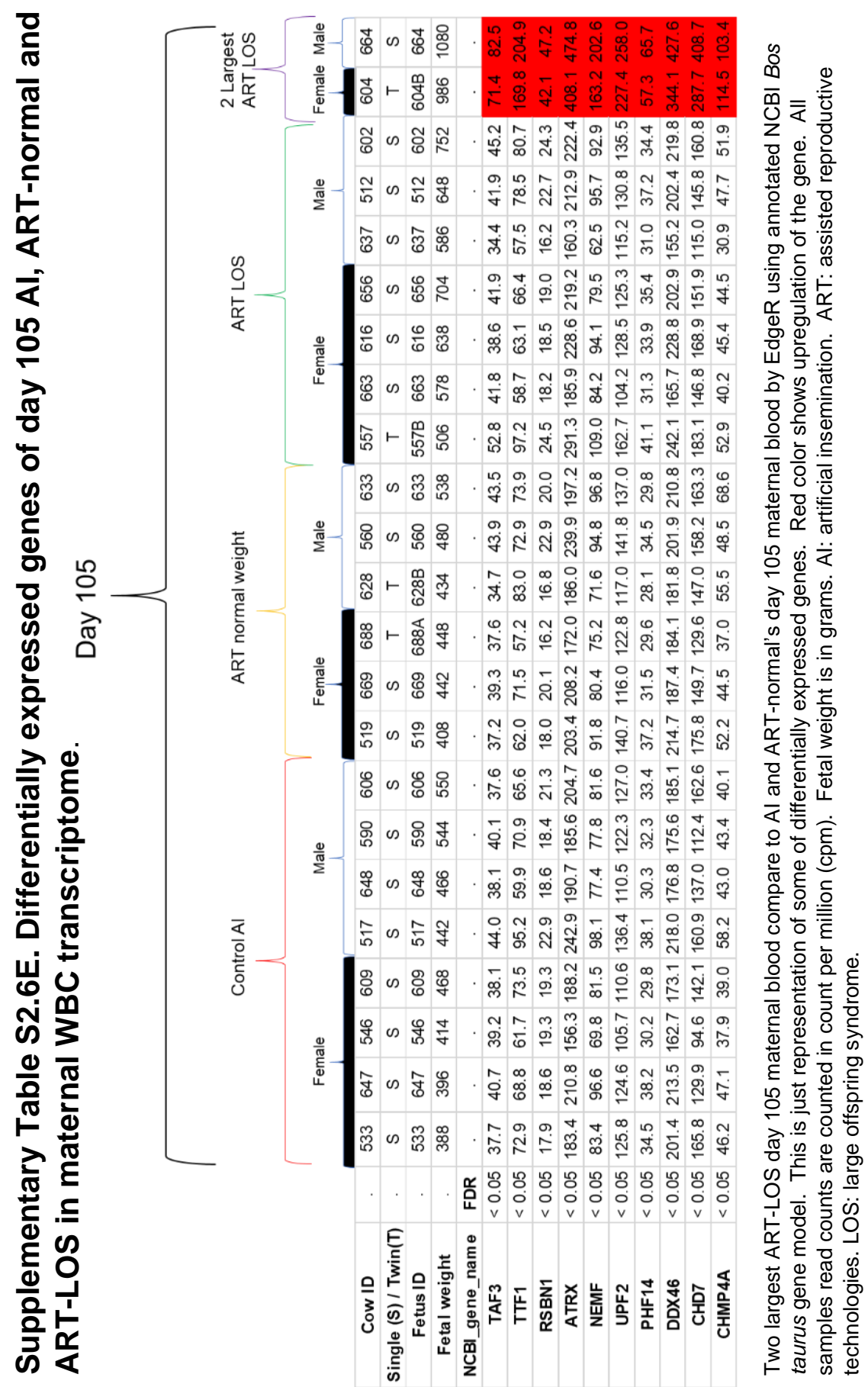




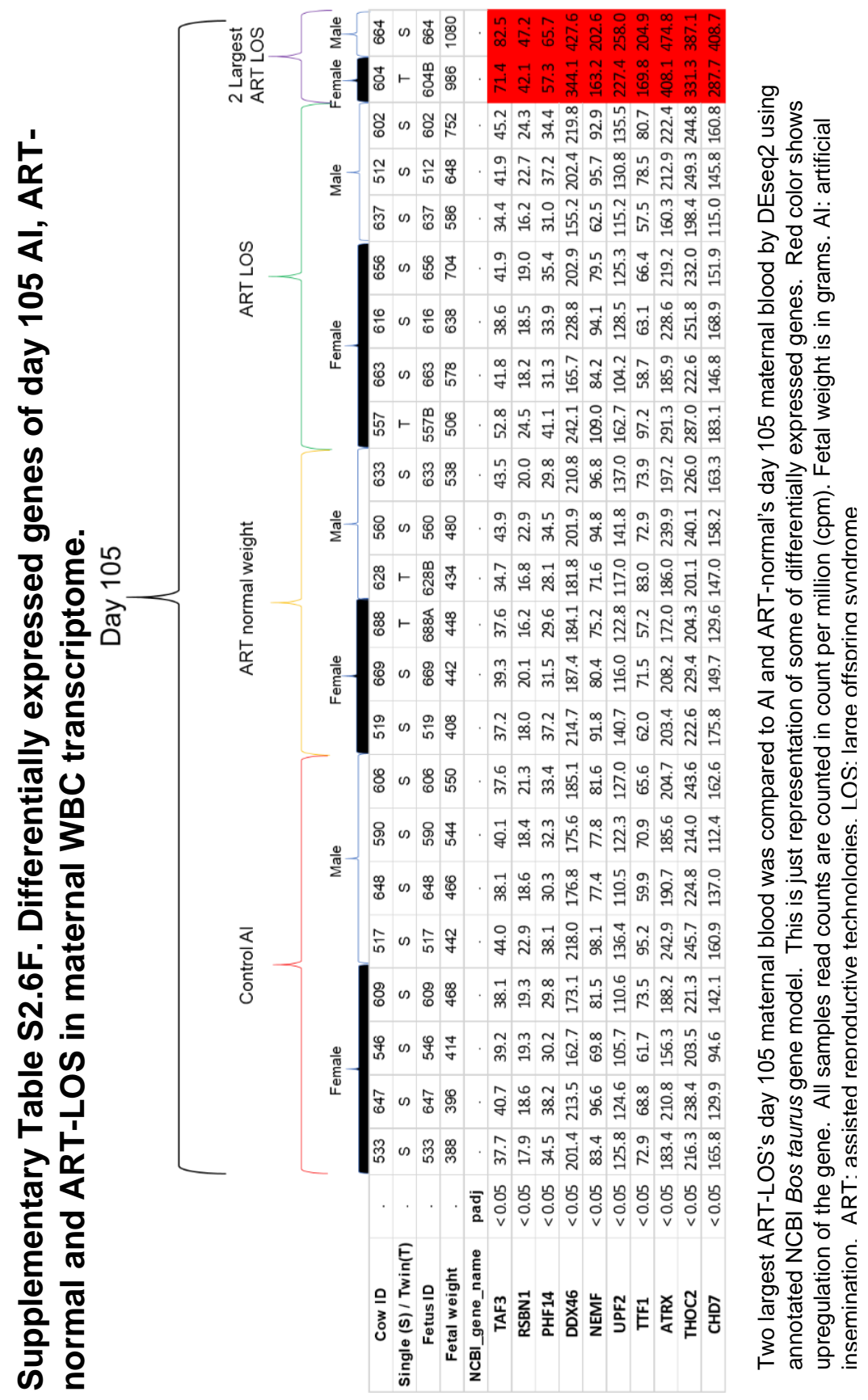




\section{References}

1. Willadsen, S., Janzen, R., McAlister, R., Shea, B., Hamilton, G., and McDermand, D. \%J T. (1991) The viability of late morulae and blastocysts produced by nuclear transplantation in cattle. 35, 161-170

2. Behboodi, E., Anderson, G., BonDurant, R., Cargill, S., Kreuscher, B., Medrano, J., and Murray, J. \%J T. (1995) Birth of large calves that developed from in vitro-derived bovine embryos. 44, 227-232

3. Farin, P. W. and Farin, C. E. \%J B. of reproduction. (1995) Transfer of bovine embryos produced in vivo or in vitro: survival and fetal development. 52, 676-682

4. Sinclair, K., Broadbent, P., and Dolman, D. (1995) In vitro produced embryos as a means of achieving pregnancy and improving productivity in beef cows. Animal Science 60, 55-64

5. Schmidt, M., Greve, T., Avery, B., Beckers, J.-F., Sulon, J., and Hansen, H. \%J T. (1996) Pregnancies, calves and calf viability after transfer of in vitro produced bovine embryos. 46, 527-539

6. Walker, S., Hartwich, K., and Seamark, R. \%J T. (1996) The production of unusually large offspring following embryo manipulation: concepts and challenges. 45, $111-120$

7. Young, L. E., Sinclair, K. D., and Wilmut, I. \%J R. of reproduction. (1998) Large offspring syndrome in cattle and sheep. 3, 155-163

8. Van Wagtendonk-de Leeuw, A., Aerts, B., and Den Daas, J. \%J T. (1998) Abnormal offspring following in vitro production of bovine preimplantation embryos: a field study. 49, 883-894 
9. Van Wagtendonk-de Leeuw, A., Mullaart, E., De Roos, A., Merton, J., Den Daas, J., Kemp, B., and De Ruigh, L. \%J T. (2000) Effects of different reproduction techniques: AI, MOET or IVP, on health and welfare of bovine offspring. 53, 575-597

10. Hill, J., Roussel, A., Cibelli, J., Edwards, J., Hooper, N., Miller, M., Thompson, J., Looney, C., Westhusin, M., and Robl, J. \%J T. (1999) Clinical and pathologic features of cloned transgenic calves and fetuses (13 case studies). 51, 1451-1465

11. Sinclair, K. D., McEvoy, T., Maxfield, E., Maltin, C., Young, L., Wilmut, I., Broadbent, P., and Robinson, J. \%J R. (1999) Aberrant fetal growth and development after in vitro culture of sheep zygotes. 116, 177-186

12. Wells, D. N., Misica, P. M., and Tervit, H. R. \%J B. of reproduction. (1999) Production of cloned calves following nuclear transfer with cultured adult mural granulosa cells. 60, 996-1005

13. Hasler, J. F. \%J H. R. (2000) In-vitro production of cattle embryos: problems with pregnancies and parturition. 15, 47-58

14. Farin, P. W., Piedrahita, J. A., and Farin, C. E. \%J T. (2006) Errors in development of fetuses and placentas from in vitro-produced bovine embryos. 65, 178191

15. Reichenbach, H., Liebrich, J., Berg, U., and Brem, G. (1992) Pregnancy rates and births after unilateral or bilateral transfer of bovine embryos produced in vitro. Reproduction 95, 363-370

16. Chen, Z., Robbins, K. M., Wells, K. D., and Rivera, R. M. \%J E. (2013) Large offspring syndrome: a bovine model for the human loss-of-imprinting overgrowth syndrome Beckwith-Wiedemann. 8, 591-601 
17. Constant, F., Guillomot, M., Heyman, Y., Vignon, X., Laigre, P., Servely, J., Renard, J., and Chavatte-Palmer, P. \%J B. of reproduction. (2006) Large offspring or large placenta syndrome? Morphometric analysis of late gestation bovine placentomes from somatic nuclear transfer pregnancies complicated by hydrallantois. $75,122-130$

18. Hill, J. R., Burghardt, R. C., Jones, K., Long, C. R., Looney, C. R., Shin, T., Spencer, T. E., Thompson, J. A., Winger, Q. A., and Westhusin, M. E. \%J B. of reproduction. (2000) Evidence for placental abnormality as the major cause of mortality in first-trimester somatic cell cloned bovine fetuses. 63, 1787-1794

19. Chen, Z., Hagen, D. E., Elsik, C. G., Ji, T., Morris, C. J., Moon, L. E., and Rivera, R. M. \%J P. of the N. A. of S. (2015) Characterization of global loss of imprinting in fetal overgrowth syndrome induced by assisted reproduction. 112, 4618-4623

20. Chen, Z., Hagen, D. E., Ji, T., Elsik, C. G., and Rivera, R. M. \%J S. reports. (2017) Global misregulation of genes largely uncoupled to DNA methylome epimutations characterizes a congenital overgrowth syndrome. 7, 1-14

21. Young, L. E., Fernandes, K., McEvoy, T. G., Butterwith, S. C., Gutierrez, C. G., Carolan, C., Broadbent, P. J., Robinson, J. J., Wilmut, I., and Sinclair, K. D. \%J N. genetics. (2001) Epigenetic change in IGF2R is associated with fetal overgrowth after sheep embryo culture. 27, 153

22. Mussa, A., Russo, S., De Crescenzo, A., Chiesa, N., Molinatto, C., Selicorni, A., Richiardi, L., Larizza, L., Silengo, M. C., and Riccio, A. (2013) Prevalence of BeckwithWiedemann syndrome in north west of Italy. American journal of medical genetics Part $A$ $161,2481-2486$ 
23. Mussa, A., Molinatto, C., Cerrato, F., Palumbo, O., Carella, M., Baldassarre, G., Carli, D., Peris, C., Riccio, A., and Ferrero, G. B. (2017) Assisted reproductive techniques and risk of Beckwith-Wiedemann syndrome. Pediatrics 140, e20164311

24. Brioude, F., Kalish, J. M., Mussa, A., Foster, A. C., Bliek, J., Ferrero, G. B., Boonen, S. E., Cole, T., Baker, R., and Bertoletti, M. (2018) Clinical and molecular diagnosis, screening and management of Beckwith-Wiedemann syndrome: an international consensus statement. Nature Reviews Endocrinology 14, 229-249

25. Choufani, S., Shuman, C., and Weksberg, R. (2013) Molecular findings in Beckwith-Wiedemann syndrome. presented at the American Journal of Medical Genetics Part C: Seminars in Medical Genetics

26. Chiesa, N., De Crescenzo, A., Mishra, K., Perone, L., Carella, M., Palumbo, O., Mussa, A., Sparago, A., Cerrato, F., and Russo, S. (2012) The KCNQ1OT1 imprinting control region and non-coding RNA: new properties derived from the study of BeckwithWiedemann syndrome and Silver-Russell syndrome cases. Human molecular genetics 21, 10-25

27. Abe, H., Yamashita, S., Itoh, T., Satoh, T., and Hoshi, H. (1999) Ultrastructure of bovine embryos developed from in vitro-matured and-fertilized oocytes: Comparative morphological evaluation of embryos cultured either in serum-free medium or in serumsupplemented medium. Molecular Reproduction and Development: Incorporating Gamete Research 53, 325-335

28. Lazzari, G., Wrenzycki, C., Herrmann, D., Duchi, R., Kruip, T., Niemann, H., and Galli, C. \%J B. of reproduction. (2002) Cellular and molecular deviations in bovine in vitro-produced embryos are related to the large offspring syndrome. $67,767-775$ 
29. Wrenzycki, C., Herrmann, D., Keskintepe, L., Martins Jr, A., Sirisathien, S., Brackett, B., and Niemann, H. \%J H. R. (2001) Effects of culture system and protein supplementation on mRNA expression in pre-implantation bovine embryos. 16, 893-901

30. Wrenzycki, C., Herrmann, D., Carnwath, J., Niemann, H. \%J M. R., and Research, D. I. G. (1999) Alterations in the relative abundance of gene transcripts in preimplantation bovine embryos cultured in medium supplemented with either serum or PVA. 53, 8-18

31. Trounson, A., Pushett, D., Maclellan, L. J., Lewis, I., and Gardner, D. \%J T. (1994) Current status of IVM/IVF and embryo culture in humans and farm animals. 41, $57-66$

32. Hiendleder, S., Wirtz, M., Mund, C., Klempt, M., Reichenbach, H.-D., Stojkovic, M., Weppert, M., Wenigerkind, H., Elmlinger, M., and Lyko, F. \%J B. of reproduction. (2006) Tissue-specific effects of in vitro fertilization procedures on genomic cytosine methylation levels in overgrown and normal sized bovine fetuses. 75, 17-23

33. Maxfield, E., Sinclair, K., Broadbent, P., McEvoy, T., Robinson, J., Maltin, C. \%J A. J. of P.-E., and Metabolism. (1998) Short-term culture of ovine embryos modifies fetal myogenesis. 274, E1121-E1123

34. Bertolini, M., Mason, J. B., Beam, S. W., Carneiro, G. F., Sween, M. L., Kominek, D. J., Moyer, A. L., Famula, T. R., Sainz, R. D., and Anderson, G. B. \%J T. (2002) Morphology and morphometry of in vivo-and in vitro-produced bovine concepti from early pregnancy to term and association with high birth weights. 58, 973-994

35. Salilew-Wondim, D., Tesfaye, D., Hossain, M., Held, E., Rings, F., Tholen, E., Looft, C., Cinar, U., Schellander, K., and Hoelker, M. (2013) Aberrant placenta gene 
expression pattern in bovine pregnancies established after transfer of cloned or in vitro produced embryos. Physiological Genomics 45, 28-46

36. Wilmut, I. and Sales, D. \%J R. (1981) Effect of an asynchronous environment on embryonic development in sheep. 61, 179-184

37. Young, L., Butterwith, S., and Wilmut, I. \%J T. (1996) Increased ovine foetal weight following transient asynchronous embryo transfer is not associated with increased placental weight at day 21 of gestation. 1, 231

38. Kleemann, D., Walker, S., Hartwich, K., Fong, L., Seamark, R., Robinson, J., and Owens, J. (2001) Fetoplacental growth in sheep administered progesterone during the first three days of pregnancy. Placenta 22, 14-23

39. Maxfield, E., Sinclair, K., Dunne, L., Broadbent, P., Robinson, J., Stewart, E., Kyle, D., and Maltin, C. \%J B. of R. (1998) Temporary exposure of ovine embryos to an advanced uterine environment does not affect fetal weight but alters fetal muscle development. 59, 321-325

40. McEvoy, T., Robinson, J., Aitken, R., Findlay, P., and Robertson, I. \%J A. R. S. (1997) Dietary excesses of urea influence the viability and metabolism of preimplantation sheep embryos and may affect fetal growth among survivors. 47, 71-90

41. Linden, T., Bicalho, R., and Nydam, D. \%J J. of dairy science. (2009) Calf birth weight and its association with calf and cow survivability, disease incidence, reproductive performance, and milk production. 92, 2580-2588

42. Barkema, H., Schukken, Y., Guard, C., Brand, A., and Van der Weyden, G. (1992) Fertility, production and culling following cesarean section in dairy cattle. Theriogenology 38, 589-599 
43. Lombard, J., Garry, F., Tomlinson, S., and Garber, L. (2007) Impacts of dystocia on health and survival of dairy calves. Journal of dairy science $90,1751-1760$

44. Rajala, P. and Gröhn, Y. (1998) Effects of dystocia, retained placenta, and metritis on milk yield in dairy cows. Journal of dairy Science 81, 3172-3181

45. Fourichon, C., Seegers, H., and Malher, X. (2000) Effect of disease on reproduction in the dairy cow: a meta-analysis. Theriogenology 53, 1729-1759

46. Wild, J. and Reid, J. M. (1953) The Effects of Biological Tissues on 15-mc Pulsed Ultrasound. The Journal of the Acoustical Society of America 25, 270-280

47. Boyd, P., Chamberlain, P., and Hicks, N. (1998) 6-year experience of prenatal diagnosis in an unselected population in Oxford, UK. The Lancet 352, 1577-1581

48. Dulgheroff, F. F., Peixoto, A. B., Petrini, C. G., Caldas, T. M. R. da C., Ramos, D. R., Magalhães, F. O., and Araujo Júnior, E. (2019) Fetal structural anomalies diagnosed during the first, second and third trimesters of pregnancy using ultrasonography: a retrospective cohort study. Sao Paulo Medical Journal 137, 391-400

49. Parretti, E., Carignani, L., Cioni, R., Bartoli, E., Borri, P., La Torre, P., Mecacci, F., Martini, E., Scarselli, G., and Mello, G. (2003) Sonographic evaluation of fetal growth and body composition in women with different degrees of normal glucose metabolism. Diabetes care 26, 2741-2748

50. White, I., Russel, A., Wright, I., and Whyte, T. (1985) Real-time ultrasonic scanning in the diagnosis of pregnancy and the estimation of gestational age in cattle. The Veterinary Record 117, 5-8 
51. Riding, G. A., Lehnert, S. A., French, A. J., and Hill, J. R. (2008) Conceptusrelated measurements during the first trimester of bovine pregnancy. The Veterinary Journal 175, 266-272

52. Kähn, W. \%J T. (1989) Sonographic fetometry in the bovine. 31, 1105-1121

53. Breukelman, S., Reinders, J., Jonker, F., De Ruigh, L., Kaal, L., Van Wagtendonk-de Leeuw, A., Vos, P., Dieleman, S., Beckers, J.-F., and Perényi, Z. \%J T. (2004) Fetometry and fetal heart rates between day 35 and 108 in bovine pregnancies resulting from transfer of either MOET, IVP-co-culture or IVP-SOF embryos. 61, 867882

54. De Sousa, P. A., King, T., Harkness, L., Young, L. E., Walker, S. K., and Wilmut, I. \%J B. of reproduction. (2001) Evaluation of gestational deficiencies in cloned sheep fetuses and placentae. 65, 23-30

55. Leiser, R. and Kaufmann, P. (1994) Placental structure: in a comparative aspect. Experimental and Clinical Endocrinology \& Diabetes 102, 122-134

56. Mess, A. and Carter, A. M. (2007) Evolution of the placenta during the early radiation of placental mammals. Comparative Biochemistry and Physiology Part A: Molecular \& Integrative Physiology 148, 769-779

57. Faas, B. H., de Ligt, J., Janssen, I., Eggink, A. J., Wijnberger, L. D., van Vugt, J. M., Vissers, L., and Geurts van Kessel, A. (2012) Non-invasive prenatal diagnosis of fetal aneuploidies using massively parallel sequencing-by-ligation and evidence that cellfree fetal DNA in the maternal plasma originates from cytotrophoblastic cells. Expert Opinion on Biological Therapy 12, S19-S26 
58. Nelson, J. L. (2012) The otherness of self: microchimerism in health and disease. Trends in immunology 33, 421-427

59. Pfarrer, C., Ebert, B., Miglino, M. A., Klisch, K., and Leiser, R. (2001) The threedimensional feto-maternal vascular interrelationship during early bovine placental development: a scanning electron microscopical study. Journal of anatomy 198, 591602

60. YAMADA, O., Todoroki, J., TAKAHASHI, T., and HASHIZUME, K. (2002) The dynamic expression of extracellular matrix in the bovine endometrium at implantation. Journal of Veterinary Medical Science 64, 207-214

61. Kizaki, K., Ushizawa, K., Takahashi, T., Yamada, O., Todoroki, J., Sato, T., Ito, A., and Hashizume, K. (2008) Gelatinase (MMP-2 and-9) expression profiles during gestation in the bovine endometrium. Reproductive Biology and Endocrinology 6, 66

62. Klisch, K., Pfarrer, C., Schuler, G., Hoffmann, B., and Leiser, R. (1999) Tripolar acytokinetic mitosis and formation of feto-maternal syncytia in the bovine placentome: different modes of the generation of multinuclear cells. Anatomy and embryology 200, 229-237

63. Hiendleder, S., Bebbere, D., Zakhartchenko, V., Reichenbach, H.-D., Wenigerkind, H., Ledda, S., and Wolf, E. (2004) Maternal-fetal transplacental leakage of mitochondrial DNA in bovine nuclear transfer pregnancies: potential implications for offspring and recipients. Cloning \& Stem Cells 6, 150-156

64. Lemos, D. C., Rios, Á. F. L., Caetano, L. C., Lôbo, R. B., Vila, R. A., Martelli, L., Takeuchi, P. L., and Ramos, E. S. (2005) Use of the TSPY gene for sexing cattle. Genetics and Molecular Biology 28, 117-119 
65. Turin, L., Invernizzi, P., Woodcock, M., Grati, F. R., Riva, F., Tribbioli, G., and Laible, G. (2007) Bovine fetal microchimerism in normal and embryo transfer pregnancies and its implications for biotechnology applications in cattle. Biotechnology Journal: Healthcare Nutrition Technology 2, 486-491

66. Pereira, F. T. V., Oliveira, L. J., Barreto, R. da S. N., Mess, A., Perecin, F., Bressan, F. F., Mesquita, L. G., Miglino, M. A., Pimentel, J. R., and Neto, P. F. (2013) Fetal-maternal interactions in the synepitheliochorial placenta using the eGFP cloned cattle model. PLoS One 8, e64399

67. Hulka, S. (1990) Overview of biological marker. Biological markers in epidemiology. 3-15

68. Bullinger, L., Döhner, K., Bair, E., Fröhling, S., Schlenk, R. F., Tibshirani, R., Döhner, H., and Pollack, J. R. \%J N. E. J. of M. (2004) Use of gene-expression profiling to identify prognostic subclasses in adult acute myeloid leukemia. 350, 1605-1616

69. Valk, P. J., Verhaak, R. G., Beijen, M. A., Erpelinck, C. A., van DoornKhosrovani, S. B. van W., Boer, J. M., Beverloo, H. B., Moorhouse, M. J., Van Der Spek, P. J., and Löwenberg, B. \%J N. E. J. of M. (2004) Prognostically useful gene-expression profiles in acute myeloid leukemia. 350, 1617-1628

70. Lei, X., Jia, S., Ye, J., Qiao, Y., Zhao, G., Li, X., Chang, H. \%J J. of B. R., and Agents, H. (2017) Application values of detection of serum CA199, CA242 and CA50 in the diagnosis of pancreatic cancer. 31, 383-388

71. Burd, C. E., Jeck, W. R., Liu, Y., Sanoff, H. K., Wang, Z., and Sharpless, N. E. \%J PI. G. (2010) Expression of linear and novel circular forms of an INK4/ARFassociated non-coding RNA correlates with atherosclerosis risk. 6, e1001233 
72. Imakawa, K., Anthony, R. V., Kazemi, M., Marotti, K. R., Polites, H. G., and Roberts, R. M. (1987) Interferon-like sequence of ovine trophoblast protein secreted by embryonic trophectoderm. Nature 330, 377-379

73. Emond, V., Asselin, E., Fortier, M. A., Murphy, B. D., and Lambert, R. D. (2000) Interferon-tau stimulates granulocyte-macrophage colony-stimulating factor gene expression in bovine lymphocytes and endometrial stromal cells. Biol Reprod 62, 17281737

74. Demmers, K. J., Derecka, K., and Flint, A. (2001) Trophoblast interferon and pregnancy. Reproduction 121, 41-49

75. Yankey, S. J., Hicks, B. A., Carnahan, K. G., Assiri, A. M., Sinor, S. J., Kodali, K., Stellflug, J. N., Stellflug, J. N., and Ott, T. L. (2001) Expression of the antiviral protein Mx in peripheral blood mononuclear cells of pregnant and bred, non-pregnant ewes. $J$ Endocrinol 170, R7-11

76. Shirasuna, K., Matsumoto, H., Kobayashi, E., Nitta, A., Haneda, S., Matsui, M., Kawashima, C., Kida, K., Shimizu, T., and Miyamoto, A. (2012) Upregulation of interferon-stimulated genes and interleukin-10 in peripheral blood immune cells during early pregnancy in dairy cows. J Reprod Dev 58, 84-90

77. Zoli, A. P., Guilbault, L. A., Delahaut, P., Ortiz, W. B., and Beckers, J.-F. \%J B. of R. (1992) Radioimmunoassay of a bovine pregnancy-associated glycoprotein in serum: its application for pregnancy diagnosis. 46, 83-92

78. Green, J. A., Parks, T. E., Avalle, M. P., Telugu, B. P., McLain, A. L., Peterson, A. J., McMillan, W., Mathialagan, N., Hook, R. R., and Xie, S. (2005) The establishment of an ELISA for the detection of pregnancy-associated glycoproteins (PAGs) in the serum of pregnant cows and heifers. Theriogenology 63, 1481-1503 
79. Paquette, A. G., Shynlova, O., Kibschull, M., Price, N. D., Lye, S. J., Global Alliance to Prevent, P., and Stillbirth Systems Biology of Preterm Birth, T. (2018) Comparative analysis of gene expression in maternal peripheral blood and monocytes during spontaneous preterm labor. Am J Obstet Gynecol 218, 345 e1-345 e30

80. Enquobahrie, D. A., Qiu, C., Muhie, S. Y., and Williams, M. A. (2011) Maternal peripheral blood gene expression in early pregnancy and preeclampsia. International journal of molecular epidemiology and genetics 2, 78

81. Bertolini, M. and Anderson, G. \%J T. (2002) The placenta as a contributor to production of large calves. 57, 181-187

82. Hiendleder, S., Mund, C., Reichenbach, H.-D., Wenigerkind, H., Brem, G., Zakhartchenko, V., Lyko, F., and Wolf, E. \%J B. of reproduction. (2004) Tissue-specific elevated genomic cytosine methylation levels are associated with an overgrowth phenotype of bovine fetuses derived by in vitro techniques. 71, 217-223

83. Miles, J. R., Farin, C. E., Rodriguez, K. F., Alexander, J. E., and Farin, P. W. \%J B. of reproduction. (2004) Angiogenesis and morphometry of bovine placentas in late gestation from embryos produced in vivo or in vitro. 71, 1919-1926

84. McEvoy, T., Sinclair, K., Broadbent, P., Goodhand, K., Robinson, J. \%J R., Fertility, and Development. (1998) Post-natal growth and development of Simmental calves derived from in vivo or in vitro embryos. 10, 459-464

85. Carolan, C., Lonergan, P., Van Langendonckt, A., and Mermillod, P. \%J T. (1995) Factors affecting bovine embryo development in synthetic oviduct fluid following oocyte maturation and fertilization in vitro. 43, 1115-1128 
86. Thompson, J. G., Allen, N. W., McGowan, L. T., Bell, A. C. S., Lambert, M. G., and Tervit, H. \%J T. (1998) Effect of delayed supplementation of fetal calf serum to culture medium on bovine embryo development in vitro and following transfer. 49, 12391249

87. Rizos, D., Lonergan, P., Boland, M., Arroyo-Garcia, R., Pintado, B., Fuente, J. de la, and Gutierrez-Adan, A. \%J B. of reproduction. (2002) Analysis of differential messenger RNA expression between bovine blastocysts produced in different culture systems: implications for blastocyst quality. 66, 589-595

88. Rizos, D., Gutierrez-Adan, A., Perez-Garnelo, S., De La Fuente, J., Boland, M., and Lonergan, P. \%J B. of reproduction. (2003) Bovine embryo culture in the presence or absence of serum: implications for blastocyst development, cryotolerance, and messenger RNA expression. 68, 236-243

89. Thompson, J. G., Gardner, D. K., Anne Pugh, P., McMillan, W. H., and Robin Tervit, H. \%J B. of reproduction. (1995) Lamb birth weight is affected by culture system utilized during in vitro pre-elongation development of ovine embryos. 53, 1385-1391

90. Rooke, J. A., McEvoy, T. G., Ashworth, C. J., Robinson, J. J., Wilmut, I., Young, L. E., and Sinclair, K. \%J T. (2007) Ovine fetal development is more sensitive to perturbation by the presence of serum in embryo culture before rather than after compaction. 67, 639-647

91. Bonilla, L., Block, J., Denicol, A., and Hansen, P. (2014) Consequences of transfer of an in vitro-produced embryo for the dam and resultant calf. Journal of dairy science 97, 229-239

92. Siqueira, L. G., Tribulo, P., Chen, Z., Denicol, A. C., Ortega, M. S., NegronPerez, V. M., Kannampuzha-Francis, J., Pohler, K. G., Rivera, R. M., and Hansen, P. J. 
(2017) Colony-stimulating factor 2 acts from days 5 to 7 of development to modify programming of the bovine conceptus at day 86 of gestationdagger. Biol Reprod $\mathbf{9 6}$, $743-757$

93. Li, Y., Donnelly, C. G., and Rivera, R. M. \%J V. C. F. A. P. (2019) Overgrowth syndrome. 35, 265-276

94. Kasinathan, P., Wei, H., Xiang, T., Molina, J. A., Metzger, J., Broek, D., Kasinathan, S., Faber, D. C., and Allan, M. F. (2015) Acceleration of genetic gain in cattle by reduction of generation interval. Scientific reports 5,8674

95. Rivera, R. and Hansen, P. \%J R.-C.-. (2001) Development of cultured bovine embryos after exposure to high temperatures in the physiological range. 121, 107-115

96. Rivera, R. M., Kelley, K. L., Erdos, G. W., and Hansen, P. J. \%J B. of reproduction. (2003) Alterations in ultrastructural morphology of two-cell bovine embryos produced in vitro and in vivo following a physiologically relevant heat shock. 69, 20682077

97. Rivera, R. M., Kelley, K. L., Erdos, G. W., and Hansen, P. J. \%J B. of R. (2004) Reorganization of microfilaments and microtubules by thermal stress in two-cell bovine embryos. 70, 1852-1862

98. Niemann, H. and Lucas-Hahn, A. (2012) Somatic cell nuclear transfer cloning: practical applications and current legislation. Reproduction in Domestic Animals 47, 210

99. Hasler, J. F. (2014) Forty years of embryo transfer in cattle: A review focusing on the journal Theriogenology, the growth of the industry in North America, and personal reminisces. Theriogenology 81, 152-169 
100. Kruip, T. A. and Den Daas, J. \%J T. (1997) In vitro produced and cloned embryos: effects on pregnancy, parturition and offspring. 47, 43-52

101. Giuliodori, M. J., Magnasco, R., Becu-Villalobos, D., Lacau-Mengido, I., Risco, C., and de la Sota, R. L. \%J J. of dairy science. (2013) Metritis in dairy cows: Risk factors and reproductive performance. 96, 3621-3631

102. Hansen, P. J., Block, J. \%J R., Fertility, and Development. (2003) Towards an embryocentric world: the current and potential uses of embryo technologies in dairy production. 16, 1-14

103. Dematawena, C. and Berger, P. \%J J. of D. S. (1997) Effect of dystocia on yield, fertility, and cow losses and an economic evaluation of dystocia scores for Holsteins. 80, $754-761$

104. Curran, S., Pierson, R., and Ginther, O. \%J J. A. V. M. A. (1986) Ultrasonographic appearance of the bovine conceptus from days 20 through 60. 189, $1295-1302$

105. Kastelic, J., Curran, S., Pierson, R., and Ginther, O. \%J T. (1988) Ultrasonic evaluation of the bovine conceptus. $29,39-54$

106. Wright, I., White, I., Russel, A., Whyte, T., and McBean, A. \%J T. V. R. (1988) Prediction of calving date in beef cows by real-time ultrasonic scanning. 123, 228-229 107. Curran, S. and Ginther, O. \%J T. (1991) Ultrasonic determination of fetal gender in horses and cattle under farm conditions. 36, 809-814

108. Fissore, R., Edmondson, A., Pashen, R., and Bondurant, R. \%J A. R. S. (1986) The use of ultrasonography for the study of the bovine reproductive tract. II. Nonpregnant, pregnant and pathological conditions of the uterus. 12, 167-177 
109. Campbell, S., Warsof, S. L., Little, D., and Cooper, D. J. (1985) Routine ultrasound screening for the prediction of gestational age. Obstetrics and Gynecology $65,613-620$

110. O'Gorman, N., Salomon, L. J. \%J B. P., Obstetrics, R. C., and Gynaecology. (2018) Fetal biometry to assess the size and growth of the fetus. 49, 3-15

111. Barker, D. J. (1997) The long-term outcome of retarded fetal growth. Clinical obstetrics and gynecology 40, 853-863

112. Kofler, J. (1995) Description and determination of the diameter of arteries and veins in the hindlimb of cattle using B-mode ultrasonography. Zentralblatt fur Veterinarmedizin. Reihe A 42, 253-266

113. Kofler, J. (1995) Application of ultrasonic examination in the diagnosis of bovine locomotory system disorders. Schweizer Archiv fur Tierheilkunde 137, 369-380

114. Kofler, J. (1997) Ultrasonography in hematogeneous, septic arthritis, polyarthritis and osteomyelitis in calves. Wiener Tierarztliche Monatsschrift 84, 129-139

115. Kofler, J. and Martinek, B. (2004) Ultrasonographic imaging of disorders of the carpal region in 42 cattle-arthritis, tenosynovitis, precarpal hygroma, periarticular abscess. TIERARZTLICHE PRAXIS AUSGABE GROSSTIERE NUTZTIERE 32, 61-72

116. Kofler, J., Martinek, B., Kubber-Heiss, A., and Kubber, P. (2004) Generalised distal limb vessel thrombosis in two cows with digital and inner organ infections. The Veterinary Journal 1, 107-110

117. Kofler, J. and Altenbrunner-Martinek, B. (2008) Ultrasonographic findings of disorders of the tarsal region in 97 cattle--arthritis, bursitis, tenosynovitis, periarticular 
abscess and vein thrombosis. Berliner und Munchener tierarztliche Wochenschrift 121, $145-158$

118. Medchill, M. T., Peterson, C. M., Kreinick, C., and Garbaciak, J. (1991) Prediction of estimated fetal weight in extremely low birth weight neonates (500-1000 g). Obstetrics and gynecology 78, 286-290

119. Perlow, J. H., Wigton, T., Hart, J., Strassner, H. T., Nageotte, M. P., and Wolk, B. M. (1996) Birth trauma. A five-year review of incidence and associated perinatal factors. The Journal of reproductive medicine 41, 754

120. Aronson, J. K. and Ferner, R. E. (2017) Biomarkers-a general review. Current protocols in pharmacology $76,9-23$

121. Chan, H.-W., Lappas, M., Yee, S. Y., Vaswani, K., Mitchell, M., and Rice, G. (2013) The expression of the let-7 miRNAs and Lin28 signalling pathway in human term gestational tissues. Placenta 34, 443-448

122. Uttley, L., Whiteman, B. L., Woods, H. B., Harnan, S., Philips, S. T., Cree, I. A., and Early Cancer Detection Consortium. (2016) Building the evidence base of bloodbased biomarkers for early detection of cancer: a rapid systematic mapping review. EBioMedicine 10, 164-173

123. Kizaki, K., Shichijo-Kizaki, A., Furusawa, T., Takahashi, T., Hosoe, M., Hashizume, K. \%J R. B., and Endocrinology. (2013) Differential neutrophil gene expression in early bovine pregnancy. 11, 6

124. Yoshino, H., Toji, N., Sasaki, K., Koshi, K., Yamagishi, N., Takahashi, T., Ishiguro-Oonuma, T., Matsuda, H., Yamanouchi, T., and Hashiyada, Y. \%J T. (2018) A 
predictive threshold value for the diagnosis of early pregnancy in cows using interferonstimulated genes in granulocytes. 107, 188-193

125. Garth Sasser, R., Ruder, C. A., Ivani, K. A., Butler, J. E., and Hamilton, W. C. \%J B. of R. (1986) Detection of pregnancy by radioimmunoassay of a novel pregnancyspecific protein in serum of cows and a profile of serum concentrations during gestation. 35, 936-942

126. Mialon, M., Renand, G., Camous, S., Martal, J., and Ménissier, F. \%J R. N. D. (1994) Detection of pregnancy by radioimmunoassay of a pregnancy serum protein (PSP60) in cattle. 34, 65-72

127. Borovecki, F., Lovrecic, L., Zhou, J., Jeong, H., Then, F., Rosas, H., Hersch, S., Hogarth, P., Bouzou, B., and Jensen, R. (2005) Genome-wide expression profiling of human blood reveals biomarkers for Huntington's disease. Proceedings of the National Academy of Sciences 102, 11023-11028

128. Lofton-Day, C., Model, F., DeVos, T., Tetzner, R., Distler, J., Schuster, M., Song, X., Lesche, R., Liebenberg, V., and Ebert, M. (2008) DNA methylation biomarkers for blood-based colorectal cancer screening. Clinical chemistry 54, 414-423

129. Rosas, I. O., Richards, T. J., Konishi, K., Zhang, Y., Gibson, K., Lokshin, A. E., Lindell, K. O., Cisneros, J., MacDonald, S. D., and Pardo, A. (2008) MMP1 and MMP7 as potential peripheral blood biomarkers in idiopathic pulmonary fibrosis. PLoS Med 5, e93

130. Votavova, H., Merkerova, M. D., Fejglova, K., Vasikova, A., Krejcik, Z., Pastorkova, A., Tabashidze, N., Topinka, J., Veleminsky Jr, M., and Sram, R. (2011) Transcriptome alterations in maternal and fetal cells induced by tobacco smoke.

Placenta 32, 763-770 
131. Olsson, B., Lautner, R., Andreasson, U., Öhrfelt, A., Portelius, E., Bjerke, M., Hölttä, M., Rosén, C., Olsson, C., and Strobel, G. (2016) CSF and blood biomarkers for the diagnosis of Alzheimer's disease: a systematic review and meta-analysis. The Lancet Neurology 15, 673-684

132. Laing, E. E., Möller-Levet, C. S., Poh, N., Santhi, N., Archer, S. N., and Dijk, D.-J. (2017) Blood transcriptome based biomarkers for human circadian phase. Elife 6, e20214

133. Koh, Y. Q., Peiris, H. N., Vaswani, K., Almughlliq, F. B., Meier, S., Burke, C. R., Roche, J. R., Reed, C. B., Arachchige, B. J., and Reed, S. (2018) Proteome profiling of exosomes derived from plasma of heifers with divergent genetic merit for fertility. Journal of dairy science 101, 6462-6473

134. Tríbulo, P., Rivera, R. M., Obando, M. S. O., Jannaman, E. A., and Hansen, P. J. (2019) Production and culture of the bovine embryo. In Comparative Embryo Culture pp. 115-129, Springer

135. ImageJ.

136. Ortega, M. S., Moraes, J. G., Patterson, D. J., Smith, M. F., Behura, S. K., Poock, S., and Spencer, T. E. (2018) Influences of sire conception rate on pregnancy establishment in dairy cattle. Biology of reproduction 99, 1244-1254

137. Babraham Bioinformatics - FastQC A Quality Control tool for High Throughput Sequence Data.

138. Ewels, P., Magnusson, M., Lundin, S., and Käller, M. (2016) MultiQC: summarize analysis results for multiple tools and samples in a single report. Bioinformatics 32 , 3047-3048 
139. Cox, M. P., Peterson, D. A., and Biggs, P. J. (2010) SolexaQA: At-a-glance quality assessment of Illumina second-generation sequencing data. BMC Bioinformatics 11, 485

140. Rosen, B. D., Bickhart, D. M., Schnabel, R. D., Koren, S., Elsik, C. G., Tseng, E., Rowan, T. N., Low, W. Y., Zimin, A., Couldrey, C., Hall, R., Li, W., Rhie, A., Ghurye, J., McKay, S. D., Thibaud-Nissen, F., Hoffman, J., Murdoch, B. M., Snelling, W. M., McDaneld, T. G., Hammond, J. A., Schwartz, J. C., Nandolo, W., Hagen, D. E., Dreischer, C., Schultheiss, S. J., Schroeder, S. G., Phillippy, A. M., Cole, J. B., Van Tassell, C. P., Liu, G., Smith, T. P. L., and Medrano, J. F. (2020) De novo assembly of the cattle reference genome with single-molecule sequencing. Gigascience 9

141. Kim, D., Paggi, J. M., Park, C., Bennett, C., and Salzberg, S. L. (2019) Graphbased genome alignment and genotyping with HISAT2 and HISAT-genotype. Nature Biotechnology 37, 907-915

142. Anders, S., Pyl, P. T., and Huber, W. (2015) HTSeq-a Python framework to work with high-throughput sequencing data. Bioinformatics 31, 166-169

143. Index of /genomes/all/GCF/002/263/795/GCF_002263795.1_ARS-UCD1.2.

144. FTP Download.

145. McCarthy, D. J., Chen, Y., and Smyth, G. K. (2012) Differential expression analysis of multifactor RNA-Seq experiments with respect to biological variation. Nucleic Acids Research 40, 4288-4297

146. Love, M. I., Huber, W., and Anders, S. (2014) Moderated estimation of fold change and dispersion for RNA-seq data with DESeq2. Genome Biology 15, 550 
147. DesCôteaux, L., Colloton, J., and Gnemmi, G. (2009) Practical atlas of ruminant and camelid reproductive ultrasonography. John Wiley \& Sons

148. Zhang, S., Kubota, C., Yang, L., Zhang, Y., Page, R., O'Neill, M., Yang, X., and Tian, X. C. (2004) Genomic imprinting of H19 in naturally reproduced and cloned cattle. Biology of reproduction 71, 1540-1544

149. Moore, K., Kramer, J., Rodriguez-Sallaberry, C., Yelich, J., and Drost, M. (2007) Insulin-like growth factor (IGF) family genes are aberrantly expressed in bovine conceptuses produced in vitro or by nuclear transfer. Theriogenology $68,717-727$

150. Curchoe, C. L., Zhang, S., Yang, L., Page, R., and Tian, X. C. (2009) Hypomethylation trends in the intergenic region of the imprinted IGF2 and H19 genes in cloned cattle. Animal reproduction science 116, 213-225

151. Hori, N., Nagai, M., Hirayama, M., Hirai, T., Matsuda, K., Hayashi, M., Tanaka, T., Ozawa, T., and Horike, S. (2010) Aberrant CpG methylation of the imprinting control region KvDMR1 detected in assisted reproductive technology-produced calves and pathogenesis of large offspring syndrome. Anim Reprod Sci 122, 303-312

152. Xu, H., Simonet, F., and Luo, Z. (2010) Optimal birth weight percentile cut-offs in defining small-or large-for-gestational-age. Acta Paediatrica 99, 550-555

153. Stice, S. L., Strelchenko, N. S., Keefer, C. L., and Matthews, L. \%J B. of reproduction. (1996) Pluripotent bovine embryonic cell lines direct embryonic development following nuclear transfer. 54, 100-110

154. Choufani, S., Shuman, C., and Weksberg, R. (2010) Beckwith-Wiedemann syndrome. presented at the American Journal of Medical Genetics Part C: Seminars in Medical Genetics 
155. Weksberg, R., Shuman, C., and Beckwith, J. B. (2010) Beckwith-Wiedemann syndrome. European journal of human genetics 18, 8-14

156. Wang, K. H., Kupa, J., Duffy, K. A., and Kalish, J. M. (2020) Diagnosis and Management of Beckwith-Wiedemann Syndrome. Frontiers in Pediatrics 7, 562

157. Gerber, L., Chaudbry, U., and DeBaun, M. R. (1996) MUSCULOSKELETAL ABNORMALITIES IN 53 CHILDREN WITH BECKWITH WIEDEMANN SYNDROME. 855. Pediatric Research 39, 145-145

158. Lapunzina, B. P., del Campo, C. M., Delicado, N. A., Fernández-Toral, J., García-Alix, A., García-Guereta, L., Pérez, J. L., Ramos, F. F., Sánchez, D. A., and Urioste, A. M. (2006) Clinical guide to the management of patients with BeckwithWiedemann syndrome. presented at the Anales de pediatria (Barcelona, Spain: 2003)

159. Sathienkijkanchai, A., Prucka, S. K., Grant, J. H., and Robin, N. H. (2008) Isolated facial hemihyperplasia: Manifestation of Beckwith-Wiedemann syndrome. Journal of Craniofacial Surgery 19, 279-283

160. Elbracht, M., Prawitt, D., Nemetschek, R., Kratz, C., and Eggermann, T. (2018) [Beckwith-Wiedemann Syndrome (BWS) Current Status of Diagnosis and Clinical Management: Summary of the First International Consensus Statement]. Klin Padiatr 230, 151-159

161. Mee, J. F. (2013) Why do so many calves die on modern dairy farms and what can we do about calf welfare in the future? Animals 3, 1036-1057

162. Hughes, E. A. and Davies, D. (1989) Practical uses of ultrasound in early pregnancy in cattle. The Veterinary Record 124, 456-458 
163. Chavatte-Palmer, P., De Sousa, N., Laigre, P., Camous, S., Ponter, A., Beckers, J.-F., and Heyman, Y. (2006) Ultrasound fetal measurements and pregnancy associated glycoprotein secretion in early pregnancy in cattle recipients carrying somatic clones.

Theriogenology 66, 829-840

164. Eley, R. M., Thatcher, W. W., Bazer, F. W., Wilcox, C. J., Becker, R. B., Head, H. H., and Adkinson, R. W. (1978) Development of the conceptus in the bovine. J Dairy Sci $61,467-473$

165. Mao, W., Albrecht, E., Teuscher, F., Yang, Q., Zhao, R., and Wegner, J. (2008) Growth-and breed-related changes of fetal development in cattle. Asian-Australasian Journal of Animal Sciences 21, 640-647 